\title{
Global and regional health impacts of future food production under climate change: a modelling study*
}

Appendix

\section{Table of Contents}

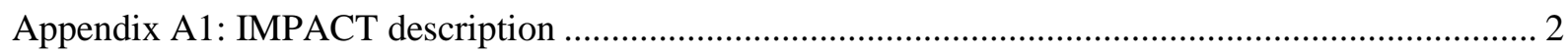

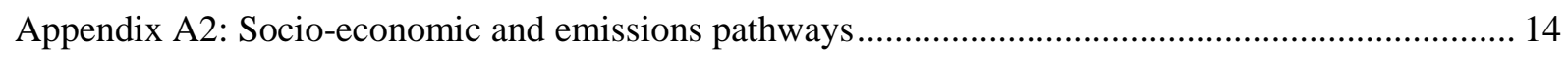

Appendix A3: Conversion from food demand into food consumption ............................................... 21

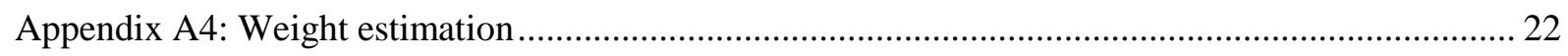

Appendix A5: Description of comparative risk assessment framework ……….................................. 35

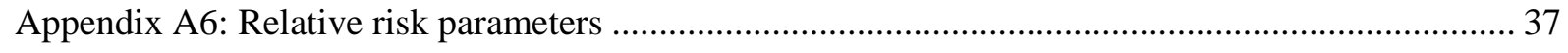

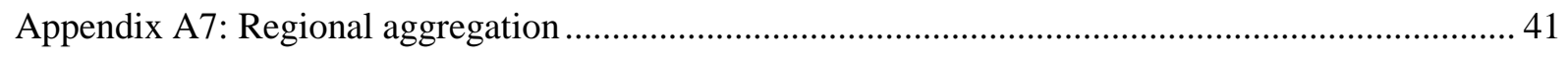



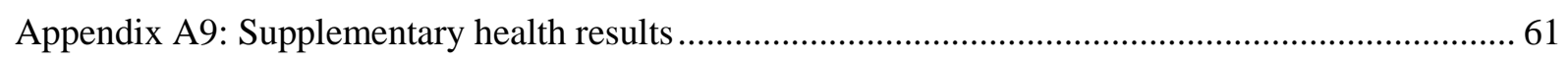

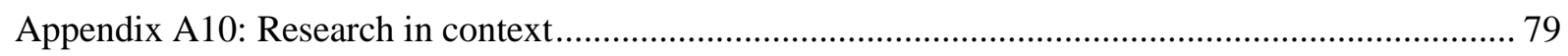

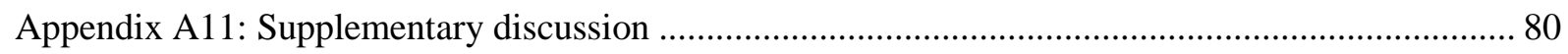

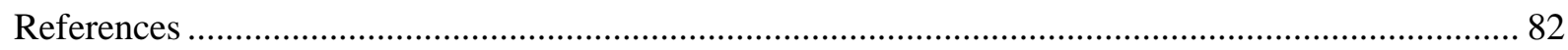

* Please note that this is the final draft (post-refereeing) and not identical to the publisher's version. The Lancet holds the copyright of the published article which can be accessed via http://dx.doi.org/10.1016/S01406736(15)01156-3. 


\section{Appendix A1: IMPACT description}

The IMPACT model was developed at IFPRI at the beginning of the 1990s to address a lack of long-term vision and consensus among policy-makers and researchers about the actions that are necessary to feed the world in the future, reduce poverty, and protect the natural resource base. Over time, this economic model has been expanded and improved, and IMPACT is now a network of linked economic, water, and crop models. At IMPACT's core is the original partial equilibrium multi-market model of global production, demand, and trade, which is linked to a suite of water models. The multi-market model focuses on national and global markets, including 159 countries. Agricultural production is specified by models of land supply, allocation of land (irrigated and rainfed) to crops, and determination of yields (which is described in more detail below).Production is modelled at a sub-national level, including 320 regions called "food production units" or FPUs. The FPUs are defined to link to the water models and correspond to river basins within national boundaries-154 basins and 159 countries.

The multi-market model simulates 62 agricultural commodity markets, which represent the bulk of food and cash crops. The multi-market model is integrated with the IMPACT water models, which simulate the availability of water for irrigation and the effects of changes in water availability on agricultural production. Similar to the global multi-market model, the water models operate at disaggregated scales. However the regions of interest for the water models are hydrological basins (i.e. Nile, Amazon, Mississippi, etc.), of which there are 154. To allow for the communication between the multi-market and water models, the IMPACT suite of models operates on a subnational unit, focusing on the 320 FPUs created by the intersection of the 156 geopolitical and 154 hydrological regions.

The IMPACT core is additionally connected to a series of modules integrating information from climate models (general circulation models, or GCMs), crop simulation models, population and demographic models, and economic growth models. These models are not dynamically linked like the water and multi-market models, with one-way communication of model results serving as IMPACT scenario inputs. Figure A1.1 describes the links between the different models that constitute the IMPACT system of models. We used IMPACT 3.1 for this study. Detailed model descriptions are provided by the IMPACT Development Team. ${ }^{1,2}$ The following sections draw on those descriptions, in particular on the description of IMPACT $3 .^{2}$

Figure A1.1: The IMPACT system of models






\section{A1.1. IMPACT Multi-Market Model}

The IMPACT model system, as described in the preceding sections, is organized around a core global partial equilibrium multi-market model of agricultural production, demand, trade, and prices. The multi-market model simulates the operation of national and global markets for agricultural commodities, solving for equilibrium prices and quantities. The model specifies supply and demand behaviour in all markets. This section describes the elements of that model.

\section{Crop Production}

Crop production in IMPACT is simulated through area and yield response functions. (In IMPACT, area is treated as harvested area, which is the total area planted and harvested within a year, and may include multicropping or multiple harvests and differ from total arable land or reported physical area). The choice of specifying crop production in this way has a long history in IMPACT and facilitates interaction with commodity experts and land-use specialists, who work in natural units (hectares, tons/hectare). Crop production in IMPACT is specified sub-nationally with the area and yield functions at the level of Food Production Units (FPU). This regional disaggregation permits linking with water models and provides the added benefit of smaller geographical units for aggregating climate change results, which can vary significantly from one location to another. Land used for crop production is divided into irrigated and rainfed systems, capturing the significant differences in yields observed across these cultivation systems and linking directly with the water models which treat irrigated and rainfed water supplies separately.

A new feature of IMPACT 3 is the implementation of a land market to manage competing demands for agricultural land from different crops, as well as providing new linkage points to land-use models that work with broader land-use changes, such as conversion of forest to grasslands and agricultural land. It also allows us to separate total area supply (irrigated and rainfed) from individual crop area demands, and allows equilibrium conditions to determine the best economic use of the available land. The total supply of land is assumed to be a function of the "scarcity value" or "shadow price index" of land, which can also be considered a summary of changes in crop prices. The shadow price (WF) is indexed to 1 in the first year and changes based on changing demands from all crops for land area.

$$
\begin{aligned}
Q F S_{\mathrm{fpu}, \text { Ind }} & =Q F S \text { Int }_{\mathrm{fpu}, \text { Ind }} \times Q F S I n t 2_{\mathrm{fpu}, \text { Ind }} \\
Q F S & =\text { Land supply } \\
Q F S I n t & =\text { Land supply intercept (base year supply) } \\
Q F S I n t 2 & =\text { Land supply growth multiplier } \\
f p u & =\text { Food production unit } \\
\text { Ind } & =\text { Land type (i.e. irrigated }, \text { rainfed) }
\end{aligned}
$$

The supply of land is considered exogenous within each year, meaning that farmers are not allowed to adjust the total crop area in the middle of the year. The total land supply over time is driven by exogenous trends on the availability of area for agriculture, as well as endogenous responses to changes in area demand, which is handled in between years. The following equation is applied at the end of each year before solving for a new year.

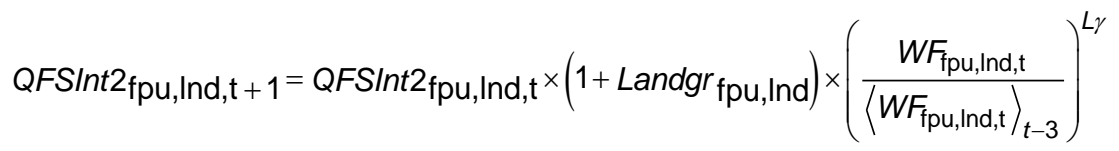

$$
\begin{aligned}
& \text { Landgr }=\text { Exogenous land supply growth rate } \\
& \left\langle W F_{\mathrm{fpu}, \text { Ind, }, \mathrm{t}}\right\rangle_{t-3}=\text { Average shadow price of past } 3 \text { years } \\
& L \gamma=\text { Land supply elasticity }
\end{aligned}
$$

Crop area is specified as an area demand function with respect to changes in the marginal revenue product, changes in land cost, and exogenous non-price trends in harvested area. Crop area elasticities simulate the supply response to changes in the marginal revenue of land represented by the following equation as the interaction of the net price of an activity and the productivity of the activity in using an additional hectare of land. 


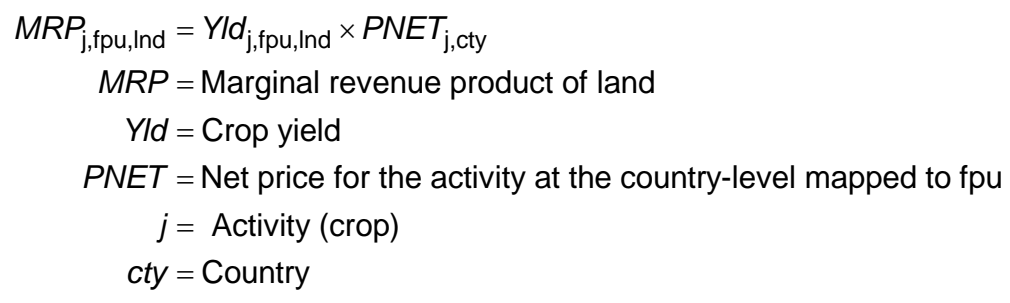

The exogenous trend in harvested area captures changes in area resulting from factors other than direct market effects, such as government programs encouraging cropping expansion, or contraction due to soil degradation, or conversion of land from agriculture to nonagricultural uses. The combination of these endogenous and exogenous factors in area demand are described in the following equation.

$$
\begin{aligned}
& \text { Area }_{\mathrm{j}, \mathrm{fpu}, \text { Ind }}=A r e a l n t_{\mathrm{j}, \mathrm{fpu}, \text { Ind }} \times A r e a l n t 2_{\mathrm{j}, \mathrm{fpu}, \mathrm{Ind}} \times W F_{\mathrm{fpu}, \text { Ind }} W F \times\left(\frac{M R P_{\mathrm{j}, \mathrm{fpu}}}{M R P 0_{\mathrm{j}, \mathrm{fpu}}}\right)^{A \varepsilon} \\
& \text { Area }=\text { Final crop area } \\
& \text { Arealnt }=\text { Crop area intercept (base year crop area) } \\
& \text { Arealnt2 }=\text { Exogenous crop area growth multiplier } \\
& W F \varepsilon=\text { Elasticity of demand with respect to land shadow price } \\
& M R P O=\text { Base year marginal revenue product (used to index prices) } \\
& A \varepsilon=\text { Elasticity of area demand with respect to marginal revenue product }
\end{aligned}
$$

Assumptions for exogenous trends are determined by a combination of historical changes in land use and expert judgment on potential future regional dynamics. They are represented as compound growth from the base and are applied between years.

$$
\begin{gathered}
\text { Arealnt2j,fpu,Ind,t+1 }=\text { Arealnt2j,fpu,Ind,t } \times\left(1+\text { Areagr }_{\mathrm{fpu}, \text { Ind }}\right) \\
\text { Areagr }=\text { Exogenous area demand growth rate }
\end{gathered}
$$

Competing demands from different crops are handled through an equilibrium equation that determines the land allocation and ensures that all crop area demand must sum up to the total land supply for each FPU.

$$
Q F S_{f p u, I n d}=\sum_{j} A{ } a_{j, f p u, I n d}
$$

Crop yields are a function of commodity prices, prices of inputs, available water, climate, and exogenous trend factors. The IMPACT model includes four ways that changes in yields are achieved. First, the model assumes a scenario of underlying improvements in yields over time that, to varying degrees, continue trends observed over the past 50-60 years in an informed extrapolation following the concepts introduced in Evenson and Rosegrant, ${ }^{3}$ and Evenson and colleagues. ${ }^{4}$ These long-run trends, or intrinsic productivity growth rates (IPRs), are intended to reflect the expected increases in inputs, improved seeds, and improvements in management practices. These trends differ and are generally higher for developing countries, where there is considerable scope to narrow the gap in yields compared to developed countries. These IPRs are exogenous to the model, and changes in them are specified as part of the definition of different scenarios. We assume that these underlying trends vary by crop and region, and that they will decline somewhat over the next fifty years as the pace of technological improvements in developed countries slows, and as developing countries "catch up" to yields in developed countries.

Second, the IMPACT model includes a short-run (annual), endogenous, response of yields to changes in both input and output prices. These yield response functions specify the change in yield as a constant elasticity function of the changes in output prices, with elasticity parameters that can vary by crop and region. The underlying assumption is that farmers will respond to changes in prices by varying the use of inputs, including inputs such as fertilizer, chemicals, and labour that will, in turn, change yields.

Third, climate is assumed to affect yields through two mechanisms. The first mechanism is through the effects of changes in temperature and "weather" due to climate change on crop yields for rainfed and irrigated crops, as calculated from the solution of a crop simulation model (DSSAT ${ }^{5,6}$ ) for different climate change scenarios. These crop simulations vary by crop type. The DSSAT model is run with detailed time, geographic, and crop 
disaggregation for different climate change scenarios that are "downscaled" to include weather variation over small geographic areas. This analysis gives changes in average yields due to climate change that are then averaged to generate yield shocks by crop and region (FPU) in the IMPACT model. These long-run climate scenarios generate yield shocks that are assumed to follow simple trends over time, and do not consider extreme events such as droughts or floods.

The fourth mechanism by which climate change affects yields is through variation in water availability for agriculture year-by-year under different climate scenarios. This mechanism is modelled through the use of the IMPACT water models. These include: (1) a global hydrology model that determines run off to the river basins included in the IMPACT model; (2) water basin management models for each FPU that optimally allocate available water to competing non-agricultural and agricultural uses, including irrigation; and (4) a water allocation and stress model that allocates available irrigation water to crops and, when the water supply is less than demand by crop, computes the impact of the water shortage on crop yields accounting for differences among crops and varieties. These yields shocks are then passed to the IMPACT model, affecting year-to-year crop yields.

$$
\begin{aligned}
\text { Yield }_{\mathrm{j}, \mathrm{fpu}, \mathrm{Ind}} & =\text { Yieldlnt }_{\mathrm{j}, \mathrm{fpu}, \mathrm{Ind}} \times \text { Yieldlnt }_{\mathrm{j}, \mathrm{fpu}, \mathrm{Ind}} \times \text { WatShk }_{\mathrm{j}, \mathrm{fpu}, \mathrm{Ind}} \times \text { CliShk }_{\mathrm{j}, \mathrm{fpu}, \mathrm{Ind}} \times\left(\frac{P N E T_{\mathrm{j}, \text { cty }}}{P N E T 0_{\mathrm{j}, \mathrm{cty}}}\right)^{Y \varepsilon} \times P F^{F \varepsilon} \\
\text { Yield } & =\text { Final yield } \\
\text { YieldInt } & =\text { Yield intercept (base year yield) } \\
\text { YieldInt2 } & =\text { Exogenous yield growth multiplier } \\
\text { WatShk } & =\text { Water stress shock (from water models) } \\
\text { CliShk } & =\text { Climate change shock (from water and crop models) } \\
Y \varepsilon & =\text { Yield supply elasticity with respect to net price } \\
P F & =\text { Input prices } \\
F_{\varepsilon} & =\text { Yield supply elasticity with respect to input prices }
\end{aligned}
$$

Final crop production for each FPU and crop (j) is estimated as the product of the solution for its respective area and yield equations, with national production $\left(\mathrm{QS}_{\mathrm{j}, \mathrm{cty}}\right)$ equal to the summation of the production in all of the relevant FPUs in that country.

$$
Q S_{\mathrm{j}, \mathrm{cty}}=\sum_{\mathrm{fpu}, \text { Ind }}\left(\text { Area }_{\mathrm{j}, \mathrm{fpu}, \text { Ind }} \times \text { Yield }_{\mathrm{j}, \mathrm{fpu}, \text { Ind }}\right)
$$

\section{Livestock Production}

Livestock production is modelled at the FPU level and includes animal numbers, with associated feed demands, and meat/dairy production based on "processing" the animals. Similar to the crop sector, this specification allows for easier translation of information from livestock experts who are used to working with herd-size and feeding requirements. In the current version of the model, there is no modelling of herd dynamics - herd size over time is set exogenously.

Feed demand is a function of the livestock's own price, the prices of intermediate (feed) inputs, and a trend variable reflecting growth in livestock herds (slaughter rates are implicitly assumed to stay more or less constant over time). The price elasticities in the livestock supply function are derived in a similar fashion to the crop area and yield elasticities. 


$$
\begin{aligned}
\text { Animals } s_{\mathrm{j}, \mathrm{fpu}, \mathrm{livsys}} & =\text { Animallnt } t_{\mathrm{j}, \mathrm{fpu}, \text { livsys }} \times \text { Animallnt2 }_{\mathrm{j}, \mathrm{fpu}, \mathrm{livsys}} \times\left(\frac{P N E T_{\mathrm{j}, \mathrm{cty}}}{P N E T 0_{\mathrm{j}, \mathrm{cty}}}\right)^{A N \varepsilon} \times \prod_{\text {cfeeds }}\left(\frac{P C_{\mathrm{c}, \mathrm{cty}}}{P C 0_{\mathrm{c}, \mathrm{cty}}}\right)^{F e e d \varepsilon} \\
\text { Animals } & =\text { Number of producing animals } \\
\text { Animallnt } & =\text { Animal intercept (initial number of animals }) \\
\text { Animallnt2 } & =\text { Exogenous population growth } \\
P C & =\text { Consumer prices } \\
P C 0 & =\text { Intial consumer prices } \\
\text { Feed } \varepsilon & =\text { Supply elasticity with respect to changes in feed prices } \\
\text { livsys } & =\text { Livestock production systems } \\
\text { cfeeds } & =\text { Feed commodities demanded by livestock sector }
\end{aligned}
$$

Livestock yields are determined through exogenous growth due to improved animals and management practices. Currently, all price responses in the livestock sector are accounted for in the animal number equations.

$$
\begin{aligned}
\text { AnimalYield }_{\mathrm{j}, \mathrm{fpu}, \text { livsys }} & =\text { AnimalYieldInt }{ }_{\mathrm{j}, \mathrm{fpu}, \text { livsys }} \times \text { AnimalYieldInt }_{\mathrm{j}, \mathrm{fpu}, \text { livsys }} \\
\text { AnimalYield } & =\text { Animal yields } \\
\text { AnimalYieldInt } & =\text { Initial animal yields } \\
\text { AnimalYieldInt2 } & =\text { Exogenous yield growth }
\end{aligned}
$$

Total national production $\left(\mathrm{QS}_{\mathrm{j}, \text { cty }}\right)$ is calculated by multiplying the slaughtered number of animals by the yield per head and summing across FPU and livestock system.

$$
Q S_{\mathrm{j}, \mathrm{cty}}=\sum_{\mathrm{fpu}, \mathrm{livsys}}\left(\text { Animals }_{\mathrm{j}, \mathrm{fpu}, \text { livsys }} \times \text { AnimalYield }_{\mathrm{j}, \mathrm{fpu}, \text { livsys }}\right)
$$

There is work underway to improve the livestock model, incorporating more animal types, a number of different feed "systems" that include pastures, fodders, and processed feeds, as well as feed grains, and also a more detailed representation of the value chain from feeds to herds to final demand commodities

\section{Production of Processed Goods}

Modelling of processed goods (i.e. food oils, oil meals, sugar) has been an active area of improvement for IMPACT 3, and the development of the activity-commodity framework allows for a general handling of all processed goods in IMPACT through Input-Output matrices (IOMATs) and the use of net prices. The IOMATs represent technical coefficients on input requirements and are specified by quantities of inputs per unit of output (i.e. $m$ t of soybeans per mt of soybean oil), and are calculated from the base data. The net price is the price the producer receives net of input costs. The net price will equal the producer price of the activity whenever there are no intermediate inputs. (Crops and livestock currently do not include intermediate inputs in the PNET equation, and instead directly take input price effects through supply elasticities in the crop yield, and animal number equations).

$$
\begin{aligned}
P N E T_{\mathrm{j}, \text { cty }} & =P P_{\mathrm{j}, \text { cty }}-\sum_{\text {inputs }}\left(I O M A T_{\text {inputs, } \mathrm{j}, \mathrm{cty}} \times\left(1-C S E I_{\text {inputs,cty }}\right) \times P C_{\text {inputs,cty }}\right) \\
P N E T & =\text { Net price } \\
P P & =\text { Producer price } \\
P C & =\text { Consumer price of inputs } \\
C S E I & =\text { Consumer support estimate on intermediate inputs } \\
I O M A T & =\text { Input-output matrix } \\
\text { inputs } & =\text { Set of commodities }(\mathrm{c}) \text { that are inputs into activity } \mathrm{j}
\end{aligned}
$$

Production of processed goods are then simulated by a supply function that incorporates both endogenous price effects, as well as exogenous technological change. As opposed to crop and livestock production, processed goods are modelled at the country level instead of at the FPU. 


$$
\begin{aligned}
Q S_{\mathrm{j}, \mathrm{cty}} & =Q S I n t_{\mathrm{j}, \mathrm{cty}} \times Q S I N T 2_{\mathrm{j}, \mathrm{cty}} \times\left(\frac{P N E T_{\mathrm{j}, \mathrm{cty}}}{P N E T 0_{\mathrm{j}, \mathrm{cty}}}\right)^{Q S \varepsilon} \\
Q S & =\text { Total production } \\
Q S I n t & =\text { Initial production } \\
Q S I n t 2 & =\text { Exogenous productivity growth } \\
Q S \varepsilon & =\text { Supply elasticity with respect to net price }
\end{aligned}
$$

\section{Commodity Supply and Demand}

Total supply of commodities requires mapping from output of production activities to supply of commodities. The mapping is given by:

$$
\begin{aligned}
Q S U P_{\mathrm{c}, \mathrm{cty}} & =\sum_{\mathrm{j}} J C R a \text { tio }_{\mathrm{j}, \mathrm{c}} \times Q S_{\mathrm{j}, \mathrm{cty}} \\
\text { QSUP } & =\text { Total commodity supply } \\
J C R a t i o & =\text { Activity to commodity mapping } \\
c & =\text { Commodity } \\
c t y & =\text { Country }
\end{aligned}
$$

The parameter JCRatio maps from the activity output to commodities. Usually, each activity produces a matched commodity (e.g., wheat growing activity produces the commodity wheat, and nothing else). The specification, however, is general. There can be many activities producing the same commodity (e.g., different wheat growing activities producing the same wheat commodity) or a single activity producing more than one commodity (e.g., oil seed processing yielding both oil and meal). By convention, the units of $j$ agree with the units of the main commodity produced by the activity (e.g., output of the wheat activity yields the commodity wheat, in the same units), so that the JCRatio for this mapped commodity always equals one. Other outputs, if any, from an activity in JCRatio are measured as a ratios to the output of the main activity (e.g., tons of meal per ton of production of oil in an oilseed processing plant).

Total domestic demand for a commodity is the sum of household food demand, agricultural intermediate demand (feed, and for process goods), and intermediate demand from other sectors (i.e. biofuels, and industrial uses).

$$
\begin{aligned}
Q D_{\mathrm{c}, \mathrm{cty}} & =\sum_{\mathrm{h}}\left(Q H_{\mathrm{c}, \mathrm{h}, \mathrm{cty}}\right)+Q I n t e r m_{\mathrm{c}, \mathrm{cty}}+Q L_{\mathrm{c}, \mathrm{cty}}+Q B F_{\mathrm{c}, \mathrm{cty}}+Q O T H_{\mathrm{c}, \mathrm{cty}} \\
Q D & =\text { Total commodity demand } \\
Q H & =\text { Household food demand } \\
Q I n t e r m & =\text { Intermediate demand from Ag-processing sector } \\
Q L & =\text { Feed demand from livestock sector } \\
Q B F & =\text { Intermediate demand for biofuel feedstock } \\
Q O t h & =\text { All other demand } \\
h & =\text { Household type }
\end{aligned}
$$

Food demand is a function of the price of the commodity and the prices of other competing commodities, per capita income, and total population. Per capita income and population increase annually according to countryspecific population and income growth rates. Population and GDP trends vary by scenario and are drawn from the Shared Socio-economic Pathway (SSP) database representing socio-economic scenarios from the IPCC's $5^{\text {th }}$ report (see Appendix A2 for more details). ${ }^{7}$ The IMPACT demand elasticities are originally based on USDA estimated elasticities and adjusted to represent a synthesis of average, aggregate elasticities for each region, given the income level and distribution of urban and rural population. ${ }^{8}$ Over time the elasticities are adjusted to accommodate the gradual shift in demand from staples to high value commodities like meat, especially in developing countries. This assumption is based on expected economic growth, increased urbanization, and continued commercialization of the agricultural sector. IMPACT is designed to simulate multiple types of households (i.e. rural, urban, rich, poor, etc.); however, currently, IMPACT treats household demand with one representative consumer per country. 


$$
\begin{aligned}
Q H_{\mathrm{c}, \mathrm{h}, \mathrm{cty}} & =Q H I n t_{\mathrm{c}, \mathrm{h}, \mathrm{cty}} \times\left(\frac{p c G D P_{\mathrm{h}, \mathrm{cty}}}{p c G D P 0_{\mathrm{h}, \mathrm{cty}}}\right)^{I n c \varepsilon} \times\left(\frac{\left(1-C S E_{\mathrm{c}, \mathrm{cty}}\right) \times P C_{\mathrm{c}, \mathrm{cty}}}{\left(1-C S E 0_{\mathrm{c}, \mathrm{cty}}\right) \times P C 0_{\mathrm{c}, \mathrm{cty}}}\right)^{H F \varepsilon} \\
& \times \prod_{c c \neq c}\left(\frac{\left(1-C S E_{\mathrm{cc}, \mathrm{cty}}\right) \times P C_{\mathrm{cc}, \mathrm{cty}}}{\left(1-C S E 0_{\mathrm{cc}, \mathrm{cty}}\right) \times P C 0_{\mathrm{cc}, \mathrm{cty}}}\right)^{H F \varepsilon} \times \frac{P o p H_{\mathrm{h}, \mathrm{cty}}}{P o p H 0_{h, c t y}} \\
Q H & =\text { Household food demand } \\
Q H I n t & =\text { Initial household food demand } \\
p c G D P & =\text { Per capita GDP } \\
p c G D P 0 & =\text { Initial per capita GDP } \\
C S E & =\text { Consumer support estimate } \\
C S E O & =\text { Initial consumer support estimate } \\
P o p H & =\text { Population disaggregated by household type } \\
P o p H O & =\text { Initial household population } \\
I n C \varepsilon & =\text { Income demand elasticity } \\
H F \varepsilon & =\text { Price demand elasticty } \\
\left(\frac{(1-C S E) \times P C}{(1-C S E 0) \times P C O}\right)^{H F \varepsilon} & =\text { Own-price response } \\
\prod_{c c \neq c}\left(\frac{(1-C S E) \times P C}{(1-C S E 0) \times P C O}\right)^{H F \varepsilon} & =\text { Cross-price response }
\end{aligned}
$$

Feed demand is a derived intermediate demand. It is determined by two components: (1) animal feed requirements determined by livestock production and livestock feed requirements and (2) price effects that take into account potential substitution possibilities among different feeds. The equation also incorporates a technology parameter that indicates improvements in feeding efficiencies over time.

$$
\begin{aligned}
Q L_{c, \text { cty }} & =\sum_{\text {jlvst }}\left(Q S_{\mathrm{j} l v s t, c t y} \times \operatorname{Re} q_{\mathrm{jlvst}, \mathrm{c}, \mathrm{cty}}\right) \times \prod_{\mathrm{cfeeds}}\left(\frac{P C_{\mathrm{c}, \mathrm{cty}}}{P C 0_{\mathrm{c}, \mathrm{cty}}}\right)^{L F D \varepsilon} \\
Q L & =\text { Total feed demand for livestock sector } \\
Q S & =\text { Total production of each livestock activity } \\
\operatorname{Re} q & =\text { Feed requirements for each livestock activity } \\
L F D \varepsilon & =\text { Price elasticity of demand for feed } \\
j / v s t & =\text { Set of livestock producing activities }
\end{aligned}
$$

Intermediate demand is a derived demand that is based on the demand for final processed goods, such as food oils and sugar. The input-output matrix determines the proportions of inputs (c) required for each producing activity (j).

$$
\begin{aligned}
Q D \text { Interm }_{\mathrm{c}, \mathrm{cty}} & =\sum_{\mathrm{j}}\left(\text { IOMat }_{\mathrm{c}, \mathrm{j}, \mathrm{cty}} \times Q S_{\mathrm{j}, \mathrm{cty}}\right) \\
Q D I \text { Interm } & =\text { Intermediate demand } \\
\text { IOMat } & =\text { Input-Output matrix }
\end{aligned}
$$

Exogenous biofuel feedstock demand is determined through exogenous growth rates which represent government mandates to encourage the production of biofuels, though adjusted in various scenarios where the mandates are infeasible, or adjusted to reflect scenarios on the role of first or second generation biofuels. The biofuel feedstock demand equation also allows for a price response for biofuels to allow for substitution across different potential feedstocks, as well as to reflect the reality that increasing food prices would put pressure to ease biofuel mandates. 


$$
\begin{aligned}
Q B F_{\mathrm{c}, \mathrm{cty}} & =Q B F I n t_{\mathrm{c}, \mathrm{cty}} \times Q B F I N T 2_{\mathrm{c}, \mathrm{cty}} \times \prod_{\mathrm{c}}\left(\frac{P C_{\mathrm{c}, \mathrm{cty}}}{P C 0_{\mathrm{c}, \mathrm{cty}}}\right)^{B F \varepsilon} \\
Q B F & =\text { Biofuel feedstock demand } \\
Q B F I n t & =\text { Initial demand from biofuel sector } \\
Q B F I n t 2 & =\text { Exogenous growth in demand from biofuels } \\
B F \varepsilon & =\text { Price elasticity of demand for biofuel feedstock }
\end{aligned}
$$

Other demand summarizes all other demands for agricultural products from sectors outside of the focus of IMPACT (e.g. seeds, industrial use, etc.). It is simulated under two different equations. The primary method follows the household food demand equation, and is sensitive to changes in income, population and prices.

$$
\begin{aligned}
& Q O h_{\mathrm{c}, \mathrm{cty}}=Q O \text { thInt }_{\mathrm{c}, \mathrm{cty}} \times\left(\frac{p c G D P_{\mathrm{cty}}}{p c G D P 0_{\mathrm{cty}}}\right)^{I O t h \varepsilon} \times\left(\frac{P O P_{\mathrm{cty}}}{P O P 0_{\mathrm{cty}}}\right) \times \prod_{c c}\left(\frac{P C_{\mathrm{c}, \mathrm{cty}}}{P C 0_{\mathrm{c}, \mathrm{cty}}}\right)^{P O \text { th } \varepsilon} \\
& \text { QOth }=\text { Other Demand } \\
& \text { QOthInt = Initial other demand } \\
& \text { IOth } \varepsilon=\text { Income demand elasticity for other demand } \\
& \text { POth } \varepsilon=\text { Price demand elasticity for other demand }
\end{aligned}
$$

\section{Markets, Trade, and Equilibrium Prices}

The system of equations is written in the General Algebraic Modeling System (GAMS) programming language. ${ }^{9}$ The solution of these equations is achieved by the Path solver, which is included in the GAMS system. This procedure finds a set of domestic and world prices for all crops that "clear" domestic and international commodity markets. The world price (PW) of a commodity is the equilibrating mechanism for traded commodities - when an exogenous shock is introduced in the model, PW will adjust to clear world markets and each adjustment is passed back to the effective producer (PS) and consumer (PD) prices via the price transmission equations. Changes in domestic prices subsequently affect commodity supply and demand, necessitating their iterative readjustments until world supply and demand balance and world net trade again equals zero. For non-traded commodities, domestic prices in each country adjust to equate supply and demand within the country.

IMPACT assumes a closed world economy — at the end of every year the world's production must equal the world's demand. This constraint is ensured by the following equation, where the sum of net trade over the globe must equal zero.

$$
\sum_{\text {cty }} N T_{\text {c,cty }}=0
$$

$$
N T=\text { Net Trade }
$$

National production and demand for tradable commodities are linked to world markets through trade. Commodity trade by country (cty) is a function of domestic production, domestic demand, and stock change. (Note that stocks are constant and exogenous). Regions with positive net trade are net exporters, while those with negative values are net importers. This specification does not permit a separate identification of international trade by country of origin and destination - all countries export to and import from a single global market.

$$
\begin{aligned}
N T_{\mathrm{c}, \mathrm{cty}} & =Q S U P_{\mathrm{c}, \mathrm{cty}}-Q D_{\mathrm{c}, \mathrm{cty}}-Q S t_{\mathrm{c}, \mathrm{cty}} \\
N T & =\text { Net trade } \\
Q S t & =\text { Change in stocks }
\end{aligned}
$$

Prices are endogenous in the system of equations for food, and are calibrated to year 2005 commodity prices. $^{10-}$ 1210-12 Prices are in constant 2005 US\$. Domestic prices of tradable commodities are a function of world prices, adjusted by the effect of trade policy represented by taxes and tariffs, price policies expressed in terms of producer support estimates (PSE), consumer support estimates (CSE), and the cost of moving products from one market to another represented by marketing margins (MM). Export taxes and import tariffs are drawn from GTAP data (Global Trade Analysis Project at Purdue University) and reflect trade policies at the national level. ${ }^{13-15}$ PSEs and CSEs represent public policies to support production and consumption by creating wedges between world and domestic prices. PSEs and CSEs are based on OECD estimates and are adjusted by expert 
judgment to reflect regional trade dynamics. ${ }^{16}$ Marketing margins (MM) reflects other factors such as transport and marketing costs of getting goods to various markets and are based on expert opinion on the quality and availability of transportation, communication, and market infrastructure.

In the model, PSEs, CSEs, and MMs are expressed as percentages (ad valorem) of the world price. To calculate producer prices the appropriate wedges are applied to the domestic consumer prices (PC) and represent the mark-up observed in domestic markets from the farm-gate or factory-gate prices producers receive. The producer price of an activity is the weighted sum of the prices of the commodities associated with that activity.

$$
\begin{aligned}
P P_{\mathrm{j}, \text { cty }} \times\left(1+M M J_{\mathrm{j}, \mathrm{cty}}\right) & =\left(1+P S E_{\mathrm{j}, \text { cty }}\right) \times \sum_{\mathrm{c}} J C R a \text { Rtio }_{\mathrm{j}, \mathrm{c}, \mathrm{cty}} \times P C_{\mathrm{c}, \mathrm{cty}} \\
P P & =\text { Producer price } \\
M M J & =\text { Farm(factory)-gate to domestic market Marketing Margin (MM) } \\
P S E & =\text { Producer support estimate, ad valorem component } \\
J C R a t i o & =\text { mapping from activities (j) to commodities (c) }
\end{aligned}
$$

How consumer prices are determined in IMPACT depends on the state of tradability of the commodity. Commodities can be specified as either tradable or non-tradable. Traded commodity prices are determined in international markets. Non-traded commodities, are those commodities whose prices are determined in national markets, without direct links to international markets. Examples include sugarcane, sugar beets, and grass, where all demand is intermediate demand from domestic sectors (sugar processing, and livestock). These commodity prices are determined endogenously by country and ensure that domestic supply equals domestic demand.

$$
Q S U P_{\mathrm{c}, \mathrm{cty}}=Q D_{\mathrm{c}, \mathrm{cty}}
$$

Non-traded commodity are indirectly linked to world markets through the demand for final products (i.e. sugar), and potential substitution from tradable commodities (i.e. grass and other feeds).

\section{A1.2. IMPACT Model System}

The IMPACT model system is a network of linked models. Below we describe the linkages to the crop and water models used for this study. Other climatic inputs are described in Appendix A2. Again, we draw on the IMPACT model description by Robinson and colleagues for this description. ${ }^{2}$ Please refer to that documentation for additional details.

\section{Crop Models}

The effect of climate change on crop yields starts by running the DSSAT family of crop models across a gridded representation of the world. Yield maps for groundnuts, maize, potatoes, rice, sorghum, soybeans, and wheat are compiled under both rainfed and irrigated conditions. Driving the model are a large collection of data. Some represent soil characteristics and conditions as well as basic management decisions while others characterize the climatic conditions under which the crops were grown.

The climate data are maps of monthly climate data that allow the random generation of daily weather data for each location typical of what might be expected for conditions of the near recent past (year 2005) as well as those of the future (year 2050). The baseline climate information come from Jones, Thornton, and Heinke. ${ }^{17}$ The future climate information is derived from data processed by the Inter-Sectoral Impact Model Intercomparison Project. ${ }^{18-20}$ The two datasets were combined by extracting the appropriate changes from the climate model data and imposing them on the common baseline climate. The crop models can then make projections about possible yields under the different climate circumstances.

The grid-based yields for each climate and crop combination are then aggregated within regions appropriate for the economic portions of the model. Specifically, they are computed as production-area-weighted-averages using maps of production areas from the Spatial Production Allocation Model as weights. ${ }^{21}$ These are then used as weights in the multi-market model to estimate final yield impacts. This follows the general approach for incorporating projected yield changes from biophysical models into economics models as outlined in Müller and Robertson. ${ }^{22}$ 


\section{Water Models}

The water modules in the IMPACT Modelling System include: (1) the IMPACT global hydrology model (IGHM), (2) the IMPACT water basin simulation model (IWSM) that manages storage by water basin and generates available irrigation water supply; and (3) the IMPACT crop water allocation and stress model (ICWASM) that allocates available irrigated water to crops and estimates the impact of water shortages on yields These three models enable the IMPACT multi-market model to assess the effects on global food and water systems of hydro-climatic variability and change, socioeconomic change-driven water demand growth, investment in water storage and irrigation infrastructure, and technological improvements.

The IGHM hydrological model is driven by climate-forcing data and computes effective rainfall, potential and actual evapotranspiration, and runoff to river basins. The IGHM-simulated hydrologic outputs are then provided in a one-way link to the IWSM water basin simulation models, which optimally manage water basin storage and provide irrigated water supply in one-way link to the ICWASM water stress models that then provides the IMPACT multi-market model with crop yields for both irrigated and rainfed crops. The solution of the IGHM model depends only on climate inputs and is completely independent of the other water models and the IMPACT multi-market model. However, there is two-way communication between the IWSM model and the IMPACT multi-market model - the demand for water in IWSM depends on the allocation of land to crops, which is part the solution of the IMPACT multi-market model. In turn, changes in water availability from IWSM affect water allocation and stress in the ICWASM model. The communication between these models to capture this endogeneity is discussed below.

\section{IMPACT Global Hydrology Model (IGHM)}

As described in the following schematic (Figure 5.5), the IGHM hydrological model is a semi-distributed parsimonious model. It simulates monthly soil moisture balance, evapotranspiration and runoff generation on each $0.5^{\circ}$ latitude $x 0.5^{\circ}$ longitude grid cell spanning the global land surface except the Antarctic. Gridded output of hydrological fluxes - namely effective rainfall, evapotranspiration and runoff - are spatially aggregated to food production units (FPU) within the river basin and weighted by grid cell areas.

The most important climatic drivers for water availability are precipitation and evaporative demand determined by net radiation at ground level, atmospheric humidity, wind speed, and temperature. In IGHM, the PriestleyTaylor equation is used to calculate potential evapotranspiration (PET) ${ }^{23}$ Soil moisture balance is simulated for each grid cell using a single layer water bucket. To represent sub-grid variability of soil water-holding capacity, we assume it spatially varies within each grid cell, following a parabolic distribution function.

Actual evapotranspiration is determined jointly by the PET and the relative soil moisture state in a grid cell. The generated runoff is divided into a surface runoff component and a deep percolation component using a partitioning factor. The base flow is linearly related to storage of the groundwater reservoir. The total runoff to the streams in a month is the sum of surface runoff and base flow.

\section{IMPACT Water Basin Simulation Model (IWSM)}

\section{Water demand}

The water demand module calculates water demand for crops, industry, households, and livestock at the FPU level. Irrigation water demand is assessed as the portion of crop water requirement not satisfied by precipitation or soil moisture based on hydrologic and agronomic characteristics. Crop demand is calculated for each crop using evapotranspiration and effective rainfall from IGHM. It relies on the FAO crop coefficient approach to calculate actual water demand for each crop every month. Irrigation demand in the FPU is calculated for a given cropping pattern after taking into account the basin efficiency of the irrigation system. ${ }^{24}$ The IMPACT multimarket model solves endogenously for the allocation of land to different crops while the IWSM model requires information on cropping pattern to calculate water demand and hence water stress that is then an input into the multi-market model, which requires two-way communication between the models (as mentioned earlier).

Industrial water demand is modelled for the manufacturing and energy sectors using growth rates for the valueadded by sector and energy production values for electricity sector from the EPPA6 Model of the MIT Joint Program on the Science and Policy of Global Change. ${ }^{25}$ For many countries in Sub-Saharan Africa, the projected industrial water demands are substantially lower than those in IMPACT2, suggesting an underestimation. 
Therefore, for countries in Sub-Saharan Africa we retained the projection method of IMPACT2 for industrial water demand which is modelled as a nonlinear function of gross domestic production per capita and technology change.

Future domestic water demands are based on projections of population and income growth. In each region or basin income elasticities of demand for domestic water use are synthesized based on the literature and available estimates. ${ }^{26,27}$ These elasticities of demand measure the propensity to consume water with respect to increases in per capita income. The elasticities also capture both direct income effects and conservation of domestic water use through technological and management change. Livestock water demand is proportional to the number of animals raised as calculated by the multi-market model.

\section{Water Supply}

The IMPACT Water Basin Simulation Model (IWSM) is a water basin management model. For FPUs where there is surface water storage capacity (e.g., dams), the model specifies a single reservoir that summarizes all water storage capacity. For a given water basin that includes more than one FPU, IWSM manages storage in all those FPUs to maximize the ratio of water supply to water demand in the water basin. IWSM uses the runoff calculated by IGHM, the climatic data and the water demands presented above to allocate available water to different uses. In each FPU, IWSM solves for a balance between the change in the amount of water stored in the reservoirs, the entering water flows (runoff from precipitation, water from non-traditional sources like desalination, and inflows from FPUs situated upstream), the exiting water flows (groundwater recharge from the stream, evaporation from the reservoirs, outflows to the FPU downstream or the ocean) and the water withdrawn for human use (surface water depletion). The model uses a simple hedging rule to avoid leaving an empty storage for next year.

Surface water depletion added to the pumped groundwater (which is limited by the monthly capacity of tubewells and other pumps) is used to meet the various water demands. The model solves by maximizing the ratio of water supplied to water demanded by water basin over a year in all FPUs. Solving for water demand and supply in all FPUs simultaneously, IWSM assumes that linked FPUs within the same water basins are operated cooperatively, optimally allocating water between upstream and downstream demanders (qualified by imposing constraints on water delivery to downstream demanders). The model is parameterized to use available storage to smooth the distribution of water over months in order to avoid dramatic swings in monthly water delivery, if possible.

Following standard practice, IWSM incorporates the basic rule that non-agricultural water demands have priority over agricultural water demands. Any shortage in water supply is absorbed by agriculture first. If the shortage is larger than irrigation water demand, then livestock, domestic and industrial supplies are reduced proportionally.

\section{IMPACT Crop Water Allocation and Stress Model (ICWASM)}

The Water Allocation and Stress module (ICWASM) then allocates water among crops in an area, given the economic value of the crop. We use the FAO Ky approach to measure water stress using a monthly approach to include seasonality of water stress. ${ }^{28}$ Because optimizing total value of production given fixed prices leads to a tendency for specializing in high-value crops, we include a measure of risk aversion for farmers in the objective function, which preserves a diversified production structure even in case of a drought. The stress model produces a measure of yield stress for every crop-both irrigated and rainfed - in each of FPUs where that crop is grown. The yield stress for the base year is recorded and the model defines for subsequent years the yield shock as the ratio of that year's yield stress to the base year yield stress. This allows for a consistent modelling framework while making sure that the base year yields from the multi-market model dataset is preserved.

\section{Linking the IMPACT water and multi-market models}

In a given year, the IMPACT multi-market model is first solved assuming exogenous trends on various parameters, yielding projected production, prices and allocation of land to crops. For this first run, expected water stress is set to the average of the previous four years, which sets harvest expectations for the allocation of land to different crops. This solution can be seen as providing projections that farmers use to make their cropping decisions.

The water demand module then calculates water demand for crops, industry, households, and livestock. Agricultural and non-agricultural water demands are then calculated as outlined above. IWSM uses these water 
demands, along with river flows provided by IGHM, to provide the monthly repartition of water amongst FPUs given the objective function described above.

ICWASM then allocates water among crops in an area, given the economic value of the crop. The stress model produces a measure of water stress on yield for every crop-both irrigated and rainfed - in each of the FPUS that is then multiplied by the temperature stress obtained from DSSAT to represent the total climate yield shock.

Finally, the new yield shocks are applied to the IMPACT multi-market model, which is solved a second time for the final equilibrium, only now assuming that the allocation of land to crops is fixed since farmers cannot change their decisions after planting. This solution yields all economic variables, including quantities and prices of outputs and inputs, and all trade flows. The model then moves to the next year, updates various parameters on trend and starts the process again. 


\section{Appendix A2: Socio-economic and emissions pathways}

Table A2.1 provides an overview of this study's model inputs and scenarios.

Table A2.1: Overview of model inputs and components used for constructing the model scenarios within the IMPACT and health analysis framework (see Panel 1 in the main text for a description of climate and development-related scenario inputs). The main scenarios include a reference scenario without climate change which follows a "middle-of-the-road" socio-economic development pathway (SSP2), and six climate change scenarios which follow the same socio-economic pathway and, in addition, a high emissions pathway (RCP8.5) with different combinations between three general circulation models (IPSL-CM5ALR, HadGEM2-ES, MIROC-ESM-CHEM) and two crop models (DSSAT, LPJmL).

\begin{tabular}{|c|c|c|c|c|}
\hline \multirow{2}{*}{ Model inputs } & \multirow{2}{*}{ Model component } & \multicolumn{2}{|c|}{ Main scenarios } & \multirow{2}{*}{$\begin{array}{l}\text { Sensitivity } \\
\text { analysis }\end{array}$} \\
\hline & & Reference scenario & Climate change scenarios & \\
\hline \multirow{6}{*}{ Climatic inputs } & \multirow{3}{*}{$\begin{array}{l}\text { Radiative forcing } \\
\text { pathway }\end{array}$} & \multirow{3}{*}{ none } & \multirow{3}{*}{$\mathrm{RCP} 8.5$} & RCP6.0 \\
\hline & & & & $\mathrm{RCP} 4.5$ \\
\hline & & & & $\mathrm{RCP} 2.6$ \\
\hline & \multirow{3}{*}{$\begin{array}{l}\text { General circulation } \\
\text { models }\end{array}$} & \multirow{3}{*}{ none } & IPSL-CM5A-LR & \\
\hline & & & HadGEM2-ES & \\
\hline & & & MIROC-ESM-CHEM & \\
\hline \multirow{2}{*}{$\begin{array}{l}\text { Biophysical } \\
\text { inputs }\end{array}$} & \multirow{2}{*}{ Crop models } & \multirow{2}{*}{ none } & DSSAT & \\
\hline & & & LPJmL & \\
\hline \multirow{2}{*}{$\begin{array}{l}\text { Socio-economic } \\
\text { inputs }\end{array}$} & \multirow{2}{*}{$\begin{array}{l}\text { Socio-economic } \\
\text { pathway }\end{array}$} & \multirow{2}{*}{ SSP2 } & \multirow{2}{*}{ SSP2 } & SSP1 \\
\hline & & & & SSP3 \\
\hline \multirow{3}{*}{ Health inputs } & \multirow{3}{*}{$\begin{array}{l}\text { Relative risk } \\
\text { parameters }\end{array}$} & $\mathrm{RR}(\Delta \mathrm{FV} ; \Delta$ red meat $)$ & $\mathrm{RR}(\Delta \mathrm{FV} ; \Delta$ red meat $)$ & \\
\hline & & $\mathrm{RR}(\Delta$ weight $)$ & $\mathrm{RR}(\Delta$ weight $)$ & \\
\hline & & Monte-Carlo analysis & Monte-Carlo analysis & \\
\hline
\end{tabular}

Abbreviations: RCP: representative concentration pathway; SSP: shared socio-economic pathway; RR: relative risk; FV: fruit and vegetable consumption 
For this study's main scenarios, we adopted a "middle-of-the-road" socioeconomic trajectory (SSP2), using GDP projections developed by the Organization for Economic Co-operation and Development (OECD) and population projections developed by the International Institute for Applied Systems Analysis (IIASA). ${ }^{29,30}$ For analysing the sensitivity to different socio-economic pathways, we adopted two alternative socio-economic pathways in the sensitivity analysis: a "Sustainability"-termed socio-economic pathway (SSP1) which is characterized by medium to high economic growth and low population growth, and a "Fragmentation"-termed socio-economic pathway (SSP3) which is characterized by slow economic growth and high population growth. ${ }^{31}$ The challenges to mitigation and adaptation increase when going from SSP1 to SSP3. Table A2.2 provides an overview of the storylines associated with each socio-economic pathway, and Table A2.3 lists the associated GDP and population estimates.

\section{Table A2.2 Summary narratives of the Shared Socio-Economic Pathways (SSPs)}

\section{SSP Narrative}

SSP 1 Sustainable development is realized, with relatively high levels of investment in research and development, which leads to rapid technological change (with a sustainable focus), decreasing inequality, lower energy intensity, and high land productivity. This development pathway leads to a future where society is able to relatively easily mitigate or adapt to climate change. There is high rates of economic growth, declining population growth, and increasing levels of education globally.

SSP 2 This is a middle of the road scenario, which follows historical trends. Economic development continues, but is not uniform. Environmental degradation continues, but at a slowing pace. There is general improvement, but it is much slower than that seen in SSP 1. Climate change presents moderate challenges to both adaptation and mitigation.

SSP 3 A fairly negative future pathway characterized by increasing nationalism, with greater levels of conflict and challenges to global and regional cooperation. Barriers to trade increase, and countries tend to look inward at the expense of global cooperation. There are lower levels of technological change. Economic development is slow, and population growth is higher. Climate change presents significant challenges for both adaptation and mitigation

SSP 4 A scenario where current levels of inequality become entrenched and worsened over time. With inequality and stratification both within and between countries increasing. These leads to a world of pockets. Rich countries and elites in poorer countries improve significantly, but the rest lag behind. High levels of integration across elites allows for some level of global coordination, which allows society to more easily mitigate to climate change. However, large segment of the population are left behind, making climate change adaptation more difficult for most

SSP 5 A future characterized by fast economic industrialization. There are high levels of technological progress and improvements in education levels around the world. Globalization increases rapidly. However, the rapid industrialization is spurred on through the intense use of fossil fuels, and as such there is little effort to mitigate the effects of climate change, with the focus on adaptation through the development of new and improved technologies.

Source: Author summary from O'Neill et al 2014 and O'Neill et al 2015 descriptions of the SSPs ${ }^{32,33}$ 
Table A2.3 Regional summary of GDP (billion 2005 USD), population (million), and GDP per capita (000 USD/person) assumptions by SSP

\begin{tabular}{|c|c|c|c|c|c|c|}
\hline & \multirow[t]{2}{*}{2010} & \multicolumn{5}{|c|}{2050} \\
\hline & & SSP1 & SSP2 & SSP3 & SSP4 & SSP5 \\
\hline \multicolumn{7}{|c|}{ East Asia and Pacific } \\
\hline GDP & 19,236 & 104,096 & 80,045 & 60,608 & 78,950 & 130,284 \\
\hline Population & 2,184 & 2,173 & 2,261 & 2,351 & 2,145 & 2,187 \\
\hline GDP per capita & 9 & 48 & 35 & 26 & 37 & 60 \\
\hline \multicolumn{7}{|l|}{ Europe } \\
\hline GDP & 14,628 & 30,571 & 27,780 & 21,342 & 28,442 & 39,228 \\
\hline Population & 537 & 592 & 577 & 498 & 544 & 662 \\
\hline GDP per capita & 27 & 52 & 48 & 43 & 52 & 59 \\
\hline \multicolumn{7}{|c|}{ Former Soviet Union (excl. Baltic States) } \\
\hline GDP & 2,855 & 10,603 & 8,984 & 7,551 & 9,174 & 13,750 \\
\hline Population & 279 & 262 & 277 & 289 & 257 & 266 \\
\hline GDP per capita & 10 & 40 & 32 & 26 & 36 & 52 \\
\hline \multicolumn{7}{|c|}{ Latin America and Caribbean } \\
\hline GDP & 5,834 & 22,838 & 19,164 & 15,894 & 17,600 & 27,492 \\
\hline Population & 585 & 674 & 742 & 853 & 705 & 651 \\
\hline GDP per capita & 10 & 34 & 26 & 19 & 25 & 42 \\
\hline \multicolumn{7}{|c|}{ Middle East and North Africa } \\
\hline GDP & 4,551 & 20,566 & 18,631 & 16,006 & 18,550 & 26,763 \\
\hline Population & 457 & 646 & 715 & 808 & 726 & 649 \\
\hline GDP per capita & 10 & 32 & 26 & 20 & 26 & 41 \\
\hline \multicolumn{7}{|l|}{ North America } \\
\hline GDP & 14,290 & 33,691 & 29,933 & 24,753 & 32,124 & 44,503 \\
\hline Population & 344 & 460 & 450 & 372 & 424 & 535 \\
\hline GDP per capita & 41 & 73 & 67 & 67 & 76 & 83 \\
\hline \multicolumn{7}{|l|}{ South Asia } \\
\hline GDP & 4,461 & 44,250 & 32,939 & 22,756 & 27,189 & 55,705 \\
\hline Population & 1,630 & 2,108 & 2,373 & 2,720 & 2,289 & 2,087 \\
\hline GDP per capita & 3 & 21 & 14 & 8 & 12 & 27 \\
\hline \multicolumn{7}{|c|}{ Sub-Saharan Africa } \\
\hline GDP & 1,705 & 19,690 & 13,962 & 9,665 & 8,843 & 25,499 \\
\hline Population & 863 & 1,564 & 1,793 & 2,084 & 2,055 & 1,543 \\
\hline GDP per capita & 2 & 13 & 8 & 5 & 4 & 17 \\
\hline \multicolumn{7}{|l|}{ World } \\
\hline GDP & 67,559 & 286,305 & 231,439 & 178,575 & 220,873 & 363,226 \\
\hline Population & 6,879 & 8,479 & 9,187 & 9,975 & 9,147 & 8,578 \\
\hline GDP per capita & 10 & 34 & 25 & 18 & 24 & 42 \\
\hline
\end{tabular}

Source: Calculated from IMPACT 3.1 with population and GDP growth rates from IIASA and OECD ${ }^{29,30}$

Note: GDP and GDP per capita are in purchasing power parity (ppp) 
In the main climate change scenarios, we adopted the highest emissions pathway (RCP8.5) to scope the full range of potential climate change impacts. That pathway leads to an increase in the global mean surface air temperature of 2.0 degrees $\mathrm{C}$ in 2046-2065 compared to the period $1986-2005 .{ }^{34}$ For analysing the sensitivity to different emissions pathways, we adopted three alternative emissions trajectories in the sensitivity analysis: two medium climate-stabilization scenarios (RCP4·5, RCP6), and one stringent climate-stabilization scenario (RCP2.6) that is based, in part, on the use of negative emissions technologies, such as carbon capture and storage (CCS) and bio-energy. ${ }^{35}$ The increases in global mean surface air temperature from the period 1986-2005 to 2046-2065 are 1.3 degrees $\mathrm{C}$ and 1.4 degrees $\mathrm{C}$ in the medium stabilization scenarios (RCP6.0, RCP4.5), and $1 \cdot 0$ degree $\mathrm{C}$ in the stringent stabilization scenario (RCP2.6). The changes in precipitation for a given change in temperature increase when going from the low emissions scenario to the higher emissions scenarios (from RCP2. 6 to to RCP8.5). ${ }^{34}$ Table A2.4 lists the range of changes in temperature and sea-level rise associated with each emissions pathway.

Table A2.4 Likely range of global warming and sea level rise by RCP

\begin{tabular}{ccccc}
\hline RCP & \multicolumn{2}{c}{ Mid Century $^{\mathrm{a}}$} & \multicolumn{2}{c}{ End of the Century $^{\mathrm{b}}$} \\
& Temperature Increase $^{\mathrm{c}}$ & Sea Level Rise & Temperature Increase & Sea Level Rise \\
\hline 2.6 & $+0.4-1.6$ & $+0.17-0.32$ & $+0.3-1.7$ & $+0.26-0.55$ \\
4.5 & $+0.9-2.0$ & $+0.19-0.33$ & $+1.1-2.6$ & $+0.32-0.63$ \\
6.0 & $+0.8-1.8$ & $+0.18-0.32$ & $+2.2-3.1$ & $+0.33-0.63$ \\
8.5 & $+1.4-2.6$ & $+0.22-0.38$ & $+2.6-4.8$ & $+0.45-0.82$ \\
\hline
\end{tabular}

Source: IPCC $^{7}$

Notes: The NoCC scenario assumes no change in temperature or sea levels

${ }^{a}$ Mid Century represents the 20 years from 2046-2065

${ }^{\mathrm{b}}$ End of Century represents the 20 years from 2081-2100

${ }^{\mathrm{c}}$ Temperature is in ${ }^{\circ} \mathrm{C}$, and Sea level rise is in $\mathrm{m}$

Regional projections of the agricultural impacts of climate change are subject to significant uncertainty. ${ }^{36} \mathrm{We}$ therefore used different combinations of general circulation models (GCMs), which project changes in temperature and precipitation, and crop models, which use those changes to project biophysical changes in crop yields, to generate a spread of input parameters for our agriculture and health assessment. The GCMs include HadGEM2-ES, ${ }^{37}$ IPSL-CM5A-LR,${ }^{38}$ and MIROC-ESM-CHEM $;{ }^{39}$ and the crop models include DSSAT and LPJmL. ${ }^{6,40}$ The pair-wise combination of GCMs with crop models resulted in six climate change scenarios for each socio-economic and emissions pathway. We calculated the mean and standard deviation of the scenario endpoints (changes in food availability and consumption, and changes in mortality) that are associated with the different climate change scenarios, and we report those in the main text to simplify exposition. Figures A2.1A2.2 show the regional distribution of changes in temperature and precipitation estimated by the three GCMs, and Figure A2.3 shows the regional distribution of soil types that is used by the globally gridded crop models. Appendix A1 provides additional detail on the interaction between crops models and the IMPACT global economic model 
Figure A2.1 Changes in maximum temperature (in degrees Celsius) in 2050 compared to 2000 under a high-emissions trajectory (RCP8.5) estimated by HadGEM2-ES ${ }^{37}$ (upper panel), IPSL-CM5A-LR ${ }^{38}$ (middle panel), and MIROC-ESM-CHEM ${ }^{39}$ (lower panel).

Figure A2.2 Changes in precipitation (in millimetres) in 2050 compared to 2000 under a high-emissions trajectory (RCP8.5) estimated by HadGEM2-ES ${ }^{37}$ (upper panel), IPSL-CM5A-LR ${ }^{38}$ (middle panel), and MIROC-ESM-CHEM ${ }^{39}$ (lower panel).
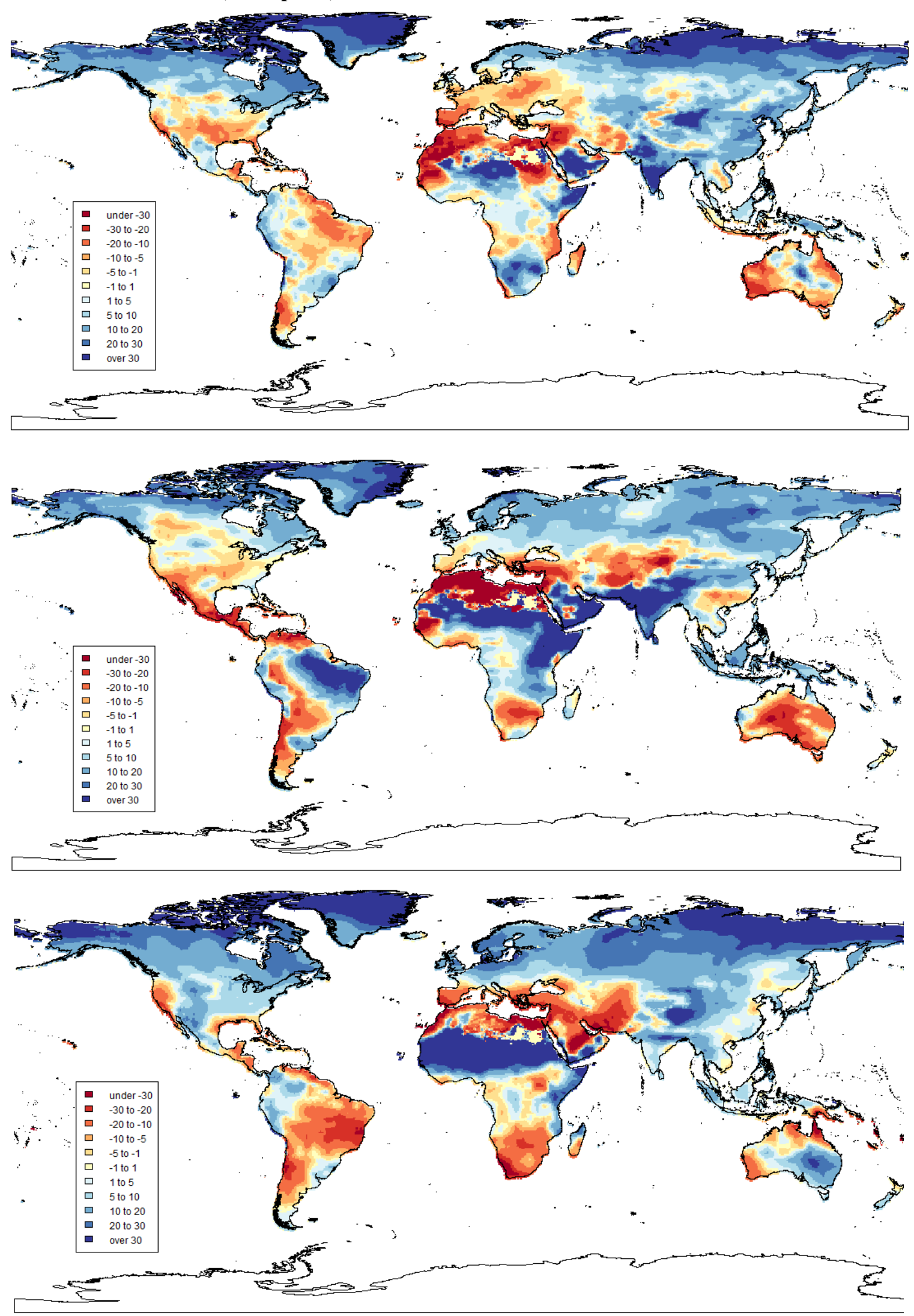
Figure A.3 Global Distribution of 27 Generic Soil Types

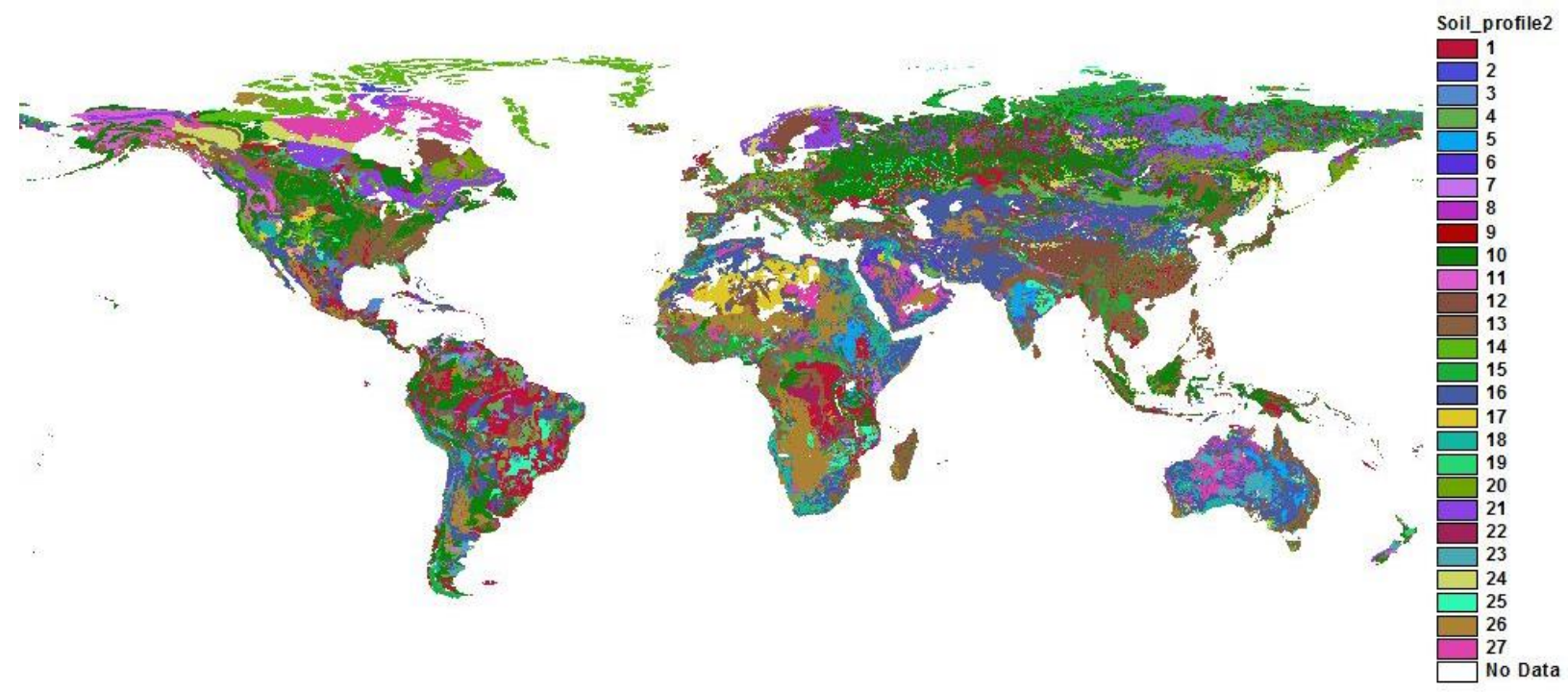

Source: The Harmonized World Soil Database (FAO/IIASA/ISRIC/ISSCAS/JRC 2012) 


\section{Appendix A3: Conversion from food demand into food consumption}

Baseline food production and availability, as estimated by the IMPACT model, are calibrated using food balance sheets supplied by the Food and Agriculture Organization of the United Nations (FAO). The FAO states that: ${ }^{41-}$ 43

The quantities of food available for human consumption, as estimated in the food balance sheet, relate to the quantities of food reaching the consumer. Waste on the farm and during distribution and processing is taken into consideration as an element in the food balance sheet. However, The amount of food actually consumed may be lower than the quantity shown in the food balance sheet depending on the degree of losses of edible food and nutrients in the household, e.g. during storage, in preparation and cooking (which affect vitamins and minerals to a greater extent than they do calories, protein and fat), as plate-waste, or quantities fed to domestic animals and pets, or thrown away.

For the dietary risk assessment, we converted the food availability estimates for fruit and vegetables and for red meat into food consumption estimates by using regional data on food wastage at the consumption level, combined with conversion factors into edible matter. ${ }^{44}$ Table A3.1 lists the waste percentages used. A conversion factor of 0.77 was used to determine the edible parts of fruits and vegetables. No conversion factor was used for red meat, because the waste percentages reported in Table A3.1 were obtained for carcass weight (including bone), and therefore included wastage of non-edible parts.

Table A3.1: Waste percentages at consumption according to $\mathrm{FAO}^{44}$

\begin{tabular}{|c|c|c|c|c|c|c|c|}
\hline \multirow[b]{2}{*}{ Food items } & \multicolumn{7}{|c|}{ Regions } \\
\hline & Europe & $\begin{array}{c}\text { USA, } \\
\text { Canada, } \\
\text { Oceania }\end{array}$ & $\begin{array}{c}\text { Industrialized } \\
\text { Asia }\end{array}$ & $\begin{array}{c}\text { Sub- } \\
\text { Saharan } \\
\text { Africa }\end{array}$ & $\begin{array}{c}\text { North } \\
\text { Africa, } \\
\text { West and } \\
\text { Central } \\
\text { Asia }\end{array}$ & $\begin{array}{c}\text { South and } \\
\text { Southeast } \\
\text { Asia }\end{array}$ & $\begin{array}{c}\text { Latin } \\
\text { America }\end{array}$ \\
\hline $\begin{array}{l}\text { Fruits and } \\
\text { vegetables }\end{array}$ & 0.19 & 0.28 & 0.15 & 0.05 & 0.12 & 0.07 & 0.1 \\
\hline Meat & 0.11 & 0.11 & 0.08 & 0.02 & 0.08 & 0.04 & 0.06 \\
\hline
\end{tabular}




\section{Appendix A4: Weight estimation}

For the weight-related risk assessment, we estimated changes in weight as shifts in the baseline weight distribution by using the historical relationship between national food availability and mean BMI. We estimated the baseline distribution by fitting a log-normal distribution to WHO estimates of mean BMI and the prevalence of overweight and obesity using a cross-entropy method. ${ }^{45}$ Cross-entropy estimation is a Bayesian technique for recovering parameters and data which have been observed imperfectly. The cross-entropy approach redefines the estimation problem as estimating and minimizing the divergence from the original prior while satisfying various constraints. In our application, we take mean BMI values as given and use the cross-entropy method to find the shape and position parameters of the log-normal distribution which jointly minimize the deviation of the estimates of the prevalence of overweight and the prevalence of obesity from the input parameters.

We estimated the relationship between national food availability and mean BMI by pairing FAO food availability data for the years 1980-2009 with WHO data on mean BMI for the same period. Using a polynomial trend yielded the following relationship $\left(\mathrm{R}^{2}=0.46\right)$ :

$$
\operatorname{BMI}(r)=\left(-9.53 \cdot 10^{-7}\right) \cdot k \operatorname{cal}(r)^{2}+\left(7.87 \cdot 10^{-3}\right) \cdot k \operatorname{cal}(r)+10.18
$$

where $k c a l(r)$ denotes food availability in region $r$ in terms of kcal per person per day, and $B M I(r)$ denotes the average mean BMI in that region. Figure A4.1 provides a graphical depiction.

Figure A4.1: Association between food availability and mean BMI based on data from FAO and WHO for the years 1980-2009.




Based on the relationship between mean BMI and food availability, we estimated the changes in the weight distribution as follows. We calculated the mean BMI values for the years 2010 and 2050 using food availability projections from the IMPACT model, and we then used the percentage change in mean BMI between 2010 and 2050 to shift the baseline BMI distribution. In shifting the weight distribution, we held constant the distribution's shape parameter, $\sigma(r)$, and re-calculated its position parameter $\mu(r)$ based on the estimated mean: $\mu(r)=$ $\log B M I(r)-\frac{\sigma(r)^{2}}{2}$. Analyses were conducted to assess the impact of holding the shape parameter constant, which showed that results were not sensitive to this assumption. Tables A4.1-A4.3 list the estimated weight distribution for the baseline in 2010, for the reference scenario without climate change in 2050, and for the mean of all climate change scenarios in 2050.

Table A4.1: Baseline weight distribution estimated for 2010, including food availability (kcal/cap/day), mean BMI $\left(\mathrm{kg} / \mathrm{m}^{2}\right)$, and the prevalence of underweight $(B M I<18 \cdot 5)$, normal weight $(18 \cdot 5<B M I<25)$, overweight $(25<\mathrm{BMI}<30)$, and obesity $(\mathrm{BMI}>30)$. See Appendix A6 for details on the regional aggregation.

\begin{tabular}{|c|c|c|c|c|c|c|}
\hline Region & kcal/day & mean BMI & underweight & normal & obese & overweight \\
\hline Global & $2,817.488$ & 23.834 & 0.126 & 0.521 & 0.116 & 0.237 \\
\hline HIC & $3,414.266$ & 26.521 & 0.049 & 0.380 & 0.242 & 0.329 \\
\hline AFR_LMIC & $2,417.637$ & 22.982 & 0.154 & 0.558 & 0.077 & 0.211 \\
\hline AMR_LMIC & $2,886.389$ & 26.674 & 0.043 & 0.369 & 0.247 & 0.341 \\
\hline EMR_LMIC & $2,661.549$ & 24.951 & 0.100 & 0.454 & 0.170 & 0.275 \\
\hline EUR_LMIC & $3,035.427$ & 26.310 & 0.056 & 0.388 & 0.231 & 0.324 \\
\hline SEA_LMIC & $2,406.471$ & 21.463 & 0.206 & 0.638 & 0.020 & 0.136 \\
\hline WPR_LMIC & $3,016.896$ & 22.958 & 0.133 & 0.582 & 0.058 & 0.227 \\
\hline AFG & $2,424.123$ & 20.897 & 0.276 & 0.588 & 0.017 & 0.120 \\
\hline AGO & $2,368.642$ & 23.056 & 0.161 & 0.532 & 0.080 & 0.228 \\
\hline ALB & $2,881.118$ & 26.202 & 0.051 & 0.396 & 0.219 & 0.334 \\
\hline ARG & $3,150.012$ & 27.600 & 0.031 & 0.319 & 0.304 & 0.346 \\
\hline ARM & $2,715.527$ & 26.429 & 0.059 & 0.380 & 0.242 & 0.319 \\
\hline AUS & $3,142.919$ & 27.348 & 0.027 & 0.329 & 0.282 & 0.362 \\
\hline AUT & $3,680.203$ & 25.782 & 0.062 & 0.418 & 0.198 & 0.323 \\
\hline AZE & $3,090.000$ & 26.809 & 0.048 & 0.362 & 0.261 & 0.330 \\
\hline BDI & $2,078.599$ & 21.498 & 0.228 & 0.595 & 0.026 & 0.150 \\
\hline BEN & $2,503.985$ & 23.154 & 0.133 & 0.560 & 0.069 & 0.238 \\
\hline BFA & $2,615.127$ & 21.502 & 0.199 & 0.645 & 0.016 & 0.140 \\
\hline BGD & $2,473.371$ & 20.549 & 0.269 & 0.645 & 0.005 & 0.081 \\
\hline BGR & $2,798.138$ & 26.133 & 0.054 & 0.399 & 0.217 & 0.330 \\
\hline BLR & $2,874.586$ & 26.560 & 0.050 & 0.375 & 0.244 & 0.331 \\
\hline BLT & $3,781.702$ & 26.244 & 0.060 & 0.390 & 0.229 & 0.321 \\
\hline BLX & $3,772.205$ & 26.066 & 0.052 & 0.404 & 0.210 & 0.333 \\
\hline BLZ & $2,677.116$ & 28.645 & 0.016 & 0.259 & 0.369 & 0.356 \\
\hline BOL & $2,158.139$ & 25.803 & 0.065 & 0.415 & 0.202 & 0.318 \\
\hline BRA & $3,130.506$ & 26.002 & 0.050 & 0.409 & 0.204 & 0.337 \\
\hline BTN & $2,200.784$ & 22.946 & 0.133 & 0.581 & 0.057 & 0.229 \\
\hline BWA & $2,174.990$ & 24.249 & 0.148 & 0.450 & 0.151 & 0.251 \\
\hline CAF & $1,959.224$ & 21.862 & 0.202 & 0.595 & 0.033 & 0.170 \\
\hline
\end{tabular}




\begin{tabular}{|c|c|c|c|c|c|c|}
\hline CAN & $3,446.720$ & 27.147 & 0.028 & 0.341 & 0.268 & 0.363 \\
\hline CHL & $2,899.668$ & 27.655 & 0.025 & 0.313 & 0.304 & 0.358 \\
\hline CHM & $3,102.757$ & 23.000 & 0.130 & 0.580 & 0.058 & 0.232 \\
\hline CHP & $3,355.467$ & 25.182 & 0.073 & 0.452 & 0.164 & 0.311 \\
\hline CIV & $2,655.107$ & 23.286 & 0.125 & 0.558 & 0.072 & 0.245 \\
\hline CMR & $2,318.619$ & 24.451 & 0.090 & 0.494 & 0.125 & 0.291 \\
\hline COD & $1,761.194$ & 20.906 & 0.254 & 0.625 & 0.011 & 0.110 \\
\hline $\mathrm{COG}$ & $2,221.470$ & 22.650 & 0.158 & 0.577 & 0.053 & 0.212 \\
\hline COL & $2,682.323$ & 25.709 & 0.062 & 0.422 & 0.192 & 0.323 \\
\hline CRB & $3,172.060$ & 27.751 & 0.032 & 0.312 & 0.316 & 0.340 \\
\hline CRI & $2,863.140$ & 26.895 & 0.035 & 0.357 & 0.256 & 0.352 \\
\hline CUB & $2,471.888$ & 26.245 & 0.053 & 0.393 & 0.224 & 0.331 \\
\hline CYP & $2,547.221$ & 26.764 & 0.049 & 0.364 & 0.258 & 0.329 \\
\hline CZE & $3,336.967$ & 27.336 & 0.042 & 0.335 & 0.293 & 0.330 \\
\hline DEU & $3,506.013$ & 26.435 & 0.045 & 0.383 & 0.231 & 0.341 \\
\hline DJI & $2,165.708$ & 23.948 & 0.123 & 0.499 & 0.114 & 0.263 \\
\hline DNK & $3,315.047$ & 25.696 & 0.051 & 0.429 & 0.182 & 0.338 \\
\hline DOM & $2,473.269$ & 26.498 & 0.045 & 0.379 & 0.236 & 0.340 \\
\hline DZA & $3,073.851$ & 25.640 & 0.066 & 0.425 & 0.191 & 0.318 \\
\hline $\mathrm{ECU}$ & $2,231.460$ & 26.449 & 0.043 & 0.382 & 0.231 & 0.343 \\
\hline EGY & $3,244.642$ & 28.492 & 0.021 & 0.271 & 0.361 & 0.347 \\
\hline ERI & $1,816.848$ & 21.051 & 0.232 & 0.645 & 0.011 & 0.112 \\
\hline ETH & $2,116.363$ & 20.600 & 0.269 & 0.639 & 0.006 & 0.086 \\
\hline FJI & $2,928.756$ & 28.119 & 0.025 & 0.292 & 0.337 & 0.345 \\
\hline FNP & $3,160.332$ & 26.240 & 0.047 & 0.394 & 0.219 & 0.340 \\
\hline FRP & $3,498.666$ & 25.317 & 0.068 & 0.446 & 0.169 & 0.317 \\
\hline GAB & $2,687.270$ & 25.197 & 0.076 & 0.449 & 0.167 & 0.308 \\
\hline GEO & $2,866.925$ & 26.176 & 0.059 & 0.395 & 0.224 & 0.323 \\
\hline GHA & $2,768.978$ & 23.757 & 0.107 & 0.535 & 0.090 & 0.267 \\
\hline GIN & $2,515.772$ & 22.600 & 0.150 & 0.595 & 0.046 & 0.209 \\
\hline GMB & $2,426.269$ & 23.416 & 0.149 & 0.514 & 0.096 & 0.241 \\
\hline GNB & $2,383.395$ & 22.354 & 0.191 & 0.559 & 0.054 & 0.197 \\
\hline GNQ & $2,621.864$ & 24.239 & 0.115 & 0.485 & 0.128 & 0.272 \\
\hline GRC & $3,592.905$ & 25.740 & 0.058 & 0.422 & 0.191 & 0.328 \\
\hline GSA & $2,655.622$ & 26.074 & 0.072 & 0.395 & 0.226 & 0.307 \\
\hline GTM & $2,185.275$ & 26.220 & 0.049 & 0.395 & 0.219 & 0.337 \\
\hline HND & $2,566.495$ & 26.050 & 0.054 & 0.404 & 0.210 & 0.332 \\
\hline HRV & $3,055.553$ & 26.020 & 0.062 & 0.403 & 0.215 & 0.320 \\
\hline HTI & $1,827.035$ & 23.798 & 0.106 & 0.533 & 0.092 & 0.269 \\
\hline HUN & $3,420.063$ & 26.660 & 0.049 & 0.370 & 0.251 & 0.330 \\
\hline IDN & $2,563.645$ & 22.547 & 0.154 & 0.595 & 0.045 & 0.206 \\
\hline IND & $2,345.640$ & 21.193 & 0.216 & 0.654 & 0.011 & 0.118 \\
\hline IRL & $3,407.594$ & 27.196 & 0.027 & 0.337 & 0.271 & 0.365 \\
\hline IRN & $3,141.308$ & 26.386 & 0.047 & 0.386 & 0.229 & 0.338 \\
\hline IRQ & $2,971.592$ & 27.640 & 0.025 & 0.314 & 0.303 & 0.358 \\
\hline
\end{tabular}




\begin{tabular}{|c|c|c|c|c|c|c|}
\hline ISL & $3,247.382$ & 26.704 & 0.037 & 0.368 & 0.244 & 0.351 \\
\hline ISR & $3,611.191$ & 27.351 & 0.033 & 0.332 & 0.288 & 0.347 \\
\hline ITP & $3,742.937$ & 25.673 & 0.057 & 0.428 & 0.185 & 0.330 \\
\hline JAM & $2,712.633$ & 26.834 & 0.054 & 0.360 & 0.267 & 0.320 \\
\hline JOR & $3,114.090$ & 28.431 & 0.023 & 0.277 & 0.358 & 0.342 \\
\hline JPN & $2,769.861$ & 22.680 & 0.133 & 0.611 & 0.042 & 0.214 \\
\hline KAZ & $2,881.231$ & 26.659 & 0.053 & 0.369 & 0.253 & 0.325 \\
\hline KEN & $2,073.255$ & 22.401 & 0.170 & 0.586 & 0.046 & 0.199 \\
\hline KGZ & $2,763.448$ & 25.406 & 0.080 & 0.432 & 0.185 & 0.304 \\
\hline KHM & $2,298.052$ & 21.503 & 0.190 & 0.660 & 0.014 & 0.136 \\
\hline KOR & $3,136.828$ & 23.748 & 0.094 & 0.553 & 0.080 & 0.273 \\
\hline LAO & $2,276.618$ & 21.653 & 0.203 & 0.618 & 0.024 & 0.155 \\
\hline LBN & $2,949.307$ & 27.402 & 0.033 & 0.329 & 0.291 & 0.346 \\
\hline LBR & $2,413.147$ & 22.696 & 0.160 & 0.569 & 0.057 & 0.214 \\
\hline LBY & $2,819.511$ & 27.920 & 0.028 & 0.303 & 0.325 & 0.344 \\
\hline LKA & $2,393.628$ & 22.659 & 0.150 & 0.588 & 0.049 & 0.213 \\
\hline LSO & $2,443.539$ & 24.497 & 0.198 & 0.386 & 0.196 & 0.219 \\
\hline MDA & $2,744.517$ & 25.819 & 0.085 & 0.402 & 0.218 & 0.295 \\
\hline MDG & $2,063.263$ & 21.149 & 0.213 & 0.665 & 0.009 & 0.112 \\
\hline MEX & $3,153.162$ & 28.223 & 0.019 & 0.280 & 0.340 & 0.361 \\
\hline MLI & $2,380.311$ & 22.546 & 0.159 & 0.586 & 0.048 & 0.207 \\
\hline MMR & $2,415.821$ & 22.317 & 0.161 & 0.608 & 0.037 & 0.193 \\
\hline MNG & $2,343.994$ & 25.452 & 0.067 & 0.437 & 0.178 & 0.318 \\
\hline MOR & $3,236.670$ & 25.612 & 0.063 & 0.428 & 0.186 & 0.322 \\
\hline MOZ & $2,182.909$ & 22.767 & 0.148 & 0.579 & 0.055 & 0.218 \\
\hline MRT & $2,743.114$ & 24.538 & 0.123 & 0.454 & 0.155 & 0.268 \\
\hline MWI & $2,282.968$ & 22.600 & 0.146 & 0.601 & 0.044 & 0.209 \\
\hline MYS & $2,851.050$ & 25.159 & 0.065 & 0.460 & 0.154 & 0.321 \\
\hline NAM & $2,305.662$ & 24.087 & 0.120 & 0.492 & 0.121 & 0.267 \\
\hline NER & $2,282.292$ & 21.648 & 0.186 & 0.649 & 0.018 & 0.147 \\
\hline NGA & $2,843.210$ & 23.495 & 0.114 & 0.552 & 0.078 & 0.256 \\
\hline NIC & $2,280.903$ & 26.809 & 0.040 & 0.362 & 0.254 & 0.344 \\
\hline NLD & $3,192.617$ & 25.646 & 0.055 & 0.430 & 0.182 & 0.333 \\
\hline NOR & $3,386.605$ & 26.449 & 0.034 & 0.383 & 0.221 & 0.361 \\
\hline NPL & $2,360.639$ & 20.800 & 0.252 & 0.642 & 0.008 & 0.098 \\
\hline NZL & $3,082.753$ & 27.696 & 0.022 & 0.308 & 0.303 & 0.367 \\
\hline OAO & $2,505.402$ & 24.408 & 0.098 & 0.489 & 0.128 & 0.285 \\
\hline OBN & $3,809.645$ & 26.396 & 0.051 & 0.384 & 0.234 & 0.331 \\
\hline OIO & $2,648.193$ & 24.659 & 0.111 & 0.458 & 0.155 & 0.277 \\
\hline OPO & $2,750.342$ & 30.384 & 0.010 & 0.188 & 0.484 & 0.318 \\
\hline OSA & $3,114.718$ & 23.359 & 0.108 & 0.574 & 0.066 & 0.252 \\
\hline PAK & $2,344.949$ & 22.935 & 0.140 & 0.573 & 0.060 & 0.227 \\
\hline PAN & $2,509.418$ & 27.142 & 0.031 & 0.342 & 0.271 & 0.356 \\
\hline PER & $2,476.102$ & 25.499 & 0.062 & 0.437 & 0.177 & 0.324 \\
\hline PHL & $2,489.712$ & 23.249 & 0.122 & 0.566 & 0.068 & 0.244 \\
\hline
\end{tabular}




\begin{tabular}{|c|c|c|c|c|c|c|}
\hline PNG & $2,293.092$ & 25.541 & 0.056 & 0.438 & 0.174 & 0.332 \\
\hline POL & $3,436.490$ & 26.383 & 0.055 & 0.384 & 0.235 & 0.326 \\
\hline PRT & $3,525.476$ & 26.542 & 0.043 & 0.377 & 0.237 & 0.343 \\
\hline PRY & $2,683.933$ & 25.849 & 0.064 & 0.413 & 0.204 & 0.320 \\
\hline RAP & $3,592.176$ & 28.496 & 0.014 & 0.260 & 0.357 & 0.369 \\
\hline ROU & $2,822.336$ & 25.544 & 0.069 & 0.429 & 0.186 & 0.315 \\
\hline RUS & $3,221.116$ & 26.791 & 0.047 & 0.363 & 0.259 & 0.331 \\
\hline RWA & $2,130.883$ & 22.441 & 0.156 & 0.602 & 0.041 & 0.200 \\
\hline SAU & $3,017.263$ & 28.743 & 0.020 & 0.261 & 0.378 & 0.341 \\
\hline SDN & $2,317.891$ & 22.949 & 0.157 & 0.547 & 0.071 & 0.225 \\
\hline SEN & $2,349.171$ & 23.225 & 0.154 & 0.524 & 0.087 & 0.235 \\
\hline SLB & $2,488.824$ & 28.184 & 0.021 & 0.285 & 0.339 & 0.355 \\
\hline SLE & $2,123.274$ & 23.406 & 0.123 & 0.548 & 0.079 & 0.250 \\
\hline SLV & $2,564.537$ & 27.286 & 0.029 & 0.334 & 0.280 & 0.357 \\
\hline SOM & $1,641.926$ & 22.451 & 0.178 & 0.567 & 0.053 & 0.202 \\
\hline SPP & $3,223.271$ & 26.992 & 0.038 & 0.352 & 0.266 & 0.344 \\
\hline SVK & $2,877.605$ & 26.789 & 0.042 & 0.363 & 0.255 & 0.340 \\
\hline SVN & $3,187.477$ & 27.145 & 0.037 & 0.344 & 0.276 & 0.343 \\
\hline SWE & $3,074.641$ & 25.847 & 0.044 & 0.422 & 0.185 & 0.349 \\
\hline SWZ & $2,403.662$ & 25.997 & 0.107 & 0.380 & 0.242 & 0.271 \\
\hline SYR & $2,826.704$ & 27.930 & 0.027 & 0.301 & 0.325 & 0.348 \\
\hline TCD & $2,047.650$ & 21.850 & 0.185 & 0.626 & 0.025 & 0.164 \\
\hline TGO & $2,344.856$ & 22.457 & 0.161 & 0.593 & 0.044 & 0.202 \\
\hline THA & $2,818.676$ & 23.763 & 0.112 & 0.530 & 0.094 & 0.265 \\
\hline TJK & $2,247.631$ & 23.950 & 0.115 & 0.509 & 0.109 & 0.267 \\
\hline TKM & $2,969.780$ & 25.046 & 0.076 & 0.460 & 0.156 & 0.308 \\
\hline TLS & $2,135.318$ & 21.193 & 0.254 & 0.589 & 0.022 & 0.135 \\
\hline TUN & $3,225.562$ & 26.658 & 0.053 & 0.369 & 0.254 & 0.324 \\
\hline TUR & $3,586.570$ & 27.563 & 0.033 & 0.322 & 0.303 & 0.342 \\
\hline TZA & $2,238.515$ & 22.950 & 0.131 & 0.585 & 0.055 & 0.229 \\
\hline UGA & $2,413.965$ & 22.550 & 0.152 & 0.596 & 0.045 & 0.207 \\
\hline UKP & $3,357.533$ & 27.297 & 0.025 & 0.331 & 0.277 & 0.367 \\
\hline UKR & $2,782.169$ & 26.031 & 0.060 & 0.403 & 0.214 & 0.323 \\
\hline URY & $2,899.434$ & 26.603 & 0.045 & 0.373 & 0.243 & 0.339 \\
\hline USA & $3,725.186$ & 28.449 & 0.016 & 0.266 & 0.355 & 0.363 \\
\hline UZB & $2,580.100$ & 25.501 & 0.069 & 0.432 & 0.183 & 0.315 \\
\hline VEN & $2,552.055$ & 27.949 & 0.020 & 0.294 & 0.321 & 0.366 \\
\hline VNM & $2,565.323$ & 21.151 & 0.209 & 0.672 & 0.008 & 0.110 \\
\hline VUT & $2,807.039$ & 27.788 & 0.025 & 0.306 & 0.313 & 0.355 \\
\hline YEM & $2,044.273$ & 25.293 & 0.083 & 0.437 & 0.179 & 0.301 \\
\hline ZAF & $3,014.589$ & 28.387 & 0.024 & 0.279 & 0.355 & 0.342 \\
\hline ZMB & $1,932.330$ & 22.002 & 0.198 & 0.585 & 0.038 & 0.178 \\
\hline ZWE & $2,062.104$ & 23.468 & 0.140 & 0.521 & 0.093 & 0.246 \\
\hline
\end{tabular}


Table A4.2: Weight distribution estimated for the reference scenario without climate change in 2050, including food availability (kcal/cap/day), mean BMI $\left(\mathrm{kg} / \mathrm{m}^{2}\right)$, and the prevalence of underweight (BMI $<18 \cdot 5)$, normal weight $(18 \cdot 5<$ BMI $<25)$, overweight $(25<$ BMI $<30)$, and obesity (BMI $>30)$. See Appendix A7 for details on the regional aggregation.

\begin{tabular}{|c|c|c|c|c|c|c|}
\hline Region & kcal/day & mean BMI & underweight & normal & obese & overweight \\
\hline Global & $3,106.920$ & 24.564 & 0.086 & 0.504 & 0.136 & 0.274 \\
\hline HIC & $3,433.591$ & 26.814 & 0.043 & 0.363 & 0.258 & 0.336 \\
\hline AFR_LMIC & $2,878.687$ & 24.133 & 0.089 & 0.531 & 0.105 & 0.274 \\
\hline AMR_LMIC & $3,051.496$ & 27.159 & 0.034 & 0.342 & 0.275 & 0.349 \\
\hline EMR_LMIC & $2,932.193$ & 25.614 & 0.076 & 0.429 & 0.198 & 0.298 \\
\hline EUR_LMIC & $3,256.108$ & 26.786 & 0.046 & 0.363 & 0.258 & 0.332 \\
\hline SEA_LMIC & $2,856.917$ & 22.599 & 0.126 & 0.635 & 0.036 & 0.203 \\
\hline WPR_LMIC & $3,512.785$ & 23.718 & 0.099 & 0.553 & 0.083 & 0.265 \\
\hline AFG & $2,707.125$ & 21.641 & 0.214 & 0.601 & 0.027 & 0.157 \\
\hline AGO & $2,414.308$ & 23.205 & 0.153 & 0.528 & 0.084 & 0.234 \\
\hline ALB & $3,137.648$ & 26.777 & 0.041 & 0.364 & 0.252 & 0.343 \\
\hline ARG & $3,312.530$ & 27.900 & 0.027 & 0.303 & 0.323 & 0.346 \\
\hline ARM & $3,130.366$ & 27.455 & 0.041 & 0.329 & 0.301 & 0.329 \\
\hline AUS & $3,180.132$ & 27.422 & 0.026 & 0.325 & 0.287 & 0.363 \\
\hline AUT & $3,725.637$ & 25.818 & 0.061 & 0.416 & 0.200 & 0.324 \\
\hline AZE & $3,086.018$ & 26.801 & 0.048 & 0.362 & 0.260 & 0.330 \\
\hline BDI & $2,911.192$ & 23.982 & 0.088 & 0.538 & 0.091 & 0.283 \\
\hline BEN & $2,878.247$ & 24.146 & 0.091 & 0.519 & 0.104 & 0.286 \\
\hline BFA & $3,002.857$ & 22.366 & 0.138 & 0.640 & 0.029 & 0.192 \\
\hline BGD & $2,782.031$ & 21.310 & 0.196 & 0.674 & 0.010 & 0.120 \\
\hline BGR & $3,062.887$ & 26.771 & 0.042 & 0.364 & 0.254 & 0.340 \\
\hline BLR & $2,881.158$ & 26.577 & 0.050 & 0.374 & 0.245 & 0.331 \\
\hline BLT & $3,805.255$ & 26.259 & 0.059 & 0.389 & 0.230 & 0.321 \\
\hline BLX & $3,748.324$ & 26.049 & 0.053 & 0.405 & 0.209 & 0.333 \\
\hline BLZ & $2,833.549$ & 29.125 & 0.013 & 0.234 & 0.402 & 0.351 \\
\hline BOL & $2,586.652$ & 27.431 & 0.035 & 0.329 & 0.295 & 0.341 \\
\hline BRA & $3,312.727$ & 26.322 & 0.044 & 0.390 & 0.222 & 0.344 \\
\hline BTN & $2,616.857$ & 24.313 & 0.076 & 0.521 & 0.104 & 0.300 \\
\hline BWA & $2,602.637$ & 25.757 & 0.096 & 0.399 & 0.220 & 0.285 \\
\hline CAF & $2,892.260$ & 24.878 & 0.061 & 0.486 & 0.130 & 0.323 \\
\hline CAN & $3,436.009$ & 27.133 & 0.028 & 0.341 & 0.267 & 0.363 \\
\hline CHL & $3,080.272$ & 28.088 & 0.021 & 0.289 & 0.332 & 0.358 \\
\hline CHM & $3,696.052$ & 23.744 & 0.096 & 0.551 & 0.082 & 0.271 \\
\hline CHP & $3,395.444$ & 25.238 & 0.072 & 0.449 & 0.166 & 0.313 \\
\hline CIV & $3,083.926$ & 24.269 & 0.085 & 0.515 & 0.108 & 0.292 \\
\hline CMR & $2,757.166$ & 25.845 & 0.052 & 0.418 & 0.194 & 0.336 \\
\hline COD & $2,329.237$ & 23.141 & 0.100 & 0.609 & 0.048 & 0.242 \\
\hline $\mathrm{COG}$ & $2,840.425$ & 24.508 & 0.076 & 0.503 & 0.117 & 0.303 \\
\hline $\mathrm{COL}$ & $2,866.867$ & 26.210 & 0.051 & 0.395 & 0.220 & 0.334 \\
\hline CRB & $3,220.390$ & 27.844 & 0.031 & 0.308 & 0.321 & 0.341 \\
\hline
\end{tabular}




\begin{tabular}{|c|c|c|c|c|c|c|}
\hline CRI & $3,084.976$ & 27.422 & 0.028 & 0.326 & 0.289 & 0.356 \\
\hline CUB & $2,731.581$ & 27.078 & 0.038 & 0.347 & 0.272 & 0.342 \\
\hline CYP & $2,487.433$ & 26.560 & 0.053 & 0.374 & 0.247 & 0.326 \\
\hline CZE & $3,524.977$ & 27.600 & 0.038 & 0.322 & 0.309 & 0.331 \\
\hline DEU & $3,523.643$ & 26.455 & 0.045 & 0.382 & 0.232 & 0.341 \\
\hline DJI & $2,586.010$ & 25.425 & 0.073 & 0.435 & 0.181 & 0.311 \\
\hline DNK & $3,344.449$ & 25.740 & 0.050 & 0.426 & 0.184 & 0.339 \\
\hline DOM & $2,699.604$ & 27.238 & 0.033 & 0.338 & 0.280 & 0.349 \\
\hline DZA & $3,181.067$ & 25.847 & 0.061 & 0.414 & 0.202 & 0.323 \\
\hline ECU & $2,439.139$ & 27.265 & 0.031 & 0.336 & 0.280 & 0.353 \\
\hline EGY & $3,554.289$ & 28.969 & 0.017 & 0.248 & 0.392 & 0.344 \\
\hline ERI & $2,269.600$ & 22.825 & 0.107 & 0.635 & 0.036 & 0.221 \\
\hline ETH & $2,598.601$ & 22.085 & 0.143 & 0.667 & 0.020 & 0.170 \\
\hline FJI & $3,746.224$ & 29.500 & 0.014 & 0.224 & 0.427 & 0.335 \\
\hline FNP & $3,165.777$ & 26.250 & 0.047 & 0.394 & 0.219 & 0.340 \\
\hline FRP & $3,470.045$ & 25.283 & 0.069 & 0.448 & 0.167 & 0.316 \\
\hline GAB & $2,994.513$ & 25.974 & 0.057 & 0.408 & 0.207 & 0.328 \\
\hline GEO & $3,466.304$ & 27.329 & 0.038 & 0.335 & 0.290 & 0.337 \\
\hline GHA & $3,131.944$ & 24.541 & 0.079 & 0.498 & 0.122 & 0.302 \\
\hline GIN & $3,319.370$ & 24.349 & 0.072 & 0.521 & 0.103 & 0.303 \\
\hline GMB & $2,947.676$ & 24.832 & 0.093 & 0.461 & 0.154 & 0.292 \\
\hline GNB & $2,753.077$ & 23.398 & 0.134 & 0.536 & 0.085 & 0.246 \\
\hline GNQ & $2,420.790$ & 23.624 & 0.141 & 0.506 & 0.104 & 0.249 \\
\hline GRC & $3,698.087$ & 25.835 & 0.056 & 0.417 & 0.196 & 0.330 \\
\hline GSA & $2,814.269$ & 26.525 & 0.062 & 0.374 & 0.251 & 0.313 \\
\hline GTM & $2,477.816$ & 27.371 & 0.031 & 0.330 & 0.288 & 0.351 \\
\hline HND & $2,940.335$ & 27.109 & 0.035 & 0.345 & 0.272 & 0.347 \\
\hline HRV & $3,153.283$ & 26.216 & 0.058 & 0.393 & 0.226 & 0.323 \\
\hline HTI & $2,264.499$ & 25.730 & 0.048 & 0.428 & 0.181 & 0.343 \\
\hline HUN & $3,593.332$ & 26.870 & 0.046 & 0.359 & 0.263 & 0.332 \\
\hline IDN & $3,113.117$ & 23.810 & 0.092 & 0.549 & 0.083 & 0.276 \\
\hline IND & $2,816.749$ & 22.451 & 0.125 & 0.652 & 0.027 & 0.196 \\
\hline IRL & $3,449.952$ & 27.256 & 0.026 & 0.334 & 0.275 & 0.365 \\
\hline IRN & $3,230.436$ & 26.551 & 0.044 & 0.376 & 0.239 & 0.341 \\
\hline IRQ & $3,247.910$ & 28.229 & 0.020 & 0.281 & 0.341 & 0.358 \\
\hline ISL & $3,351.063$ & 26.874 & 0.035 & 0.358 & 0.254 & 0.353 \\
\hline ISR & $3,875.938$ & 27.553 & 0.031 & 0.321 & 0.301 & 0.348 \\
\hline ITP & $3,774.865$ & 25.694 & 0.057 & 0.426 & 0.186 & 0.331 \\
\hline JAM & $3,070.686$ & 27.757 & 0.039 & 0.315 & 0.320 & 0.326 \\
\hline JOR & $3,645.939$ & 29.277 & 0.017 & 0.236 & 0.412 & 0.335 \\
\hline JPN & $2,761.541$ & 22.660 & 0.134 & 0.612 & 0.042 & 0.212 \\
\hline $\mathrm{KAZ}$ & $3,204.642$ & 27.373 & 0.040 & 0.333 & 0.295 & 0.332 \\
\hline KEN & $2,879.523$ & 24.938 & 0.061 & 0.480 & 0.135 & 0.323 \\
\hline KGZ & $3,195.221$ & 26.380 & 0.056 & 0.384 & 0.236 & 0.324 \\
\hline KHM & $2,507.912$ & 22.141 & 0.144 & 0.659 & 0.022 & 0.175 \\
\hline
\end{tabular}




\begin{tabular}{|c|c|c|c|c|c|c|}
\hline KOR & $3,317.767$ & 24.038 & 0.083 & 0.539 & 0.091 & 0.288 \\
\hline LAO & $2,430.677$ & 22.140 & 0.169 & 0.617 & 0.032 & 0.182 \\
\hline LBN & $3,237.990$ & 28.023 & 0.025 & 0.296 & 0.331 & 0.348 \\
\hline LBR & $2,880.931$ & 23.964 & 0.100 & 0.526 & 0.099 & 0.276 \\
\hline LBY & $3,039.940$ & 28.486 & 0.022 & 0.274 & 0.361 & 0.342 \\
\hline LKA & $2,622.342$ & 23.338 & 0.115 & 0.567 & 0.069 & 0.250 \\
\hline LSO & $2,757.836$ & 25.441 & 0.163 & 0.369 & 0.235 & 0.233 \\
\hline MDA & $3,228.035$ & 26.922 & 0.060 & 0.354 & 0.276 & 0.310 \\
\hline MDG & $2,516.018$ & 22.649 & 0.107 & 0.657 & 0.028 & 0.208 \\
\hline MEX & $3,224.335$ & 28.364 & 0.018 & 0.272 & 0.350 & 0.360 \\
\hline MLI & $2,677.022$ & 23.413 & 0.114 & 0.560 & 0.073 & 0.253 \\
\hline MMR & $2,683.389$ & 23.077 & 0.119 & 0.589 & 0.056 & 0.237 \\
\hline MNG & $3,481.703$ & 28.318 & 0.021 & 0.279 & 0.349 & 0.351 \\
\hline MOR & $3,707.639$ & 26.198 & 0.050 & 0.396 & 0.218 & 0.335 \\
\hline $\mathrm{MOZ}$ & $2,677.191$ & 24.363 & 0.078 & 0.514 & 0.109 & 0.299 \\
\hline MRT & $3,314.221$ & 25.731 & 0.085 & 0.408 & 0.211 & 0.296 \\
\hline MWI & $2,466.631$ & 23.198 & 0.114 & 0.582 & 0.060 & 0.243 \\
\hline MYS & $3,376.694$ & 26.186 & 0.042 & 0.399 & 0.209 & 0.349 \\
\hline NAM & $2,920.079$ & 25.923 & 0.063 & 0.408 & 0.209 & 0.320 \\
\hline NER & $2,965.293$ & 23.476 & 0.081 & 0.600 & 0.055 & 0.264 \\
\hline NGA & $3,233.595$ & 24.261 & 0.084 & 0.516 & 0.107 & 0.293 \\
\hline NIC & $2,714.033$ & 28.365 & 0.021 & 0.277 & 0.352 & 0.350 \\
\hline NLD & $3,207.693$ & 25.673 & 0.055 & 0.429 & 0.183 & 0.333 \\
\hline NOR & $3,325.685$ & 26.357 & 0.036 & 0.389 & 0.216 & 0.359 \\
\hline NPL & $2,899.462$ & 22.164 & 0.142 & 0.659 & 0.022 & 0.177 \\
\hline NZL & $3,233.707$ & 28.001 & 0.019 & 0.290 & 0.324 & 0.368 \\
\hline OAO & $2,818.539$ & 25.301 & 0.071 & 0.445 & 0.170 & 0.314 \\
\hline OBN & $3,915.727$ & 26.449 & 0.050 & 0.381 & 0.237 & 0.332 \\
\hline OIO & $2,785.324$ & 25.033 & 0.098 & 0.443 & 0.172 & 0.287 \\
\hline OPO & $2,886.749$ & 30.804 & 0.009 & 0.171 & 0.511 & 0.309 \\
\hline OSA & $3,100.348$ & 23.334 & 0.109 & 0.575 & 0.065 & 0.251 \\
\hline PAK & $2,677.749$ & 23.940 & 0.095 & 0.534 & 0.093 & 0.278 \\
\hline PAN & $2,771.974$ & 27.986 & 0.022 & 0.294 & 0.325 & 0.359 \\
\hline PER & $2,691.282$ & 26.176 & 0.047 & 0.398 & 0.214 & 0.340 \\
\hline PHL & $2,673.562$ & 23.777 & 0.099 & 0.544 & 0.086 & 0.271 \\
\hline PNG & $3,170.018$ & 28.108 & 0.018 & 0.284 & 0.331 & 0.366 \\
\hline POL & $3,613.968$ & 26.590 & 0.051 & 0.373 & 0.247 & 0.329 \\
\hline PRT & $3,638.748$ & 26.662 & 0.041 & 0.370 & 0.244 & 0.345 \\
\hline PRY & $2,904.583$ & 26.442 & 0.051 & 0.381 & 0.237 & 0.331 \\
\hline RAP & $3,742.360$ & 28.639 & 0.013 & 0.252 & 0.367 & 0.368 \\
\hline ROU & $3,004.479$ & 25.978 & 0.059 & 0.407 & 0.209 & 0.325 \\
\hline RUS & $3,402.141$ & 27.085 & 0.042 & 0.347 & 0.276 & 0.334 \\
\hline RWA & $3,098.934$ & 25.209 & 0.047 & 0.469 & 0.141 & 0.343 \\
\hline SAU & $3,145.813$ & 29.035 & 0.018 & 0.247 & 0.397 & 0.338 \\
\hline SDN & $2,641.594$ & 23.950 & 0.110 & 0.514 & 0.106 & 0.270 \\
\hline
\end{tabular}




\begin{tabular}{|c|c|c|c|c|c|c|}
\hline SEN & $2,753.128$ & 24.429 & 0.103 & 0.483 & 0.133 & 0.282 \\
\hline SLB & $3,026.394$ & 29.842 & 0.010 & 0.202 & 0.450 & 0.337 \\
\hline SLE & $2,415.567$ & 24.479 & 0.081 & 0.500 & 0.120 & 0.299 \\
\hline SLV & $2,715.097$ & 27.770 & 0.024 & 0.306 & 0.311 & 0.359 \\
\hline SOM & $2,971.678$ & 27.497 & 0.024 & 0.319 & 0.290 & 0.367 \\
\hline SPP & $3,183.723$ & 26.919 & 0.039 & 0.356 & 0.262 & 0.343 \\
\hline SVK & $3,004.414$ & 27.097 & 0.038 & 0.346 & 0.273 & 0.343 \\
\hline SVN & $3,313.082$ & 27.367 & 0.034 & 0.331 & 0.290 & 0.345 \\
\hline SWE & $3,098.274$ & 25.895 & 0.043 & 0.419 & 0.188 & 0.350 \\
\hline SWZ & $2,823.338$ & 27.332 & 0.074 & 0.333 & 0.309 & 0.284 \\
\hline SYR & $3,355.548$ & 29.106 & 0.016 & 0.242 & 0.401 & 0.341 \\
\hline TCD & $2,547.272$ & 23.557 & 0.090 & 0.579 & 0.065 & 0.266 \\
\hline TGO & $2,826.957$ & 23.817 & 0.094 & 0.547 & 0.085 & 0.275 \\
\hline THA & $3,173.737$ & 24.496 & 0.084 & 0.496 & 0.123 & 0.297 \\
\hline TJK & $2,644.186$ & 25.270 & 0.071 & 0.447 & 0.168 & 0.314 \\
\hline TKM & $3,363.641$ & 25.764 & 0.057 & 0.421 & 0.193 & 0.329 \\
\hline TLS & $2,669.442$ & 22.837 & 0.141 & 0.582 & 0.055 & 0.222 \\
\hline TUN & $3,632.475$ & 27.220 & 0.043 & 0.341 & 0.286 & 0.330 \\
\hline TUR & $3,628.229$ & 27.607 & 0.032 & 0.319 & 0.306 & 0.342 \\
\hline TZA & $2,748.297$ & 24.533 & 0.067 & 0.510 & 0.111 & 0.312 \\
\hline UGA & $2,961.830$ & 23.985 & 0.085 & 0.542 & 0.089 & 0.285 \\
\hline UKP & $3,412.285$ & 27.378 & 0.024 & 0.326 & 0.282 & 0.367 \\
\hline UKR & $3,013.545$ & 26.602 & 0.048 & 0.373 & 0.246 & 0.333 \\
\hline URY & $3,105.435$ & 27.074 & 0.037 & 0.347 & 0.271 & 0.344 \\
\hline USA & $3,608.789$ & 28.339 & 0.017 & 0.272 & 0.347 & 0.364 \\
\hline UZB & $3,021.062$ & 26.678 & 0.044 & 0.369 & 0.248 & 0.339 \\
\hline VEN & $2,661.363$ & 28.317 & 0.017 & 0.273 & 0.346 & 0.364 \\
\hline VNM & $2,840.574$ & 21.807 & 0.156 & 0.681 & 0.014 & 0.149 \\
\hline VUT & $3,511.302$ & 29.247 & 0.013 & 0.230 & 0.410 & 0.347 \\
\hline YEM & $2,230.944$ & 26.096 & 0.062 & 0.398 & 0.221 & 0.319 \\
\hline $\mathrm{ZAF}$ & $3,529.134$ & 29.330 & 0.016 & 0.234 & 0.416 & 0.334 \\
\hline ZMB & $2,913.071$ & 25.214 & 0.056 & 0.462 & 0.150 & 0.331 \\
\hline ZWE & $2,761.390$ & 25.869 & 0.059 & 0.414 & 0.201 & 0.326 \\
\hline
\end{tabular}


Table A4.3: Average weight distribution estimated for climate change scenarios in 2050, including food availability $(\mathrm{kcal} / \mathrm{cap} / \mathrm{day})$, mean BMI $\left(\mathrm{kg} / \mathrm{m}^{2}\right)$, and the prevalence of underweight $(B M I<18 \cdot 5)$, normal weight $(18 \cdot 5<$ BMI $<25)$, overweight $(25<\mathrm{BMI}<30)$, and obesity $(\mathrm{BMI}>30)$. See Appendix A7 for details on the regional aggregation.

\begin{tabular}{|c|c|c|c|c|c|c|}
\hline Region & kcal/day & mean BMI & underweight & normal & obese & overweight \\
\hline Global & $3,008.334$ & 24.369 & 0.095 & 0.511 & 0.129 & 0.265 \\
\hline HIC & $3,372.514$ & 26.729 & 0.045 & 0.367 & 0.254 & 0.335 \\
\hline AFR_LMIC & $2,756.536$ & 23.841 & 0.101 & 0.544 & 0.095 & 0.260 \\
\hline AMR_LMIC & $2,979.039$ & 26.996 & 0.037 & 0.351 & 0.265 & 0.347 \\
\hline EMR_LMIC & $2,855.424$ & 25.444 & 0.081 & 0.435 & 0.190 & 0.293 \\
\hline EUR_LMIC & $3,198.842$ & 26.681 & 0.048 & 0.369 & 0.252 & 0.331 \\
\hline SEA_LMIC & $2,740.550$ & 22.334 & 0.142 & 0.640 & 0.031 & 0.187 \\
\hline WPR_LMIC & $3,401.541$ & 23.590 & 0.105 & 0.557 & 0.079 & 0.258 \\
\hline AFG & $2,603.710$ & 21.385 & 0.234 & 0.599 & 0.023 & 0.144 \\
\hline AGO & $2,301.279$ & 22.834 & 0.173 & 0.536 & 0.073 & 0.218 \\
\hline ALB & $3,079.460$ & 26.659 & 0.043 & 0.370 & 0.245 & 0.342 \\
\hline ARG & $3,259.228$ & 27.809 & 0.028 & 0.308 & 0.317 & 0.346 \\
\hline ARM & $3,061.184$ & 27.310 & 0.043 & 0.336 & 0.292 & 0.328 \\
\hline AUS & $3,124.020$ & 27.310 & 0.027 & 0.331 & 0.280 & 0.362 \\
\hline AUT & $3,662.037$ & 25.766 & 0.062 & 0.419 & 0.197 & 0.322 \\
\hline AZE & $3,014.498$ & 26.647 & 0.051 & 0.370 & 0.251 & 0.328 \\
\hline BDI & $2,773.836$ & 23.661 & 0.101 & 0.553 & 0.079 & 0.267 \\
\hline BEN & $2,707.567$ & 23.728 & 0.107 & 0.539 & 0.088 & 0.266 \\
\hline BFA & $2,912.107$ & 22.184 & 0.150 & 0.643 & 0.026 & 0.181 \\
\hline BGD & $2,641.667$ & 20.984 & 0.225 & 0.665 & 0.008 & 0.102 \\
\hline BGR & $3,014.495$ & 26.666 & 0.044 & 0.370 & 0.247 & 0.339 \\
\hline BLR & $2,838.406$ & 26.467 & 0.052 & 0.380 & 0.239 & 0.329 \\
\hline BLT & $3,786.180$ & 26.247 & 0.060 & 0.390 & 0.230 & 0.321 \\
\hline BLX & $3,716.807$ & 26.026 & 0.053 & 0.406 & 0.208 & 0.333 \\
\hline BLZ & $2,762.356$ & 28.916 & 0.014 & 0.245 & 0.387 & 0.353 \\
\hline BOL & $2,516.782$ & 27.195 & 0.038 & 0.341 & 0.281 & 0.339 \\
\hline BRA & $3,240.580$ & 26.204 & 0.046 & 0.397 & 0.215 & 0.342 \\
\hline BTN & $2,506.436$ & 23.985 & 0.087 & 0.538 & 0.091 & 0.284 \\
\hline BWA & $2,506.698$ & 25.455 & 0.105 & 0.411 & 0.205 & 0.279 \\
\hline CAF & $2,757.180$ & 24.545 & 0.070 & 0.506 & 0.115 & 0.309 \\
\hline CAN & $3,371.179$ & 27.040 & 0.029 & 0.347 & 0.261 & 0.362 \\
\hline CHL & $3,017.499$ & 27.947 & 0.022 & 0.296 & 0.323 & 0.359 \\
\hline CHM & $3,582.217$ & 23.649 & 0.100 & 0.555 & 0.078 & 0.266 \\
\hline CHP & $3,340.717$ & 25.161 & 0.074 & 0.453 & 0.163 & 0.311 \\
\hline CIV & $2,925.556$ & 23.945 & 0.096 & 0.531 & 0.095 & 0.277 \\
\hline CMR & $2,624.798$ & 25.466 & 0.061 & 0.440 & 0.173 & 0.326 \\
\hline COD & $2,231.305$ & 22.799 & 0.117 & 0.622 & 0.040 & 0.220 \\
\hline $\mathrm{COG}$ & $2,698.107$ & 24.145 & 0.088 & 0.522 & 0.102 & 0.287 \\
\hline $\mathrm{COL}$ & $2,799.614$ & 26.037 & 0.055 & 0.405 & 0.210 & 0.330 \\
\hline CRB & $3,211.960$ & 27.828 & 0.031 & 0.308 & 0.320 & 0.341 \\
\hline
\end{tabular}




\begin{tabular}{|c|c|c|c|c|c|c|}
\hline CRI & $3,008.371$ & 27.253 & 0.030 & 0.336 & 0.278 & 0.355 \\
\hline CUB & $2,646.762$ & 26.823 & 0.042 & 0.361 & 0.257 & 0.339 \\
\hline CYP & $2,446.420$ & 26.417 & 0.056 & 0.382 & 0.238 & 0.324 \\
\hline CZE & $3,474.722$ & 27.536 & 0.039 & 0.325 & 0.305 & 0.331 \\
\hline DEU & $3,465.907$ & 26.385 & 0.046 & 0.386 & 0.228 & 0.340 \\
\hline DJI & $2,478.944$ & 25.083 & 0.083 & 0.451 & 0.164 & 0.301 \\
\hline DNK & $3,290.507$ & 25.657 & 0.052 & 0.431 & 0.179 & 0.337 \\
\hline DOM & $2,629.289$ & 27.021 & 0.036 & 0.350 & 0.267 & 0.347 \\
\hline DZA & $3,113.659$ & 25.721 & 0.064 & 0.420 & 0.195 & 0.320 \\
\hline ECU & $2,377.236$ & 27.032 & 0.034 & 0.349 & 0.266 & 0.351 \\
\hline EGY & $3,439.596$ & 28.818 & 0.018 & 0.255 & 0.382 & 0.345 \\
\hline ERI & 2,198.901 & 22.573 & 0.121 & 0.644 & 0.031 & 0.204 \\
\hline ETH & $2,525.782$ & 21.886 & 0.157 & 0.669 & 0.017 & 0.157 \\
\hline FJI & $3,627.226$ & 29.389 & 0.015 & 0.229 & 0.420 & 0.336 \\
\hline FNP & $3,115.141$ & 26.151 & 0.049 & 0.400 & 0.214 & 0.338 \\
\hline FRP & $3,410.642$ & 25.208 & 0.071 & 0.452 & 0.163 & 0.314 \\
\hline GAB & $2,853.491$ & 25.640 & 0.064 & 0.426 & 0.190 & 0.320 \\
\hline GEO & $3,402.069$ & 27.241 & 0.040 & 0.339 & 0.285 & 0.336 \\
\hline GHA & $2,969.647$ & 24.220 & 0.090 & 0.514 & 0.108 & 0.288 \\
\hline GIN & $3,128.097$ & 24.036 & 0.083 & 0.539 & 0.091 & 0.288 \\
\hline GMB & $2,828.785$ & 24.549 & 0.102 & 0.474 & 0.141 & 0.283 \\
\hline GNB & $2,588.984$ & 22.963 & 0.155 & 0.548 & 0.071 & 0.226 \\
\hline GNQ & $2,294.714$ & 23.196 & 0.161 & 0.518 & 0.089 & 0.232 \\
\hline GRC & $3,635.301$ & 25.781 & 0.057 & 0.420 & 0.194 & 0.329 \\
\hline GSA & $2,766.360$ & 26.394 & 0.065 & 0.380 & 0.244 & 0.312 \\
\hline GTM & $2,410.201$ & 27.127 & 0.034 & 0.344 & 0.273 & 0.349 \\
\hline HND & $2,868.705$ & 26.932 & 0.038 & 0.355 & 0.261 & 0.346 \\
\hline HRV & $3,108.022$ & 26.128 & 0.060 & 0.397 & 0.221 & 0.322 \\
\hline HTI & $2,195.821$ & 25.455 & 0.054 & 0.445 & 0.166 & 0.335 \\
\hline HUN & $3,544.223$ & 26.817 & 0.047 & 0.361 & 0.260 & 0.332 \\
\hline IDN & $2,958.390$ & 23.510 & 0.105 & 0.563 & 0.073 & 0.260 \\
\hline IND & $2,708.079$ & 22.195 & 0.140 & 0.658 & 0.023 & 0.179 \\
\hline IRL & $3,391.759$ & 27.174 & 0.027 & 0.339 & 0.269 & 0.365 \\
\hline IRN & $3,146.162$ & 26.396 & 0.047 & 0.385 & 0.230 & 0.339 \\
\hline IRQ & $3,150.363$ & 28.039 & 0.021 & 0.291 & 0.329 & 0.358 \\
\hline ISL & $3,300.591$ & 26.794 & 0.036 & 0.362 & 0.249 & 0.352 \\
\hline ISR & $3,778.313$ & 27.495 & 0.031 & 0.324 & 0.297 & 0.347 \\
\hline ITP & $3,735.681$ & 25.667 & 0.057 & 0.428 & 0.185 & 0.330 \\
\hline JAM & $2,997.507$ & 27.591 & 0.041 & 0.323 & 0.310 & 0.325 \\
\hline JOR & $3,566.894$ & 29.190 & 0.017 & 0.240 & 0.407 & 0.336 \\
\hline JPN & $2,701.615$ & 22.514 & 0.143 & 0.615 & 0.038 & 0.204 \\
\hline $\mathrm{KAZ}$ & $3,137.640$ & 27.244 & 0.042 & 0.340 & 0.287 & 0.331 \\
\hline KEN & $2,746.762$ & 24.614 & 0.071 & 0.499 & 0.120 & 0.310 \\
\hline KGZ & $3,126.617$ & 26.251 & 0.059 & 0.390 & 0.229 & 0.322 \\
\hline KHM & $2,385.770$ & 21.779 & 0.169 & 0.661 & 0.017 & 0.152 \\
\hline
\end{tabular}




\begin{tabular}{|c|c|c|c|c|c|c|}
\hline KOR & $3,247.010$ & 23.932 & 0.087 & 0.544 & 0.087 & 0.282 \\
\hline LAO & $2,312.454$ & 21.770 & 0.195 & 0.619 & 0.026 & 0.161 \\
\hline LBN & $3,170.715$ & 27.895 & 0.027 & 0.303 & 0.322 & 0.348 \\
\hline LBR & $2,703.794$ & 23.531 & 0.118 & 0.544 & 0.083 & 0.256 \\
\hline LBY & $2,976.762$ & 28.336 & 0.024 & 0.281 & 0.352 & 0.343 \\
\hline LKA & $2,512.824$ & 23.025 & 0.130 & 0.578 & 0.059 & 0.233 \\
\hline LSO & $2,624.721$ & 25.075 & 0.176 & 0.376 & 0.220 & 0.228 \\
\hline MDA & $3,174.837$ & 26.825 & 0.062 & 0.359 & 0.271 & 0.309 \\
\hline MDG & $2,315.432$ & 22.030 & 0.144 & 0.672 & 0.018 & 0.166 \\
\hline MEX & $3,139.737$ & 28.199 & 0.019 & 0.281 & 0.339 & 0.361 \\
\hline MLI & $2,560.522$ & 23.089 & 0.129 & 0.572 & 0.063 & 0.236 \\
\hline MMR & $2,564.709$ & 22.755 & 0.136 & 0.599 & 0.047 & 0.218 \\
\hline MNG & $3,407.848$ & 28.215 & 0.022 & 0.284 & 0.342 & 0.352 \\
\hline MOR & $3,637.094$ & 26.138 & 0.052 & 0.399 & 0.215 & 0.334 \\
\hline $\mathrm{MOZ}$ & $2,526.864$ & 23.931 & 0.094 & 0.536 & 0.092 & 0.279 \\
\hline MRT & $3,190.408$ & 25.526 & 0.090 & 0.416 & 0.201 & 0.292 \\
\hline MWI & 2,339.197 & 22.798 & 0.135 & 0.595 & 0.049 & 0.221 \\
\hline MYS & $3,300.369$ & 26.070 & 0.044 & 0.406 & 0.203 & 0.347 \\
\hline NAM & $2,813.869$ & 25.660 & 0.069 & 0.422 & 0.195 & 0.315 \\
\hline NER & $2,873.653$ & 23.270 & 0.090 & 0.611 & 0.049 & 0.251 \\
\hline NGA & $3,095.978$ & 24.021 & 0.093 & 0.528 & 0.097 & 0.281 \\
\hline NIC & $2,629.341$ & 28.098 & 0.023 & 0.291 & 0.335 & 0.351 \\
\hline NLD & $3,156.621$ & 25.581 & 0.057 & 0.434 & 0.178 & 0.331 \\
\hline NOR & $3,267.871$ & 26.264 & 0.037 & 0.395 & 0.210 & 0.357 \\
\hline NPL & $2,774.081$ & 21.893 & 0.160 & 0.662 & 0.019 & 0.159 \\
\hline NZL & $3,175.783$ & 27.890 & 0.020 & 0.296 & 0.316 & 0.368 \\
\hline OAO & $2,790.378$ & 25.229 & 0.073 & 0.449 & 0.166 & 0.312 \\
\hline OBN & $3,894.018$ & 26.440 & 0.050 & 0.382 & 0.236 & 0.332 \\
\hline OIO & $2,761.079$ & 24.970 & 0.100 & 0.445 & 0.169 & 0.286 \\
\hline OPO & $2,866.541$ & 30.745 & 0.009 & 0.174 & 0.507 & 0.311 \\
\hline OSA & $3,078.170$ & 23.293 & 0.111 & 0.577 & 0.064 & 0.249 \\
\hline PAK & $2,618.338$ & 23.777 & 0.101 & 0.542 & 0.087 & 0.270 \\
\hline PAN & $2,690.248$ & 27.741 & 0.024 & 0.308 & 0.309 & 0.359 \\
\hline PER & $2,604.714$ & 25.916 & 0.053 & 0.413 & 0.199 & 0.335 \\
\hline PHL & $2,577.985$ & 23.511 & 0.110 & 0.556 & 0.076 & 0.258 \\
\hline PNG & $3,092.304$ & 27.944 & 0.020 & 0.294 & 0.320 & 0.366 \\
\hline POL & $3,564.332$ & 26.538 & 0.052 & 0.376 & 0.244 & 0.328 \\
\hline PRT & $3,562.047$ & 26.584 & 0.042 & 0.375 & 0.239 & 0.344 \\
\hline PRY & $2,836.179$ & 26.271 & 0.054 & 0.390 & 0.227 & 0.328 \\
\hline RAP & $3,633.230$ & 28.540 & 0.014 & 0.258 & 0.360 & 0.369 \\
\hline ROU & $2,955.780$ & 25.869 & 0.061 & 0.413 & 0.203 & 0.323 \\
\hline RUS & $3,343.155$ & 26.998 & 0.044 & 0.352 & 0.271 & 0.333 \\
\hline RWA & $2,965.556$ & 24.933 & 0.054 & 0.487 & 0.127 & 0.332 \\
\hline SAU & $3,070.149$ & 28.869 & 0.019 & 0.255 & 0.386 & 0.340 \\
\hline SDN & $2,580.594$ & 23.776 & 0.118 & 0.521 & 0.099 & 0.263 \\
\hline
\end{tabular}




\begin{tabular}{|c|c|c|c|c|c|c|}
\hline SEN & $2,594.740$ & 23.993 & 0.119 & 0.500 & 0.115 & 0.266 \\
\hline SLB & $2,930.027$ & 29.592 & 0.011 & 0.214 & 0.433 & 0.342 \\
\hline SLE & $2,267.776$ & 23.957 & 0.100 & 0.526 & 0.098 & 0.276 \\
\hline SLV & $2,645.514$ & 27.557 & 0.026 & 0.318 & 0.297 & 0.358 \\
\hline SOM & $2,905.087$ & 27.334 & 0.025 & 0.329 & 0.280 & 0.366 \\
\hline SPP & $3,125.722$ & 26.807 & 0.041 & 0.362 & 0.255 & 0.342 \\
\hline SVK & $2,959.067$ & 26.991 & 0.039 & 0.352 & 0.267 & 0.342 \\
\hline SVN & $3,262.594$ & 27.283 & 0.035 & 0.336 & 0.285 & 0.345 \\
\hline SWE & $3,046.829$ & 25.789 & 0.045 & 0.425 & 0.182 & 0.347 \\
\hline SWZ & $2,696.766$ & 26.975 & 0.082 & 0.346 & 0.290 & 0.282 \\
\hline SYR & $3,284.065$ & 28.983 & 0.017 & 0.247 & 0.393 & 0.342 \\
\hline TCD & $2,464.367$ & 23.302 & 0.101 & 0.591 & 0.057 & 0.251 \\
\hline TGO & $2,664.886$ & 23.411 & 0.111 & 0.565 & 0.071 & 0.254 \\
\hline THA & $3,094.619$ & 24.353 & 0.089 & 0.503 & 0.117 & 0.291 \\
\hline TJK & $2,582.287$ & 25.086 & 0.076 & 0.457 & 0.159 & 0.309 \\
\hline TKM & $3,285.401$ & 25.646 & 0.060 & 0.428 & 0.186 & 0.326 \\
\hline TLS & $2,570.095$ & 22.572 & 0.156 & 0.589 & 0.048 & 0.208 \\
\hline TUN & $3,557.115$ & 27.142 & 0.044 & 0.345 & 0.282 & 0.329 \\
\hline TUR & $3,550.512$ & 27.523 & 0.033 & 0.324 & 0.301 & 0.342 \\
\hline TZA & $2,614.599$ & 24.170 & 0.079 & 0.531 & 0.096 & 0.294 \\
\hline UGA & $2,851.265$ & 23.739 & 0.094 & 0.554 & 0.080 & 0.272 \\
\hline UKP & $3,351.729$ & 27.288 & 0.025 & 0.332 & 0.276 & 0.367 \\
\hline UKR & $2,963.393$ & 26.489 & 0.050 & 0.379 & 0.240 & 0.331 \\
\hline URY & $3,037.813$ & 26.931 & 0.039 & 0.355 & 0.263 & 0.343 \\
\hline USA & $3,545.683$ & 28.267 & 0.017 & 0.276 & 0.342 & 0.364 \\
\hline UZB & $2,948.452$ & 26.512 & 0.047 & 0.378 & 0.238 & 0.336 \\
\hline VEN & $2,599.386$ & 28.114 & 0.018 & 0.284 & 0.332 & 0.365 \\
\hline VNM & $2,720.226$ & 21.536 & 0.176 & 0.680 & 0.012 & 0.132 \\
\hline VUT & $3,395.074$ & 29.079 & 0.014 & 0.238 & 0.399 & 0.349 \\
\hline YEM & $2,182.585$ & 25.897 & 0.067 & 0.408 & 0.210 & 0.315 \\
\hline $\mathrm{ZAF}$ & $3,427.580$ & 29.193 & 0.017 & 0.240 & 0.407 & 0.336 \\
\hline ZMB & $2,754.758$ & 24.831 & 0.066 & 0.485 & 0.132 & 0.317 \\
\hline ZWE & $2,651.872$ & 25.567 & 0.066 & 0.430 & 0.185 & 0.319 \\
\hline
\end{tabular}




\section{Appendix A5: Description of comparative risk assessment framework}

We estimated the mortality and disease burden attributable to dietary and weight-related risk factors by calculating population attributable fractions (PAFs) using the general formula: ${ }^{46,47}$

$$
P A F=\frac{\int R R(x) P(x) d x-\int R R(x) P^{\prime}(x) d x}{\int R R(x) P(x) d x}
$$

where $R R(x)$ is the relative risk of disease for risk factor level $x, P(x)$ is the number of people in the population with risk factor level $x$ in the baseline scenario, and $P^{\prime}(x)$ is the number of people in the population with risk factor level $x$ in the counterfactual scenario.

PAFs are defined as the proportions of disease cases that would be avoided when the risk exposure was changed from the counterfactual situation to the baseline situation, whilst the distribution of other risk factors in the population remain unchanged. ${ }^{48}$ The combined burden attributable to independent risk factors was calculated by multiplying the PAF complements and taking its complement: ${ }^{47,49}$

$$
P A F_{T O T}=1-\prod_{i}\left(1-P A F_{i}\right), \quad i=\{\text { diet }, \text { weight }\}
$$

where $P A F_{\text {TOT }}$ is the final PAF after all PAFs for risk factors $i$ have been combined.

We reported the health impacts of changes in risk exposure in terms of changes in the number of deaths. The number of avoided deaths due to the change in risk exposure of risk $i, \Delta$ death $s_{i}$, was calculated by multiplying the associated PAF by disease-specific death rates, $D R$, and by the number of people alive within a population, $P$ :

$$
\Delta \operatorname{death}_{i}(r, a, d)=P A F_{i}(r, d) \cdot D R(r, a, d) \cdot P(r, a)
$$

where PAFs are differentiated by region $r$ and disease/cause of death $d$; the death rates are differentiated by region, age group $a$, and disease; the population groups are differentiated by region and age group; and the change in the number of deaths is differentiated by region, age group and disease.

We included two dietary risk factors (fruit and vegetable consumption and red-meat consumption), and four levels of weight-related risks (underweight, normal weight, overweight, obesity). We treated each risk factor as discrete for ease of analysis. For discrete risk factors with $i$ levels, Equation (26) becomes: ${ }^{46}$

$$
P A F=\frac{\sum P_{i} R R_{i}-\sum P_{i}^{\prime} R R_{i}}{\sum P_{i} R R_{i}}=1-\frac{\sum P_{i}^{\prime} R R_{i}}{\sum P_{i} R R_{i}}
$$

The following summarizes the specific expressions of the equations above as used in the comparative risk assessment.

\section{Dietary risk factors}

For the dietary risk factors, it was assumed that the whole population of a region is subject to the dietary risks associated with its regional consumption level $c$ measured in $\mathrm{g} / \mathrm{cap} / \mathrm{day}$, and that risks begin increasing at zero consumption and are unbounded. We adopted standard serving sizes of $80 \mathrm{~g}$ for fruit and vegetables $\left(s_{F V}\right)$ and $100 \mathrm{~g}$ for red meat $\left(s_{\text {meat }}\right)$. Taking into account regional consumption levels $c$, the relative risk associated with the consumption-based risk factor $f=\{F V$, meat $\}$ was calculated by raising the risk factor to the power of the consumption level over the serving size, i.e. $R R_{r, f}=R R_{f}^{c_{r} / s_{f}}$. The associated PAF for region $r$, risk factor $f$, and disease/cause of death $d$ was expressed as: 


$$
P A F_{r, f, d}^{\text {diet }}=\frac{R R_{f, d}^{c_{r e f, r} / s_{f}}-R R_{f, d}^{c_{s c n, r} / s_{f}}}{R R_{f, d}^{c_{r e f, r} / s_{f}}}=1-\frac{R R_{f, d}^{c_{s c n, r} / s_{f}}}{R R_{f, d}^{c_{r e f, r} / s_{f}}}, f=\{F V, \text { meat }\}
$$

where $c_{r e f}$ denotes the consumption level in the baseline scenario, and $c_{s c n}$ the consumption level in the counterfactual scenario.

We calculated the combined disease and mortality burden of changes in dietary risk factors by using equation (27):

$$
\begin{aligned}
P A F_{r, d}^{\text {diet }}=1-\prod_{f}\left(1-P A F_{r, f, d}^{\text {diet }}\right) \\
=P A F_{r, f=F V, d}^{\text {diet }}+P A F_{r, f=m e a t, d}^{\text {diet }}-P A F_{r, f=F V, d}^{\text {diet }} P A F_{r, f=\text { meat }, d}^{\text {diet }}
\end{aligned}
$$

\section{Weight-related risk factors}

The weight-related PAFs accounted for the weight status of different population fractions and the associated risks. Following equation (29), they were expressed as:

$$
\begin{gathered}
P A F_{r, d}^{\text {weight }}=\frac{\sum_{w} p_{r, w}^{r e f} R R_{w, d}-\sum_{w} p_{r, w}^{s c n} R R_{w, d}}{\sum_{w} p_{r . w}^{r e f} R R_{w, d}}=1-\frac{\sum_{w} p_{r, w}^{s c n} R R_{w, d}}{\sum_{w} p_{r . w}^{r e f} R R_{w, d}}, \\
w=\{\text { underweight, normal, overweight,obese }\}
\end{gathered}
$$

where the relative risks $R R$ are differentiated by disease $d$ and weight category $w$; and the population fractions $p$ are differentiated by region and weight category; they are indexed by $r e f$ and $s c n$ for their levels in the baseline and counterfactual scenario, respectively.

The PAFs given by equation (32) account for the combined disease burden of all weight categories. We decomposed those combined PAFs, $P A F_{r, d}^{\text {weight }}$, into PAFs associated with single weight categories (e.g. overweight), $P A F_{r, d, w_{1}}^{\text {weight }}$, by using the same equation and assigning only the change in prevalence of that specific weight category to $p_{r, w}^{s c n}$, whilst keeping all other population fractions associated with weight risks unchanged from the baseline scenario, and absorbing the change in population fractions from the selected category by the risk-neutral normal weight category:

$$
\begin{gathered}
P A F_{r, d, w_{1}}^{\text {weight }}=P A F_{r, d}^{\text {weight }} \text { with } p_{w=w_{1}}^{s c n}=p_{w_{1}}^{\prime} ; p_{w=w_{2}}^{s c n}=p_{w_{2}} ; \\
p_{w=w_{3}}^{s c n}=p_{w_{3}} ; p_{\text {normal }}^{s c n}=p_{\text {normal }}+\left(1-\sum_{w_{i}} p_{w_{i}}^{s c n}\right)
\end{gathered}
$$

This was done successively for each weight category $w_{1} \ldots w_{3}$.

\section{Changes in mortality}

We calculated the number of disease-specific deaths that would be avoided when the risk exposure was changed from the counterfactual situation to the baseline situation by multiplying the PAFs differentiated by risk factor and disease by disease-specific death rates and population numbers:

$$
\Delta \text { deaths }_{r, a, f, d}=P A F_{r, f, d} D R_{r, a, d} P_{r, a}
$$

The number of avoided deaths was differentiated by region, age group, risk factor, and disease. 


\section{Appendix A6: Relative risk parameters}

We used publically available data sources to parameterize the comparative risk analysis. Given that dietary and weight-related risk factors are predominantly associated with chronic disease mortality, we focused on the health implications of changes in those risk factors for adults (aged 20 and older). We restricted the selection of relative risk parameters to meta-analyses and pooled prospective cohort studies. The diet and weight-related relative risk parameters were adopted from pooled analyses of prospective cohort studies, ${ }^{50,51}$ and from meta-analysis of prospective cohort and case-control studies. ${ }^{52-56}$ The cancer associations have been judged as probable or convincing by the World Cancer Research Fund, ${ }^{56}$ and in each case a dose-response relationship was apparent and consistent evidence suggests plausible mechanisms. Table A6.1 provides an overview of the relative risk parameters adopted in this study, and the short reviews below detail the selection process.

Table A6.1: Relative risk parameters (mean and $95 \%$ confidence intervals in parenthesis)

\begin{tabular}{lccc}
\hline \multirow{2}{*}{ Risk factor } & \multicolumn{2}{c}{ Relative risk per cause of death } \\
\cline { 2 - 4 } & CHD & Stroke & Cancer \\
\hline FV consumption & $0.96(0.93-0.99)$ & $0.95(0.92-0.97)$ & $0.93(0.84-0.99)^{*}$ \\
meat consumption & $1.25(1.21-1.29)$ & $1.10(1.05-1.15)$ & $1.01(1.00-1.05)^{*}$ \\
underweight & $0.67(0.65-0.70)$ & $1.03(0.71-1.47)$ & $1.11(0.94-1.32)$ \\
normal weight & 1.00 & 1.00 & 1.00 \\
overweight & $1.31(1.24-1.39)$ & $1.07(0.73-1.59)$ & $1.10(1.04-1.17)$ \\
obese & $1.78(1.64-1.92)$ & $1.55(1.14-2.11)$ & 1.00 \\
\hline
\end{tabular}

* global average, actual RR is region-specific.

\section{Weight-related risk parameters}

Excess weight is an established risk factor for several causes of death, including ischaemic heart disease, ${ }^{57,58}$ stroke, ${ }^{58-60}$ and various cancers. ${ }^{56,61-63}$ Plausible biological explanations ${ }^{50,64,65}$ and the identification of mediating factors $^{50,66}$ suggest that the association between body weight and mortality is not merely statistical association, but a causal link independent of other factors, such as diet and exercise. ${ }^{67-71}$

We inferred the parameters describing relative mortality risk due to weight categories from two large, pooled analyses of prospective cohort studies.$^{50,51} \mathrm{We}$ concentrated on four broad causes of death: ischaemic/coronary heart disease, stroke, cancers, and all other causes. We adopted the relative risks for ischaemic heart disease and stroke from the Prospective Studies Collaboration, ${ }^{50}$ which analysed the association between BMI and mortality among 900,000 persons in 57 prospective studies that were primarily designed to evaluate risk factors for cardiovascular disease; and we adopted the relative risks for cancer and all other causes from Berrington de Gonzalez and colleagues, ${ }^{51}$ who examined the relationship between BMI and mortality in a pooled analysis of 19 prospective studies which included 1.46 million adults and which were predominantly designed to study cancer.

From each study, we adopted the relative risk rates for lifelong non-smokers to minimize confounding and reverse causality, and, to increase comparability, we normalized the relative-risk schedule to the lowest risk which, in each case corresponded to a body-mass index (BMI) of 22.5-25. We then used the number of causespecific deaths to aggregate the BMI intervals of 2.5 that have been used in the studies to the WHO classification of BMI ranges, ${ }^{72}$ i.e. BMI < 18.5: underweight; 18.5-24.9: normal range; 25-29.9: overweight; and 30-39.9: obesity. 


\section{Dietary risk parameters}

Dietary risks have been the leading risk factors for death globally in $2010 .{ }^{47}$ The Global Burden of Disease Study included 14 different components as dietary risks, such as not eating enough fruit, nuts and seeds, vegetables, whole grains, and omega-3s and eating too much salt and processed meat. ${ }^{47}$ Dietary factors have been associated with the development of cardiovascular diseases, diabetes, and various cancers, and total mortality. ${ }^{47,73,74}$

In this study, we focused on changes in the consumption of fruits, vegetables, and meat. Those categories constituted about two thirds of the total dietary risk in 2010 (excluding potential double counting, e.g. of fibre found in vegetables and sodium found in processed meat), ${ }^{47}$ and country-level trends and data are available for most countries worldwide. We adopted relative-risk parameters for developing specific diseases from recent meta-analyses of existing studies.

\section{Meat consumption}

Meat consumption has been associated with increases in total mortality, ${ }^{75}$ a greater incidence of cardiovascular diseases, ${ }^{52}$ and colorectal cancer. ${ }^{56}$

\section{Meat consumption and cardiovascular disease}

The relative risks of coronary heart diseases due to meat consumption were adopted from Micha and colleagues ${ }^{52}$ (for an updated discussion, see a new contribution by Micha and others ${ }^{76}$ ). Their comprehensive systematic review and meta-analysis of the relationship between meat consumption (processed, red, and total meat) and cardiovascular diseases (coronary heart disease (CHD), diabetes mellitus, and stroke) included 20 studies (17 prospective cohorts and 3 case-control studies) with 1,218,380 individuals from 10 countries. However, analyses of specific subcategories, e.g. total meat consumption and stroke, included significantly less studies. The results show positive associations between consumption of processed and total meat and the incidence of CHD, diabetes mellitus, and stroke.

Since the publication of Micha et al. ${ }^{52}$, updated reviews of the association between meat consumption and stroke have become available. We therefore only adopted the estimates for the association between meat consumption and coronary heart disease. We excluded the findings for diabetes mellitus, because we focused on mortality, and diabetes mellitus is not an immediate or leading cause of death. We adopted the findings for total meat. The final estimate adopted is as follows:

- $\quad$ Consumption of $100 \mathrm{~g}$ per day increases CHD risk by 25\% ( $\mathrm{RR}=1.25 ; 95 \% \mathrm{CI}, 1.21$ to 1.29$)$. The estimate is based on data from 4 prospective cohort studies; one extremely positive finding from a casecontrol study was excluded in the estimate ${ }^{52}$.

The relative risk of stroke due to meat consumption was adopted from Chen et al. ${ }^{53}$ which, for stroke, provided an updated meta-analysis of Micha et al. ${ }^{52}$ containing five large independent cohort studies (compared to two in Micha et al. ${ }^{52}$ ). It should be noted that another recent meta-analysis, Kaluza et al. ${ }^{77}$, produced very similar estimates. Chen et al. ${ }^{53}$ found that consumption of red and/or processed meat increases the risk of stroke, in particular, ischemic stroke. Their dose-response analysis of the primary studies showed that the risk of stroke increased significantly by $10 \%$ for each $100 \mathrm{~g}$ per day increment in total meat consumption $(\mathrm{RR}=1.10 ; 95 \% \mathrm{CI}$, $1.05-1.15)$, by $13 \%$ for each $100 \mathrm{~g}$ per day increment in red meat consumption ( $\mathrm{RR}=1.13 ; 95 \% \mathrm{CI}, 1.03-1.23$ ) and by $11 \%$ for each $50 \mathrm{~g}$ per day increment in processed meat consumption ( $\mathrm{RR}=1.11$; 95\% CI, 1.02-1.20), with low study heterogeneity. We adopted the estimate for total meat consumption.

\section{Meat consumption and cancer}

The association between meat consumption and cancer was reviewed in the Second Expert Report "Food, Nutrition, Physical Activity, and the Prevention of Cancer: a Global Perspective" published in 2007 by the 
World Cancer Research Fund together with the American Institute for Cancer Research. ${ }^{56}$ The report is based on reviews and meta-analysis of over 7,000 scientific studies published on cancer prevention. It was the outcome of a 5 -year project which involved a panel of 21 leading scientists and 9 research centres around the world.

With respect to meat, the report concluded that: ${ }^{56}$ red and processed meats are convincing causes of colorectal cancer; there is substantial amount of evidence, with a dose-response relationship apparent from case-control studies (red meat) and cohort studies (processed meat); there is evidence (red meat) and strong evidence (processed meat) for plausible mechanisms operating in humans. The report also noted that there is limited evidence suggesting that red meat is a cause of cancers of the oesophagus, lung, pancreas and endometrium; and that processed meat is a cause of cancers of the oesophagus, lung, stomach and prostate.

Since the expert report was published in 2007, several meta-analyses of the association between meat consumption and different cancers have become available. The export report was updated for colorectal cancer which preserved its main conclusions, but changed the numerical relative-risk value. One meta-analyses has become available, ${ }^{78}$ which summarized the evidence from prospective studies of red and processed meat consumption and pancreatic cancer risk. It found a positive association for processed meat. In line with that, a WCRF update on pancreatic cancer found that the evidence for processed meat and pancreatic cancer is now stronger but remains limited. ${ }^{79}$ Several other meta-analyses found that meat consumption is associated with increased risks of stomach/gastric cancer, ${ }^{80,81}$ and oesophageal cancer, ${ }^{82-85}$ but the associations became insignificant in most cases when restricted to prospective cohort studies.

We followed the conclusions of the expert report (and its updates) that highlighted a convincing causal link between meat consumption and colorectal cancer and adopted the following estimate: ${ }^{56,86}$

- Consumption of $100 \mathrm{~g} /$ day of red and processed meat increases the risk of colorectal cancer by $16 \%$ $(\mathrm{RR}=1.16, \mathrm{CI}=1.04-1.30) .{ }^{86} \mathrm{We}$ aggregated the estimate to region-specific relative risks for all cancers by weighing it by the ratio of regional deaths due to colorectal cancer to all cancer deaths in that region. Globally, this resulted in a relative risk of cancer of $\mathrm{RR}=1.01$.

\section{Fruit and vegetable consumption}

The WHO stated that diets high in fruits and vegetables play an important role in the prevention of chronic diseases ${ }^{87}$ Most prospective studies have consistently shown lower all-cause mortality when comparing people with high and low fruit and vegetable consumption, ${ }^{88-92}$ and findings from a large cohort study including 451,151 participants from 10 European countries have supported the evidence that fruit and vegetable consumption is associated with lower risk of all-cause and cause-specific mortality. ${ }^{93}$

\section{Fruit and vegetable consumption and cardiovascular disease}

The relative risks of stroke and CHD due to fruit and vegetable consumption were adopted from Dauchet and colleagues. ${ }^{54,55}$ Dauchet et al. ${ }^{55}$ conducted a meta-analysis for CHD (see He et al. ${ }^{94}$ for a similar analysis). The analysis included nine prospective cohort studies that consisted of 91,379 men, 129,701 women, and 5,007 CHD events. Pooled relative risks showed that CHD was decreased by 4\% [RR (95\% CI): 0.96 (0.93-0.99)] for each additional portion per day of fruit and vegetable intake and by $7 \%$ [0.93 (0.89-0.96)] for fruit intake. We adopted the estimate for the aggregate of fruit and vegetable consumption, i.e. $R R=0.96$ (0.93-0.99).

Dauchet et al. ${ }^{54}$ undertook a similar meta-analysis for stroke. The analysis included seven cohort studies with 90,513 men, 141,536 women, and 2,955 strokes. Pooled relative risks showed that the risk of stroke was decreased by $11 \%$ (RR 95\% CI: 0.89 [0.85 to 0.93]) for each additional portion per day of fruit, by 5\% (RR: 0.95 [0.92 to 0.97]) for fruit and vegetables, and by 3\% (RR: 0.97 [0.92 to 1.02]) for vegetables. The study found that the association between fruit or fruit and vegetables and stroke was linear, suggesting a dose-response relationship. We adopted the estimate for the aggregate of fruit and vegetable consumption, i.e. RR=0.95 (0.920.97). 
The relative risks of various cancers due to fruit and vegetable consumption were adopted from the 2007 expert report of the World Cancer Research Fund and the American Institute for Cancer Research. ${ }^{56}$ The export report concluded that:

"[N]on-starchy vegetables and also fruits probably protect against cancers of the mouth, larynx, pharynx, oesophagus, and stomach, and that fruits also probably protect against lung cancer. The case that vegetables, fruits, and pulses (legumes) may be protective against cancers of some sites is supported by evidence on foods containing micronutrients found in these and other plant foods. Foods containing carotenoids probably protect against cancers of the mouth, pharynx, larynx, and lung; foods containing beta-carotene and also vitamin $\mathrm{C}$ probably protect against oesophageal cancer; foods containing selenium and also lycopene probably protect against prostate cancer; and foods containing folate probably protect against pancreatic cancer. [..] [It was also found that] foods containing dietary fibre, found in plant foods (particularly when in whole or relatively unprocessed forms), probably protect against colorectal cancer."

We adopted the following relative risk parameters for which the export report indicated a substantial amount of consistent evidence for plausible mechanisms and a dose-response relationship:

Cancers of the mouth, pharynx, and larynx:

- Consumption of non-starchy vegetables reduces the risk of cancers of the mouth, pharynx, and larynx by $28 \%$ per 50 -g serving per day ( $R R=0.72$; $95 \%$ CI: $0.63-0.82)$.

- Consumption of fruits reduces the risk of cancers of the mouth, pharynx, and larynx by $28 \%$ per $100-\mathrm{g}$ serving per day (95\% CI: 0.59-0.87).

- We adopted the simple average of vegetable and fruit consumption for the relative risk of cancers of the mouth, pharynx, and larynx, i.e. RR=0.72 (0.61-0.85).

Oesophageal cancer:

- Consumption of raw vegetables reduces the risk of oesophageal cancer by $31 \%$ per 50 -g serving per day ( RR=0.69; 95\% CI: 0.58-0.83).

- Consumption of fruits reduces the risk of oesophageal cancer by $44 \%$ per 100 -g serving per day (RR=0.56; 95\% CI: 0.42-0.74).

- We adopted the simple average of vegetable and fruit consumption for the relative risk of oesophageal cancer, i.e. $\mathrm{RR}=0.63(0.50-0.79)$.

Stomach cancer:

- Consumption of non-starchy vegetables reduces the risk of stomach cancer by $30 \%$ per 100 -g serving per day (RR=0.70; 95\% CI: 0.62-0.79).

[Estimates of green-yellow vegetables yield $\mathrm{RR}=0.59(0.46-0.75)$ per $100 \mathrm{~g} / \mathrm{d}$; green, leafy vegetables yield $R R=0.43(0.24-0.77)$ per $50 \mathrm{~g} / \mathrm{d}$; and raw vegetables yield $\mathrm{RR}=0.5(0.38-0.65)$ per $100 \mathrm{~g} / \mathrm{d}]$

- Consumption of fruits reduces the risk of stomach cancer by $33 \%$ per $100-\mathrm{g}$ serving per day $(\mathrm{RR}=0.67$; 95\% CI: 0.59-0.76).

- We adopted the simple average of vegetable and fruit consumption for the relative risk of stomach cancer, i.e. $\mathrm{RR}=0.69$.

Lung cancer:

- $\quad$ Consumption of fruits reduces the risk of lung cancer by $6 \%$ per 80 -g serving per day $(\mathrm{RR}=0.94 ; 95 \%$ CI: 0.90-0.97).

- We adopted the simple average of vegetable and fruit consumption for the relative risk of lung cancer (assuming no effect of vegetable consumption, $R R=1$ ), i.e. $R R=0.97$.

Overall relative risk:

- We aggregated the cause-specific relative-risk estimates to region-specific all-cancer estimates by weighing each risk by the ratio of regional deaths due to the specific cancer divided by all cancer deaths in that region. Globally, this yielded an aggregate all-cancer risk of RR=0.93. 


\section{Appendix A7: Regional aggregation}

Our analysis yielded results for 155 regions. We aggregated the results for individual countries into results for regional aggregates to provide an overview and ease the presentation of results. For that purpose, we used the WHO-World Bank classification. WHO Member States were classified according to the World Bank income category for the year 2011 (World Bank list of economies, July 2012) and WHO region:

HIC: $\quad$ high-income countries;

AFR_LMIC: low and middle-income countries of Africa;

AMR_LMIC: low and middle-income countries of America;

EMR_LMIC: low and middle-income countries of the Eastern Mediterranean;

EUR_LMIC: low and middle income countries of Europe;

SEA_LMIC: low and middle-income countries of South-East Asia;

WPR_LMIC: low and middle-income countries of the Western Pacific.

The assignment of countries to the regional aggregates is detailed below.

HIC High-income countries

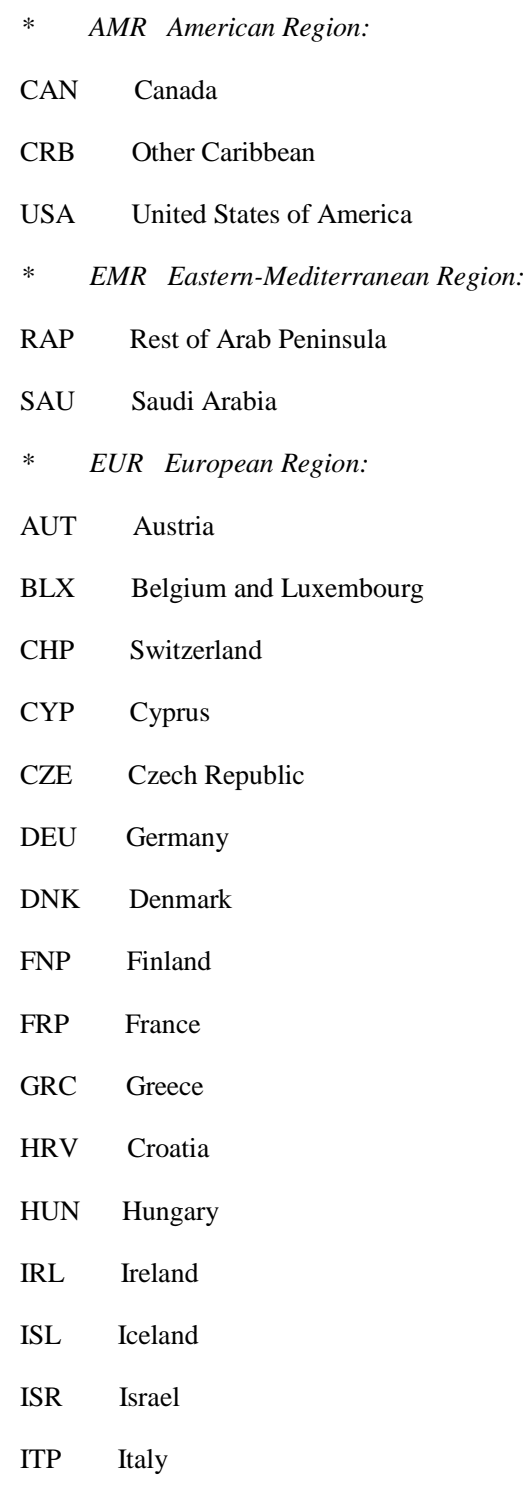




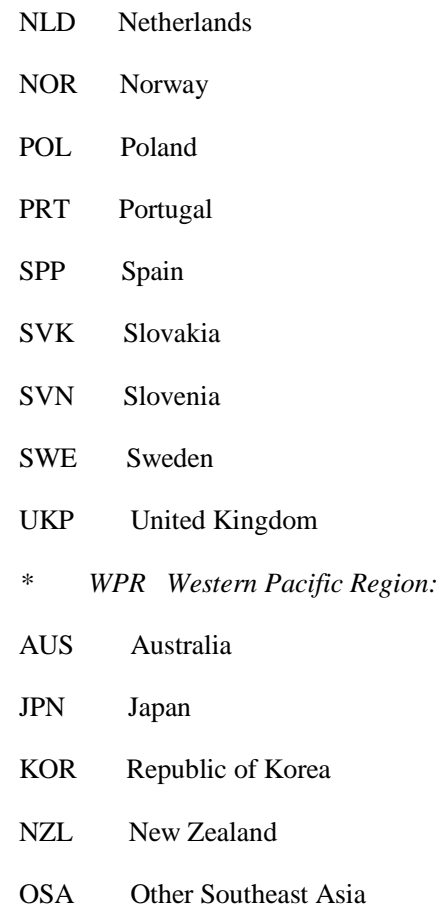

(Note: GNQ, Equatorial Guinea, was re-classified as UMC in accordance with WHO mortality projections)

\section{AFR_LMIC Low and middle-income Africa}

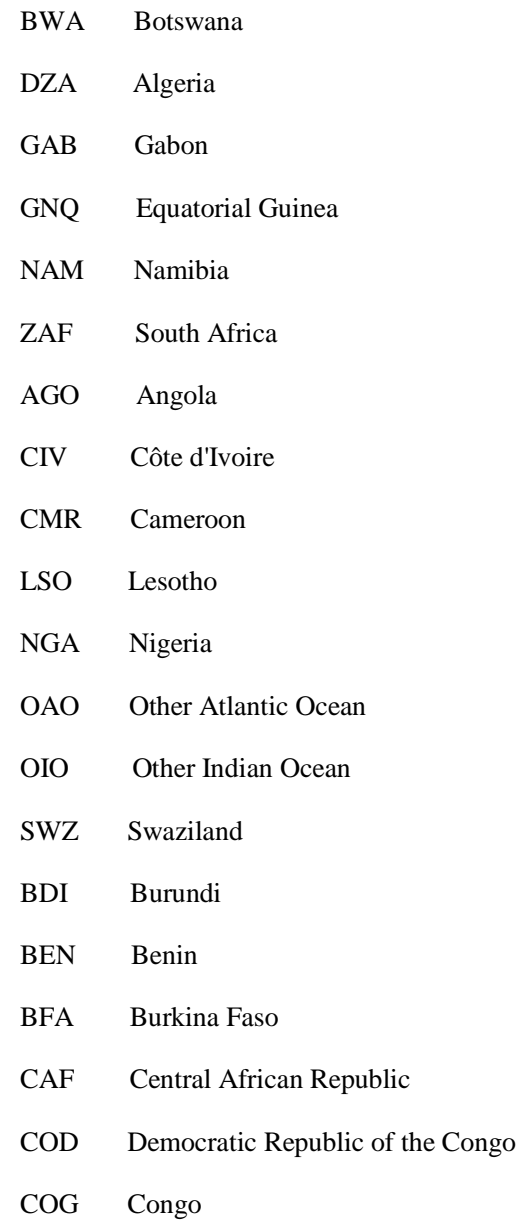




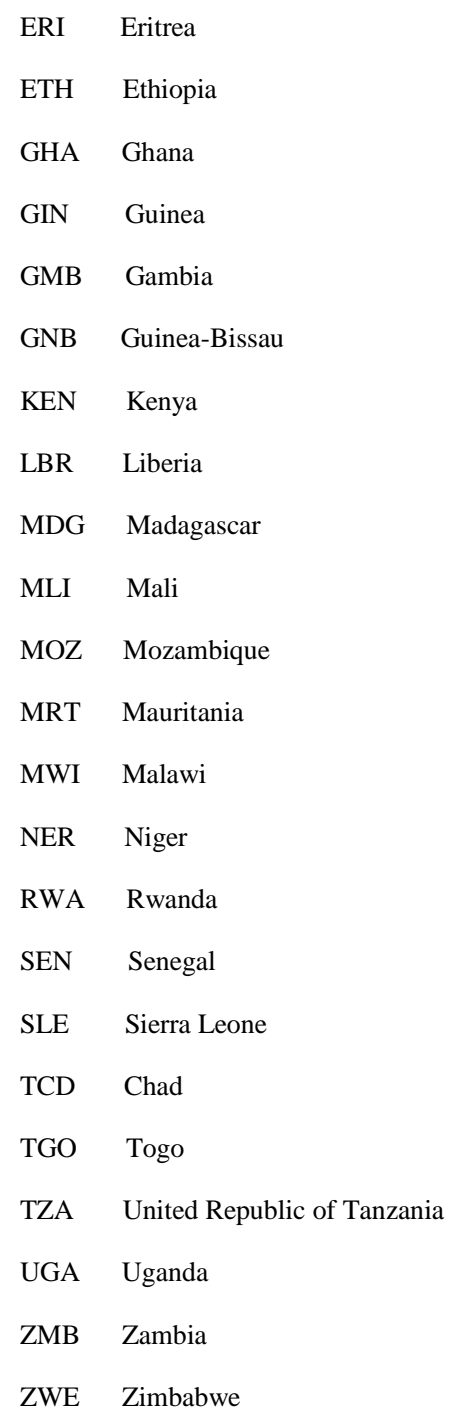

\section{AMR_LMIC Low and middle-income America}

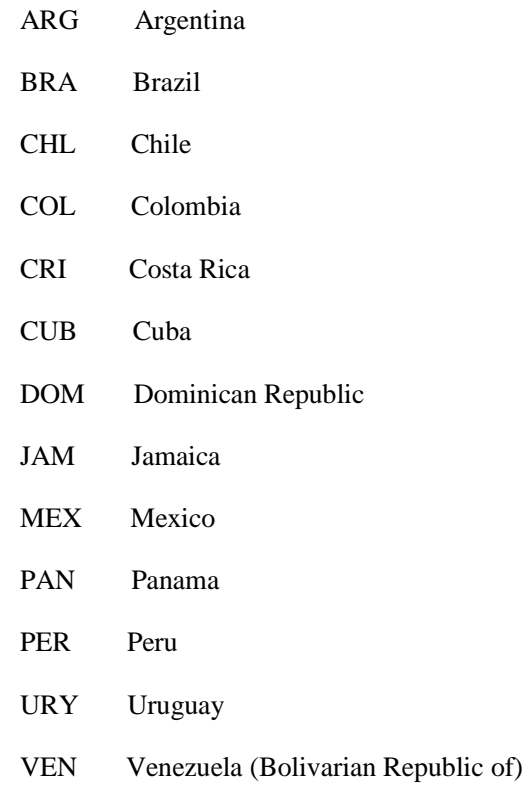




$\begin{array}{ll}\text { GEO } & \text { Georgia } \\ \text { MDA } & \text { Republic of Moldova } \\ \text { TKM } & \text { Turkmenistan } \\ \text { UKR } & \text { Ukraine } \\ \text { KGZ } & \text { Kyrgyzstan } \\ \text { TJK } & \text { Tajikistan } \\ \text { UZB } & \text { Uzbekistan }\end{array}$

SEA_LMIC Low and middle-income South-East Asia

$\begin{array}{ll}\text { BTN } & \text { Bhutan } \\ \text { IDN } & \text { Indonesia } \\ \text { IND } & \text { India } \\ \text { LKA } & \text { Sri Lanka } \\ \text { THA } & \text { Thailand } \\ \text { TLS } & \text { Timor-Leste } \\ \text { BGD } & \text { Bangladesh } \\ \text { MMR } & \text { Myanmar } \\ \text { NPL } & \text { Nepal }\end{array}$

WPR_LMIC Low and middle-income Western Pacific

FJI Fiji

MYS Malaysia

OPO Other Pacific Ocean

CHM China

MNG Mongolia

PHL Philippines

PNG Papua New Guinea

VUT Vanuatu

KHM Cambodia

LAO Lao People's Democratic Republic

SLB Solomon Islands

VNM Viet Nam 


\section{Appendix A8: Supplementary agricultural results}

The units of reporting used for health analyses differ from those used in agricultural and economic research. Health and nutrition analysis is built around per-capita consumption values, whilst agriculture and economic analyses frequently (but not always) focus on production and consumption systems in terms of total quantities. In Tables A8.1-A8.2, we report our agricultural results in terms of total quantities (million tonnes per year) to enable comparisons between those different research fields. The economic model adopted in this study (IMPACT) formed part of a recent model comparison of global agriculture-economic models, ${ }^{95,96}$ where its demand projections fell within the middle two quartiles of the range of model results. ${ }^{96}$

Tables A8.3-A8.5 list the agricultural results by country (in the units adopted in the main text), and Table A8.6 lists the climate-related changes in caloric availability in 2050 by food group and aggregate region.

Table A8.1: Global and regional consumption of fruits and vegetables (in million tonnes per year) in 2010 and 2050 for the reference scenario without climate change and for the mean of the main climate change scenarios (including standard deviation), with and without accounting for waste at the consumption level.

\begin{tabular}{|c|c|c|c|c|c|}
\hline \multirow{3}{*}{ Region and consumption item } & \multirow{3}{*}{$\begin{array}{l}\text { Baseline } \\
\text { of } 2010\end{array}$} & \multicolumn{4}{|c|}{ Model scenarios of 2050} \\
\hline & & \multirow[b]{2}{*}{$\begin{array}{c}\text { Reference scenario } \\
\text { (without climate change) }\end{array}$} & \multirow{2}{*}{\multicolumn{3}{|c|}{$\begin{array}{l}\text { Climate change scenarios } \\
\text { (mean } \pm \text { standard deviation) }\end{array}$}} \\
\hline & & & & & \\
\hline \multicolumn{6}{|c|}{ Fruit and vegetable consumption [million tonnes/year] } \\
\hline \multicolumn{6}{|l|}{ Global } \\
\hline net of waste at consumption & 856.23 & $1,263.87$ & $1,213.95$ & \pm & 8.92 \\
\hline total & $1,289.81$ & $1,877.99$ & $1,803.88$ & \pm & 13.26 \\
\hline \multicolumn{6}{|l|}{ HIC } \\
\hline net of waste at consumption & 149.70 & 187.59 & 180.32 & \pm & 1.29 \\
\hline total & 247.77 & 311.61 & 299.42 & \pm & 2.15 \\
\hline \multicolumn{6}{|l|}{ AFR_LMIC } \\
\hline net of waste at consumption & 60.13 & 152.88 & 147.12 & \pm & 1.15 \\
\hline total & 82.70 & 209.75 & 201.86 & \pm & 1.58 \\
\hline \multicolumn{6}{|l|}{ AMR_LMIC } \\
\hline net of waste at consumption & 68.88 & 97.73 & 94.08 & \pm & 0.50 \\
\hline total & 99.40 & 141.02 & 135.76 & \pm & 0.72 \\
\hline \multicolumn{6}{|l|}{ EMR_LMIC } \\
\hline net of waste at consumption & 64.43 & 113.14 & 108.80 & \pm & 0.71 \\
\hline total & 95.09 & 166.98 & 160.57 & \pm & 1.05 \\
\hline \multicolumn{6}{|l|}{ EUR_LMIC } \\
\hline net of waste at consumption & 38.32 & 43.60 & 42.00 & \pm & 0.37 \\
\hline total & 61.43 & 69.90 & 67.34 & \pm & 0.59 \\
\hline \multicolumn{6}{|l|}{ SEA_LMIC } \\
\hline net of waste at consumption & 140.14 & 283.89 & 271.09 & \pm & 2.29 \\
\hline total & 195.69 & 396.44 & 378.57 & \pm & 3.20 \\
\hline \multicolumn{6}{|l|}{ WPR_LMIC } \\
\hline net of waste at consumption & 313.06 & 354.98 & 341.44 & \pm & 2.52 \\
\hline total & 474.76 & 536.23 & 515.78 & \pm & 3.81 \\
\hline
\end{tabular}


Table A8.2: Global and regional consumption of red meat (in million tonnes per year) in 2010 and 2050 for the reference scenario without climate change and for the mean of the main climate change scenarios (including standard deviation), with and without accounting for waste at the consumption level.

Model scenarios of 2050

\begin{tabular}{|c|c|c|c|c|c|}
\hline Region and consumption item & Baseline of 2010 & $\begin{array}{c}\text { Reference scenario } \\
\text { (without climate change) }\end{array}$ & \multicolumn{3}{|c|}{$\begin{array}{l}\text { Climate change scenarios } \\
\text { (mean } \pm \text { standard deviation) }\end{array}$} \\
\hline \multicolumn{6}{|c|}{ Red meat consumption [million tonnes/year] } \\
\hline \multicolumn{6}{|l|}{ Global } \\
\hline net of waste at consumption & 156.63 & 222.40 & 220.80 & \pm & 0.22 \\
\hline total & 171.03 & 240.92 & 239.18 & \pm & 0.24 \\
\hline \multicolumn{6}{|l|}{$\mathrm{HIC}$} \\
\hline net of waste at consumption & 54.10 & 63.16 & 62.64 & \pm & 0.08 \\
\hline total & 60.59 & 70.71 & 70.13 & \pm & 0.08 \\
\hline \multicolumn{6}{|l|}{ AFR_LMIC } \\
\hline net of waste at consumption & 5.56 & 22.93 & 22.69 & \pm & 0.04 \\
\hline total & 5.69 & 23.43 & 23.18 & \pm & 0.04 \\
\hline \multicolumn{6}{|l|}{ AMR_LMIC } \\
\hline net of waste at consumption & 19.09 & 26.77 & 26.54 & \pm & 0.03 \\
\hline total & 20.31 & 28.48 & 28.23 & \pm & 0.04 \\
\hline \multicolumn{6}{|l|}{ EMR_LMIC } \\
\hline net of waste at consumption & 3.75 & 12.33 & 12.25 & \pm & 0.02 \\
\hline total & 4.08 & 13.40 & 13.32 & \pm & 0.02 \\
\hline \multicolumn{6}{|l|}{ EUR_LMIC } \\
\hline net of waste at consumption & 8.64 & 9.39 & 9.32 & \pm & 0.01 \\
\hline total & 9.71 & 10.55 & 10.47 & \pm & 0.01 \\
\hline \multicolumn{6}{|l|}{ SEA_LMIC } \\
\hline net of waste at consumption & 5.91 & 12.44 & 12.35 & \pm & 0.01 \\
\hline total & 6.15 & 12.96 & 12.87 & \pm & 0.01 \\
\hline \multicolumn{6}{|l|}{ WPR_LMIC } \\
\hline net of waste at consumption & 59.06 & 74.25 & 73.89 & \pm & 0.07 \\
\hline total & 63.94 & 80.16 & 79.77 & \pm & 0.08 \\
\hline
\end{tabular}

Table A8.3: Regional and country-level consumption of fruits and vegetables (in g/cap/day) in 2010 and 2050 for the reference scenario without climate change and for the mean of the main climate change scenarios (including standard deviation), net of food waste at the consumption level.

\begin{tabular}{|c|c|c|c|c|}
\hline \multirow[b]{2}{*}{ Region } & \multirow[b]{2}{*}{$\begin{array}{c}\text { Baseline of } \\
2010\end{array}$} & \multicolumn{3}{|c|}{ Model scenarios of 2050} \\
\hline & & $\begin{array}{c}\text { Reference scenario } \\
\text { (without climate change) }\end{array}$ & $\begin{array}{l}\text { Climate change } \\
\text { (mean } \pm \text { standard }\end{array}$ & $\begin{array}{l}\text { ios } \\
\text { ion) }\end{array}$ \\
\hline Global & 342.17 & 378.00 & 363.07 & 2.67 \\
\hline $\mathrm{HIC}$ & 375.87 & 397.73 & $382.31 \pm$ & 2.73 \\
\hline AFR_LMIC & 196.54 & 242.34 & 233.22 & 1.82 \\
\hline AMR_LMIC & 324.07 & 362.27 & 348.74 & 1.84 \\
\hline
\end{tabular}




\begin{tabular}{|c|c|c|c|c|c|}
\hline EMR_LMIC & 332.43 & 340.78 & 327.71 & \pm & 2.15 \\
\hline EUR_LMIC & 313.98 & 366.02 & 352.63 & \pm & 3.08 \\
\hline SEA_LMIC & 215.34 & 321.81 & 307.30 & \pm & 2.60 \\
\hline WPR_LMIC & 539.04 & 602.15 & 579.18 & \pm & 4.28 \\
\hline AFG & 121.18 & 156.12 & 149.59 & \pm & 1.71 \\
\hline AGO & 118.54 & 114.75 & 109.52 & \pm & 0.73 \\
\hline ALB & 523.69 & 572.60 & 551.75 & \pm & 4.42 \\
\hline ARG & 298.87 & 321.75 & 309.96 & \pm & 1.75 \\
\hline ARM & 575.39 & 647.33 & 623.81 & \pm & 5.34 \\
\hline AUS & 309.60 & 320.07 & 307.15 & \pm & 2.58 \\
\hline AUT & 408.62 & 435.65 & 422.56 & \pm & 2.96 \\
\hline AZE & 439.91 & 420.56 & 404.93 & \pm & 3.23 \\
\hline BDI & 394.31 & 547.50 & 526.33 & \pm & 3.55 \\
\hline BEN & 164.61 & 195.16 & 186.22 & \pm & 1.48 \\
\hline BFA & 68.07 & 84.00 & 80.43 & \pm & 0.72 \\
\hline BGD & 76.44 & 105.36 & 100.20 & \pm & 0.97 \\
\hline BGR & 208.60 & 234.92 & 226.42 & \pm & 1.80 \\
\hline BLR & 344.01 & 396.14 & 381.39 & \pm & 3.50 \\
\hline BLT & 280.80 & 328.50 & 316.91 & \pm & 2.68 \\
\hline BLX & 347.72 & 372.72 & 360.18 & \pm & 2.73 \\
\hline BLZ & 526.26 & 587.83 & 568.20 & \pm & 1.70 \\
\hline BOL & 224.97 & 289.00 & 280.40 & \pm & 1.99 \\
\hline BRA & 340.82 & 371.56 & 356.09 & \pm & 1.69 \\
\hline BTN & 325.71 & 472.15 & 450.71 & \pm & 2.60 \\
\hline BWA & 133.06 & 180.04 & 174.92 & \pm & 1.35 \\
\hline $\mathrm{CAF}$ & 134.76 & 168.36 & 160.84 & \pm & 1.15 \\
\hline CAN & 369.91 & 382.25 & 365.18 & \pm & 2.95 \\
\hline CHL & 298.96 & 357.50 & 346.98 & \pm & 2.54 \\
\hline CHM & 580.91 & 663.34 & 638.17 & \pm & 4.78 \\
\hline CHP & 276.94 & 291.84 & 282.05 & \pm & 1.97 \\
\hline CIV & 236.15 & 290.34 & 278.69 & \pm & 3.60 \\
\hline CMR & 342.57 & 406.54 & 390.14 & \pm & 3.81 \\
\hline COD & 105.77 & 146.06 & 139.95 & \pm & 1.32 \\
\hline $\mathrm{COG}$ & 203.25 & 251.08 & 240.25 & \pm & 2.05 \\
\hline $\mathrm{COL}$ & 294.29 & 336.66 & 327.31 & \pm & 1.80 \\
\hline CRB & 102.72 & 116.38 & 114.06 & \pm & 0.43 \\
\hline CRI & 342.05 & 384.71 & 372.54 & \pm & 1.36 \\
\hline CUB & 487.41 & 597.51 & 579.95 & \pm & 3.30 \\
\hline CYP & 384.31 & 390.76 & 377.69 & \pm & 2.08 \\
\hline CZE & 271.28 & 300.35 & 290.28 & \pm & 2.07 \\
\hline DEU & 304.48 & 325.67 & 314.84 & \pm & 2.35 \\
\hline DJI & 130.08 & 146.71 & 140.97 & \pm & 1.14 \\
\hline DNK & 379.58 & 401.68 & 388.29 & \pm & 2.62 \\
\hline DOM & 423.72 & 474.61 & 459.95 & \pm & 2.23 \\
\hline DZA & 352.85 & 387.21 & 374.53 & \pm & 2.20 \\
\hline
\end{tabular}




\begin{tabular}{|c|c|c|c|c|c|}
\hline ECU & 346.25 & 424.57 & 412.13 & \pm & 2.49 \\
\hline EGY & 582.21 & 641.97 & 617.83 & \pm & 3.96 \\
\hline ERI & 16.42 & 19.68 & 18.80 & \pm & 0.19 \\
\hline ETH & 55.92 & 66.25 & 63.56 & \pm & 0.46 \\
\hline FJI & 158.50 & 184.72 & 180.48 & \pm & 0.82 \\
\hline FNP & 285.44 & 303.47 & 293.00 & \pm & 1.90 \\
\hline FRP & 366.67 & 383.89 & 370.10 & \pm & 2.38 \\
\hline GAB & 375.31 & 410.64 & 394.58 & \pm & 5.62 \\
\hline GEO & 223.90 & 265.35 & 255.92 & \pm & 1.94 \\
\hline GHA & 364.92 & 441.87 & 424.08 & \pm & 5.66 \\
\hline GIN & 343.12 & 442.24 & 422.77 & \pm & 3.43 \\
\hline GMB & 83.25 & 97.48 & 93.15 & \pm & 0.93 \\
\hline GNB & 143.28 & 176.74 & 169.13 & \pm & 1.78 \\
\hline GNQ & 204.49 & 203.77 & 194.98 & \pm & 2.55 \\
\hline GRC & 729.74 & 786.39 & 758.99 & \pm & 5.56 \\
\hline GSA & 170.60 & 214.88 & 208.00 & \pm & 1.02 \\
\hline GTM & 233.11 & 279.81 & 270.26 & \pm & 1.25 \\
\hline HND & 268.08 & 319.22 & 310.19 & \pm & 1.75 \\
\hline HRV & 266.03 & 289.88 & 280.61 & \pm & 2.10 \\
\hline HTI & 183.36 & 255.77 & 247.97 & \pm & 1.18 \\
\hline HUN & 372.60 & 409.55 & 395.96 & \pm & 3.09 \\
\hline IDN & 203.00 & 252.19 & 239.24 & \pm & 1.69 \\
\hline IND & 226.50 & 355.83 & 339.86 & \pm & 2.96 \\
\hline IRL & 310.65 & 327.83 & 315.46 & \pm & 1.71 \\
\hline IRN & 719.96 & 755.76 & 729.54 & \pm & 4.70 \\
\hline IRQ & 311.50 & 348.67 & 334.95 & \pm & 1.86 \\
\hline ISL & 304.37 & 334.10 & 322.58 & \pm & 1.98 \\
\hline ISR & 623.03 & 650.29 & 618.51 & \pm & 5.29 \\
\hline ITP & 560.60 & 591.69 & 570.61 & \pm & 3.88 \\
\hline JAM & 387.57 & 429.31 & 420.65 & \pm & 1.01 \\
\hline JOR & 340.86 & 391.74 & 378.76 & \pm & 2.43 \\
\hline JPN & 292.95 & 306.92 & 297.77 & \pm & 1.78 \\
\hline KAZ & 321.35 & 361.41 & 346.92 & \pm & 2.94 \\
\hline KEN & 206.10 & 248.94 & 239.44 & \pm & 1.61 \\
\hline KGZ & 305.31 & 355.30 & 340.85 & \pm & 3.18 \\
\hline KHM & 126.07 & 164.97 & 159.27 & \pm & 0.95 \\
\hline KOR & 544.16 & 608.49 & 589.14 & \pm & 3.64 \\
\hline LAO & 373.07 & 465.79 & 448.95 & \pm & 2.65 \\
\hline LBN & 622.85 & 665.64 & 642.61 & \pm & 3.90 \\
\hline LBR & 186.93 & 222.84 & 212.98 & \pm & 1.75 \\
\hline LBY & 473.89 & 512.17 & 494.97 & \pm & 2.94 \\
\hline LKA & 141.34 & 172.77 & 165.80 & \pm & 1.69 \\
\hline LSO & 77.96 & 124.67 & 120.91 & \pm & 1.00 \\
\hline MDA & 279.09 & 344.71 & 332.83 & \pm & 2.87 \\
\hline MDG & 125.79 & 151.54 & 144.35 & \pm & 0.73 \\
\hline
\end{tabular}




\begin{tabular}{|c|c|c|c|c|c|}
\hline MEX & 378.42 & 421.91 & 403.52 & \pm & 2.36 \\
\hline MLI & 142.82 & 163.12 & 155.73 & \pm & 1.11 \\
\hline MMR & 248.41 & 343.90 & 333.14 & \pm & 3.71 \\
\hline MNG & 100.05 & 145.53 & 141.77 & \pm & 0.93 \\
\hline MOR & 458.51 & 518.41 & 501.62 & \pm & 3.00 \\
\hline MOZ & 49.73 & 74.52 & 71.53 & \pm & 0.46 \\
\hline MRT & 51.28 & 59.20 & 56.58 & \pm & 0.38 \\
\hline MWI & 188.02 & 253.63 & 244.88 & \pm & 2.21 \\
\hline MYS & 186.36 & 210.83 & 203.62 & \pm & 1.14 \\
\hline NAM & 108.18 & 150.84 & 145.76 & \pm & 1.09 \\
\hline NER & 123.40 & 143.90 & 137.37 & \pm & 1.20 \\
\hline NGA & 277.46 & 334.97 & 323.15 & \pm & 1.76 \\
\hline NIC & 75.89 & 104.55 & 101.31 & \pm & 0.59 \\
\hline NLD & 382.28 & 405.41 & 390.86 & \pm & 2.56 \\
\hline NOR & 345.05 & 354.18 & 342.23 & \pm & 2.15 \\
\hline NPL & 220.92 & 287.38 & 275.82 & \pm & 2.67 \\
\hline NZL & 364.82 & 380.55 & 363.32 & \pm & 3.29 \\
\hline OAO & 186.67 & 281.11 & 275.62 & \pm & 1.22 \\
\hline OBN & 277.05 & 315.44 & 305.11 & \pm & 2.50 \\
\hline OIO & 155.06 & 194.25 & 190.62 & \pm & 0.77 \\
\hline OPO & 145.13 & 165.31 & 162.06 & \pm & 0.62 \\
\hline OSA & 27.60 & 29.09 & 28.11 & \pm & 0.22 \\
\hline PAK & 131.65 & 153.96 & 146.83 & \pm & 1.00 \\
\hline PAN & 235.90 & 282.61 & 273.97 & \pm & 1.75 \\
\hline PER & 290.17 & 343.97 & 333.65 & \pm & 2.20 \\
\hline PHL & 340.18 & 392.77 & 377.32 & \pm & 1.58 \\
\hline PNG & 798.68 & $1,039.31$ & $1,015.20$ & \pm & 6.70 \\
\hline POL & 296.81 & 326.04 & 314.11 & \pm & 2.64 \\
\hline PRT & 503.98 & 531.05 & 512.59 & \pm & 3.65 \\
\hline PRY & 293.76 & 344.87 & 332.80 & \pm & 1.28 \\
\hline RAP & 280.73 & 306.19 & 296.02 & \pm & 1.72 \\
\hline ROU & 459.26 & 505.12 & 486.96 & \pm & 4.03 \\
\hline RUS & 292.48 & 342.09 & 329.60 & \pm & 2.98 \\
\hline RWA & 406.84 & 516.22 & 498.35 & \pm & 6.65 \\
\hline SAU & 372.19 & 400.32 & 384.47 & \pm & 2.06 \\
\hline SDN & 244.19 & 288.70 & 276.86 & \pm & 1.86 \\
\hline SEN & 143.12 & 162.37 & 155.24 & \pm & 1.17 \\
\hline SLB & 136.87 & 173.88 & 169.16 & \pm & 1.49 \\
\hline SLE & 169.48 & 201.66 & 192.40 & \pm & 1.56 \\
\hline SLV & 270.05 & 305.61 & 296.48 & \pm & 1.63 \\
\hline SOM & 62.68 & 99.32 & 96.53 & \pm & 0.65 \\
\hline SPP & 435.02 & 445.98 & 429.73 & \pm & 2.79 \\
\hline SVK & 243.40 & 264.27 & 255.26 & \pm & 1.90 \\
\hline SVN & 407.02 & 450.55 & 436.54 & \pm & 3.65 \\
\hline SWE & 335.87 & 358.34 & 345.95 & \pm & 2.25 \\
\hline
\end{tabular}




\begin{tabular}{|c|c|c|c|c|c|}
\hline SWZ & 196.77 & 219.46 & 208.54 & \pm & 0.89 \\
\hline SYR & 385.40 & 454.64 & 439.03 & \pm & 2.57 \\
\hline TCD & 42.51 & 57.79 & 55.65 & \pm & 0.42 \\
\hline TGO & 79.28 & 94.12 & 89.92 & \pm & 0.80 \\
\hline THA & 357.15 & 429.91 & 411.72 & \pm & 1.75 \\
\hline TJK & 234.25 & 260.87 & 250.67 & \pm & 2.09 \\
\hline TKM & 344.39 & 404.82 & 388.90 & \pm & 3.47 \\
\hline TLS & 80.94 & 93.37 & 91.43 & \pm & 0.29 \\
\hline TUN & 557.88 & 628.60 & 607.72 & \pm & 3.64 \\
\hline TUR & 611.20 & 658.55 & 637.51 & \pm & 4.25 \\
\hline TZA & 215.41 & 264.99 & 255.00 & \pm & 1.72 \\
\hline UGA & 404.73 & 488.74 & 473.38 & \pm & 6.51 \\
\hline UKP & 375.96 & 403.29 & 389.54 & \pm & 2.54 \\
\hline UKR & 288.48 & 351.76 & 339.37 & \pm & 2.74 \\
\hline URY & 263.59 & 303.74 & 293.24 & \pm & 1.98 \\
\hline USA & 382.75 & 399.64 & 381.27 & \pm & 3.03 \\
\hline UZB & 337.58 & 428.79 & 413.07 & \pm & 3.87 \\
\hline VEN & 246.35 & 270.13 & 261.48 & \pm & 1.31 \\
\hline VNM & 304.91 & 385.05 & 366.88 & \pm & 4.00 \\
\hline VUT & 275.55 & 323.52 & 317.07 & \pm & 1.46 \\
\hline YEM & 139.31 & 162.96 & 156.78 & \pm & 0.93 \\
\hline ZAF & 156.85 & 182.87 & 174.46 & \pm & 1.38 \\
\hline ZMB & 72.12 & 93.36 & 89.52 & \pm & 0.62 \\
\hline ZWE & 53.97 & 69.19 & 66.14 & \pm & 0.44 \\
\hline
\end{tabular}

Table A8.4: Regional and country-level consumption of red meat (in g/cap/day) in 2010 and 2050 for the reference scenario without climate change and for the mean of the main climate change scenarios (including standard deviation), net of food waste at the consumption level.

\begin{tabular}{|c|c|c|c|c|c|}
\hline \multirow[b]{2}{*}{ Region } & \multirow[b]{2}{*}{$\begin{array}{c}\text { Baseline of } \\
2010\end{array}$} & \multicolumn{4}{|c|}{ Model scenarios of 2050} \\
\hline & & $\begin{array}{c}\text { Reference scenario } \\
\text { (without climate change) }\end{array}$ & $\begin{array}{l}\text { Climate ch } \\
(\text { mean } \pm \text { sta }\end{array}$ & $\begin{array}{l}\text { inge } \\
\text { darc }\end{array}$ & $\begin{array}{l}\text { rios } \\
\text { tion) }\end{array}$ \\
\hline Global & 62.59 & 66.52 & 66.04 & \pm & 0.07 \\
\hline $\mathrm{HIC}$ & 135.84 & 133.91 & 132.81 & \pm & 0.16 \\
\hline AFR_LMIC & 18.16 & 36.36 & 35.96 & \pm & 0.06 \\
\hline AMR_LMIC & 89.80 & 99.25 & 98.38 & \pm & 0.12 \\
\hline EMR_LMIC & 19.36 & 37.13 & 36.90 & \pm & 0.05 \\
\hline EUR_LMIC & 70.82 & 78.82 & 78.21 & \pm & 0.09 \\
\hline SEA_LMIC & 9.08 & 14.10 & 14.00 & \pm & 0.01 \\
\hline WPR_LMIC & 101.69 & 125.95 & 125.33 & \pm & 0.12 \\
\hline AFG & 16.70 & 35.45 & 35.16 & \pm & 0.06 \\
\hline AGO & 39.10 & 43.82 & 43.37 & \pm & 0.07 \\
\hline ALB & 66.39 & 70.35 & 69.86 & \pm & 0.07 \\
\hline ARG & 162.32 & 163.06 & 161.84 & \pm & 0.23 \\
\hline
\end{tabular}




\begin{tabular}{|c|c|c|c|c|c|}
\hline ARM & 53.25 & 77.75 & 77.48 & \pm & 0.04 \\
\hline AUS & 146.88 & 159.27 & 157.98 & \pm & 0.18 \\
\hline AUT & 207.62 & 196.26 & 194.12 & \pm & 0.38 \\
\hline AZE & 32.45 & 34.06 & 33.98 & \pm & 0.02 \\
\hline BDI & 6.96 & 21.15 & 20.91 & \pm & 0.03 \\
\hline BEN & 9.39 & 17.61 & 17.43 & \pm & 0.03 \\
\hline BFA & 28.04 & 92.37 & 91.25 & \pm & 0.19 \\
\hline BGD & 4.09 & 8.65 & 8.61 & \pm & 0.01 \\
\hline BGR & 72.35 & 80.85 & 80.21 & \pm & 0.10 \\
\hline BLR & 123.63 & 131.97 & 130.86 & \pm & 0.17 \\
\hline BLT & 103.07 & 110.60 & 109.59 & \pm & 0.18 \\
\hline BLX & 128.77 & 124.98 & 123.72 & \pm & 0.19 \\
\hline BLZ & 45.94 & 53.08 & 52.60 & \pm & 0.07 \\
\hline BOL & 84.39 & 119.20 & 118.33 & \pm & 0.12 \\
\hline BRA & 127.66 & 138.52 & 137.11 & \pm & 0.21 \\
\hline BTN & 30.43 & 53.69 & 53.35 & \pm & 0.07 \\
\hline BWA & 32.60 & 62.10 & 61.46 & \pm & 0.13 \\
\hline CAF & 58.98 & 143.33 & 141.67 & \pm & 0.27 \\
\hline CAN & 141.26 & 131.44 & 130.53 & \pm & 0.13 \\
\hline CHL & 102.18 & 118.36 & 117.41 & \pm & 0.13 \\
\hline CHM & 108.42 & 133.96 & 133.28 & \pm & 0.13 \\
\hline CHP & 128.03 & 123.46 & 122.21 & \pm & 0.19 \\
\hline CIV & 7.86 & 18.50 & 18.30 & \pm & 0.03 \\
\hline CMR & 16.88 & 29.41 & 29.12 & \pm & 0.05 \\
\hline COD & 1.81 & 8.86 & 8.76 & \pm & 0.01 \\
\hline $\mathrm{COG}$ & 10.55 & 23.30 & 23.05 & \pm & 0.03 \\
\hline $\mathrm{COL}$ & 54.18 & 62.14 & 61.72 & \pm & 0.07 \\
\hline CRB & 14.47 & 23.67 & 23.55 & \pm & 0.02 \\
\hline CRI & 59.20 & 71.13 & 70.60 & \pm & 0.07 \\
\hline CUB & 35.00 & 45.90 & 45.46 & \pm & 0.07 \\
\hline CYP & 110.23 & 108.45 & 108.24 & \pm & 0.04 \\
\hline CZE & 133.25 & 141.30 & 140.02 & \pm & 0.25 \\
\hline DEU & 158.03 & 148.69 & 147.05 & \pm & 0.29 \\
\hline DJI & 25.49 & 92.37 & 91.16 & \pm & 0.22 \\
\hline DNK & 192.81 & 183.99 & 182.09 & \pm & 0.30 \\
\hline DOM & 47.20 & 55.48 & 54.99 & \pm & 0.07 \\
\hline DZA & 16.92 & 26.59 & 26.59 & \pm & 0.01 \\
\hline ECU & 73.19 & 94.43 & 93.70 & \pm & 0.10 \\
\hline EGY & 30.06 & 54.74 & 54.32 & \pm & 0.09 \\
\hline ERI & 8.04 & 17.51 & 17.31 & \pm & 0.04 \\
\hline ETH & 13.60 & 14.97 & 14.80 & \pm & 0.03 \\
\hline FJI & 37.27 & 71.19 & 70.89 & \pm & 0.04 \\
\hline FNP & 125.80 & 121.61 & 120.36 & \pm & 0.19 \\
\hline FRP & 141.51 & 137.40 & 136.04 & \pm & 0.19 \\
\hline GAB & 40.30 & 56.67 & 56.13 & \pm & 0.07 \\
\hline
\end{tabular}




\begin{tabular}{|c|c|c|c|c|c|}
\hline GEO & 56.16 & 87.54 & 87.12 & \pm & 0.06 \\
\hline GHA & 6.57 & 21.72 & 21.47 & \pm & 0.04 \\
\hline GIN & 12.91 & 37.04 & 36.64 & \pm & 0.07 \\
\hline GMB & 9.96 & 29.88 & 29.56 & \pm & 0.06 \\
\hline GNB & 32.52 & 65.08 & 64.32 & \pm & 0.12 \\
\hline GNQ & 0.90 & 0.85 & 0.84 & \pm & 0.00 \\
\hline GRC & 107.53 & 110.16 & 109.29 & \pm & 0.13 \\
\hline GSA & 11.94 & 16.88 & 16.74 & \pm & 0.02 \\
\hline GTM & 27.05 & 36.38 & 36.07 & \pm & 0.05 \\
\hline HND & 34.55 & 46.00 & 45.70 & \pm & 0.04 \\
\hline HRV & 95.74 & 96.51 & 95.66 & \pm & 0.16 \\
\hline HTI & 21.58 & 34.98 & 34.69 & \pm & 0.04 \\
\hline HUN & 117.99 & 123.27 & 122.12 & \pm & 0.23 \\
\hline IDN & 12.54 & 17.78 & 17.74 & \pm & 0.01 \\
\hline IND & 5.99 & 8.84 & 8.75 & \pm & 0.02 \\
\hline IRL & 155.92 & 150.04 & 148.54 & \pm & 0.22 \\
\hline IRN & 16.85 & 24.22 & 24.21 & \pm & 0.01 \\
\hline IRQ & 4.13 & 4.47 & 4.45 & \pm & 0.00 \\
\hline ISL & 72.28 & 71.33 & 70.61 & \pm & 0.11 \\
\hline ISR & 68.93 & 67.28 & 66.82 & \pm & 0.09 \\
\hline ITP & 156.43 & 149.55 & 148.02 & \pm & 0.23 \\
\hline JAM & 27.19 & 42.85 & 42.66 & \pm & 0.03 \\
\hline JOR & 22.09 & 39.21 & 39.22 & \pm & 0.01 \\
\hline JPN & 70.21 & 80.00 & 79.27 & \pm & 0.13 \\
\hline KAZ & 89.07 & 109.23 & 108.40 & \pm & 0.12 \\
\hline KEN & 30.70 & 48.35 & 47.79 & \pm & 0.11 \\
\hline KGZ & 56.93 & 91.10 & 90.72 & \pm & 0.06 \\
\hline KHM & 40.47 & 60.80 & 60.60 & \pm & 0.03 \\
\hline KOR & 107.28 & 184.48 & 183.94 & \pm & 0.11 \\
\hline LAO & 41.65 & 67.22 & 67.02 & \pm & 0.03 \\
\hline LBN & 64.40 & 96.88 & 96.83 & \pm & 0.03 \\
\hline LBR & 9.63 & 34.55 & 34.15 & \pm & 0.08 \\
\hline LBY & 13.39 & 20.47 & 20.48 & \pm & 0.01 \\
\hline LKA & 5.21 & 14.32 & 14.22 & \pm & 0.02 \\
\hline LSO & 24.48 & 49.12 & 48.58 & \pm & 0.08 \\
\hline MDA & 37.42 & 46.89 & 46.49 & \pm & 0.07 \\
\hline MDG & 24.54 & 48.26 & 47.72 & \pm & 0.08 \\
\hline MEX & 77.06 & 88.77 & 88.07 & \pm & 0.10 \\
\hline MLI & 21.67 & 43.79 & 43.30 & \pm & 0.10 \\
\hline MMR & 29.67 & 66.66 & 66.47 & \pm & 0.03 \\
\hline MNG & 56.72 & 215.46 & 215.34 & \pm & 0.08 \\
\hline MOR & 15.46 & 32.19 & 32.16 & \pm & 0.01 \\
\hline MOZ & 18.56 & 68.85 & 68.11 & \pm & 0.14 \\
\hline MRT & 23.46 & 50.20 & 49.54 & \pm & 0.13 \\
\hline MWI & 10.06 & 22.91 & 22.65 & \pm & 0.04 \\
\hline
\end{tabular}




\begin{tabular}{|c|c|c|c|c|c|}
\hline MYS & 39.69 & 59.70 & 59.60 & \pm & 0.02 \\
\hline NAM & 35.99 & 68.26 & 67.56 & \pm & 0.11 \\
\hline NER & 35.85 & 112.54 & 111.17 & \pm & 0.28 \\
\hline NGA & 10.00 & 25.07 & 24.76 & \pm & 0.04 \\
\hline NIC & 15.91 & 24.52 & 24.36 & \pm & 0.02 \\
\hline NLD & 123.67 & 118.60 & 117.37 & \pm & 0.19 \\
\hline NOR & 106.68 & 101.33 & 100.33 & \pm & 0.14 \\
\hline NPL & 20.82 & 52.36 & 52.01 & \pm & 0.08 \\
\hline NZL & 105.20 & 113.95 & 113.16 & \pm & 0.11 \\
\hline OAO & 15.89 & 64.93 & 64.58 & \pm & 0.07 \\
\hline OBN & 30.89 & 33.35 & 33.08 & \pm & 0.04 \\
\hline OIO & 8.89 & 17.54 & 17.48 & \pm & 0.01 \\
\hline $\mathrm{OPO}$ & 44.46 & 72.79 & 72.47 & \pm & 0.05 \\
\hline OSA & 3.38 & 3.81 & 3.80 & \pm & 0.00 \\
\hline PAK & 17.96 & 29.89 & 29.57 & \pm & 0.07 \\
\hline PAN & 75.33 & 97.91 & 97.23 & \pm & 0.09 \\
\hline PER & 19.86 & 26.09 & 25.89 & \pm & 0.03 \\
\hline PHL & 60.38 & 92.03 & 91.67 & \pm & 0.07 \\
\hline PNG & 33.72 & 70.53 & 70.15 & \pm & 0.08 \\
\hline POL & 134.94 & 139.80 & 138.50 & \pm & 0.26 \\
\hline PRT & 137.06 & 131.49 & 130.11 & \pm & 0.22 \\
\hline PRY & 106.88 & 126.56 & 125.35 & \pm & 0.19 \\
\hline RAP & 9.05 & 12.30 & 12.29 & \pm & 0.00 \\
\hline ROU & 91.57 & 98.57 & 97.72 & \pm & 0.15 \\
\hline RUS & 80.58 & 86.47 & 85.75 & \pm & 0.10 \\
\hline RWA & 10.04 & 26.02 & 25.72 & \pm & 0.04 \\
\hline SAU & 11.83 & 15.97 & 15.95 & \pm & 0.01 \\
\hline SDN & 27.03 & 77.24 & 77.06 & \pm & 0.05 \\
\hline SEN & 16.76 & 32.10 & 31.75 & \pm & 0.06 \\
\hline SLB & 24.97 & 58.09 & 57.78 & \pm & 0.06 \\
\hline SLE & 5.07 & 12.42 & 12.28 & \pm & 0.02 \\
\hline SLV & 27.87 & 34.54 & 34.31 & \pm & 0.03 \\
\hline SOM & 17.61 & 87.11 & 85.95 & \pm & 0.23 \\
\hline SPP & 170.99 & 158.06 & 156.35 & \pm & 0.30 \\
\hline SVK & 104.56 & 109.49 & 108.50 & \pm & 0.19 \\
\hline SVN & 158.53 & 161.73 & 160.42 & \pm & 0.21 \\
\hline SWE & 142.55 & 138.99 & 137.59 & \pm & 0.21 \\
\hline SWZ & 71.90 & 107.28 & 106.05 & \pm & 0.21 \\
\hline SYR & 8.33 & 17.56 & 17.54 & \pm & 0.01 \\
\hline TCD & 22.19 & 45.84 & 45.32 & \pm & 0.10 \\
\hline TGO & 8.61 & 26.87 & 26.56 & \pm & 0.04 \\
\hline THA & 43.69 & 75.34 & 75.04 & \pm & 0.06 \\
\hline TJK & 13.74 & 25.04 & 24.97 & \pm & 0.01 \\
\hline TKM & 58.87 & 87.20 & 86.92 & \pm & 0.06 \\
\hline TLS & 31.32 & 61.72 & 61.42 & \pm & 0.06 \\
\hline
\end{tabular}




\begin{tabular}{lrrrrr} 
TUN & 17.66 & 35.97 & 35.92 & \pm & 0.02 \\
TUR & 12.78 & 19.83 & 19.75 & \pm & 0.02 \\
TZA & 20.80 & 38.86 & 38.40 & \pm & 0.09 \\
UGA & 21.74 & 42.31 & 41.83 & \pm & 0.07 \\
UKP & 113.65 & 111.03 & 109.94 & \pm & 0.16 \\
UKR & 57.37 & 64.68 & 64.15 & \pm & 0.08 \\
URY & 98.69 & 112.89 & 112.04 & \pm & 0.12 \\
USA & 179.66 & 169.53 & 168.34 & \pm & 0.17 \\
UZB & 53.36 & 63.77 & 63.34 & \pm & 0.08 \\
VEN & 59.16 & 69.87 & 69.41 & \pm & 0.07 \\
VNM & 84.97 & 124.70 & 124.00 & \pm & 0.14 \\
VUT & 67.21 & 139.80 & 139.07 & \pm & 0.13 \\
YEM & 9.95 & 15.65 & 15.64 & \pm & 0.01 \\
ZAF & 52.66 & 85.49 & 85.01 & \pm & 0.07 \\
ZMB & 17.77 & 36.45 & 36.07 & \pm & 0.06 \\
ZWE & 27.70 & 106.73 & 105.63 & \pm & 0.18 \\
\hline
\end{tabular}

Table A8.5: Regional and country-level food availability (in kcal/cap/day) in 2010 and 2050 for the reference scenario without climate change and for the mean of the main climate change scenarios (including standard deviation).

Model scenarios of 2050

\begin{tabular}{|c|c|c|c|c|c|}
\hline \multirow[b]{2}{*}{ Region } & \multirow[b]{2}{*}{ Baseline of 2010} & & & & \\
\hline & & $\begin{array}{c}\text { Reference scenario } \\
\text { (without climate change) }\end{array}$ & \multicolumn{3}{|c|}{$\begin{array}{l}\text { Climate change scenarios } \\
\text { (mean } \pm \text { standard deviation) }\end{array}$} \\
\hline Global & $2,568.91$ & $2,878.29$ & $2,787.23$ & \pm & 9.36 \\
\hline $\mathrm{HIC}$ & $2,892.16$ & $2,899.93$ & $2,850.39$ & \pm & 7.78 \\
\hline AFR_LMIC & $2,374.85$ & $2,833.26$ & $2,712.98$ & \pm & 12.73 \\
\hline AMR_LMIC & $2,713.57$ & $2,872.06$ & $2,805.39$ & \pm & 10.17 \\
\hline EMR_LMIC & $2,439.68$ & $2,695.64$ & $2,626.70$ & \pm & 12.70 \\
\hline EUR_LMIC & $2,591.03$ & $2,778.24$ & $2,732.29$ & \pm & 11.37 \\
\hline SEA_LMIC & $2,345.65$ & $2,785.64$ & $2,672.81$ & \pm & 12.87 \\
\hline WPR_LMIC & $2,650.87$ & $3,141.85$ & $3,046.52$ & \pm & 12.82 \\
\hline AFG & $2,166.25$ & $2,426.39$ & $2,334.85$ & \pm & 31.87 \\
\hline AGO & $2,336.34$ & $2,382.51$ & $2,271.10$ & \pm & 12.98 \\
\hline ALB & $2,442.59$ & $2,643.21$ & $2,597.18$ & \pm & 14.78 \\
\hline ARG & $2,971.43$ & $3,124.75$ & $3,075.68$ & \pm & 8.59 \\
\hline ARM & $2,270.27$ & $2,624.85$ & $2,569.69$ & \pm & 15.11 \\
\hline AUS & $2,618.69$ & $2,636.20$ & $2,591.98$ & \pm & 6.48 \\
\hline AUT & $3,232.42$ & $3,246.99$ & $3,194.86$ & \pm & 10.39 \\
\hline AZE & $2,505.94$ & $2,496.93$ & $2,441.17$ & \pm & 19.69 \\
\hline BDI & $2,036.38$ & $2,855.44$ & $2,720.56$ & \pm & 15.84 \\
\hline $\mathrm{BEN}$ & $2,467.06$ & $2,838.55$ & $2,670.17$ & \pm & 16.98 \\
\hline BFA & $2,586.76$ & $2,969.45$ & $2,879.65$ & \pm & 11.49 \\
\hline
\end{tabular}




\begin{tabular}{|c|c|c|c|c|c|}
\hline BGD & $2,405.57$ & $2,708.65$ & $2,572.45$ & \pm & 9.82 \\
\hline BGR & $2,416.75$ & $2,641.89$ & $2,602.91$ & \pm & 8.51 \\
\hline BLR & $2,483.91$ & $2,503.42$ & $2,467.96$ & \pm & 5.86 \\
\hline BLT & $3,330.88$ & $3,354.26$ & $3,338.53$ & \pm & 3.14 \\
\hline BLX & $3,348.70$ & $3,320.64$ & $3,294.87$ & \pm & 4.89 \\
\hline BLZ & $2,512.42$ & $2,661.30$ & $2,595.86$ & \pm & 5.71 \\
\hline BOL & $2,012.84$ & $2,420.49$ & $2,356.45$ & \pm & 7.79 \\
\hline BRA & $2,951.12$ & $3,124.47$ & $3,057.80$ & \pm & 5.42 \\
\hline BTN & $2,145.54$ & $2,553.34$ & $2,445.92$ & \pm & 26.62 \\
\hline BWA & $2,153.47$ & $2,576.14$ & $2,481.25$ & \pm & 12.84 \\
\hline CAF & $1,931.00$ & $2,853.15$ & $2,720.00$ & \pm & 16.80 \\
\hline CAN & $2,807.53$ & $2,774.58$ & $2,724.48$ & \pm & 7.29 \\
\hline CHL & $2,719.06$ & $2,889.27$ & $2,831.42$ & \pm & 6.53 \\
\hline $\mathrm{CHM}$ & $2,683.92$ & $3,246.90$ & $3,152.40$ & \pm & 14.35 \\
\hline $\mathrm{CHP}$ & $2,993.80$ & $3,009.32$ & $2,964.32$ & \pm & 8.52 \\
\hline CIV & $2,614.23$ & $3,039.83$ & $2,883.80$ & \pm & 14.96 \\
\hline CMR & $2,282.70$ & $2,716.05$ & $2,585.71$ & \pm & 14.85 \\
\hline COD & $1,721.88$ & $2,279.59$ & $2,183.67$ & \pm & 13.75 \\
\hline $\mathrm{COG}$ & $2,187.50$ & $2,801.53$ & $2,661.52$ & \pm & 24.63 \\
\hline COL & $2,525.22$ & $2,704.78$ & $2,642.80$ & \pm & 9.64 \\
\hline $\mathrm{CRB}$ & $3,040.44$ & $3,085.53$ & $3,077.75$ & \pm & 1.32 \\
\hline CRI & $2,711.87$ & $2,927.25$ & $2,856.64$ & \pm & 5.56 \\
\hline CUB & $2,315.58$ & $2,562.73$ & $2,484.96$ & \pm & 7.33 \\
\hline CYP & $2,254.85$ & $2,198.73$ & $2,163.66$ & \pm & 4.69 \\
\hline CZE & $2,910.71$ & $3,071.67$ & $3,030.26$ & \pm & 9.55 \\
\hline DEU & $3,077.61$ & $3,081.58$ & $3,034.38$ & \pm & 8.38 \\
\hline DJI & $2,007.09$ & $2,406.09$ & $2,310.15$ & \pm & 21.32 \\
\hline DNK & $2,895.43$ & $2,911.06$ & $2,866.72$ & \pm & 9.84 \\
\hline DOM & $2,336.51$ & $2,554.99$ & $2,490.23$ & \pm & 4.57 \\
\hline DZA & $2,816.93$ & $2,922.70$ & $2,861.79$ & \pm & 16.46 \\
\hline ECU & $2,094.17$ & $2,290.18$ & $2,233.55$ & \pm & 5.15 \\
\hline EGY & $2,938.87$ & $3,239.16$ & $3,136.58$ & \pm & 9.92 \\
\hline ERI & $1,798.42$ & $2,246.41$ & $2,176.44$ & \pm & 25.32 \\
\hline ETH & $2,090.91$ & $2,568.45$ & $2,496.55$ & \pm & 16.42 \\
\hline FJI & $2,861.28$ & $3,657.93$ & $3,542.05$ & \pm & 22.28 \\
\hline FNP & $2,753.72$ & $2,744.07$ & $2,702.80$ & \pm & 11.54 \\
\hline FRP & $3,073.72$ & $3,039.39$ & $2,991.07$ & \pm & 8.42 \\
\hline GAB & $2,639.15$ & $2,942.37$ & $2,803.59$ & \pm & 17.97 \\
\hline GEO & $2,416.85$ & $2,942.95$ & $2,891.10$ & \pm & 11.47 \\
\hline GHA & $2,715.96$ & $3,074.28$ & $2,914.92$ & \pm & 19.58 \\
\hline GIN & $2,478.67$ & $3,273.80$ & $3,085.25$ & \pm & 16.81 \\
\hline GMB & $2,403.94$ & $2,921.54$ & $2,803.85$ & \pm & 17.19 \\
\hline GNB & $2,354.85$ & $2,720.19$ & $2,558.06$ & \pm & 11.13 \\
\hline GNQ & $2,554.19$ & $2,357.11$ & $2,234.08$ & \pm & 21.87 \\
\hline GRC & $3,142.68$ & $3,213.80$ & $3,162.23$ & \pm & 12.49 \\
\hline
\end{tabular}




\begin{tabular}{|c|c|c|c|c|c|}
\hline GSA & $2,517.33$ & $2,668.42$ & $2,624.58$ & \pm & 3.21 \\
\hline GTM & $2,040.73$ & $2,321.75$ & $2,259.70$ & \pm & 24.68 \\
\hline HND & $2,407.21$ & $2,769.91$ & $2,704.19$ & \pm & 21.56 \\
\hline HRV & $2,656.24$ & $2,729.88$ & $2,693.13$ & \pm & 7.84 \\
\hline HTI & $1,708.11$ & $2,128.28$ & $2,065.35$ & \pm & 5.50 \\
\hline HUN & $2,992.72$ & $3,141.69$ & $3,101.61$ & \pm & 9.34 \\
\hline IDN & $2,495.40$ & $3,034.37$ & $2,884.31$ & \pm & 9.83 \\
\hline IND & $2,288.29$ & $2,747.69$ & $2,642.33$ & \pm & 16.27 \\
\hline IRL & $2,969.12$ & $2,991.52$ & $2,944.43$ & \pm & 9.87 \\
\hline IRN & $2,864.70$ & $2,954.71$ & $2,879.10$ & \pm & 16.24 \\
\hline IRQ & $2,645.62$ & $2,899.76$ & $2,812.72$ & \pm & 23.72 \\
\hline ISL & $2,867.31$ & $2,947.22$ & $2,905.09$ & \pm & 8.64 \\
\hline ISR & $3,095.28$ & $3,292.61$ & $3,214.40$ & \pm & 13.71 \\
\hline ITP & $3,292.32$ & $3,311.34$ & $3,279.65$ & \pm & 8.15 \\
\hline JAM & $2,560.79$ & 2,894.69 & $2,827.27$ & \pm & 8.79 \\
\hline JOR & $2,897.25$ & $3,415.35$ & $3,343.11$ & \pm & 10.05 \\
\hline JPN & $2,453.90$ & $2,443.27$ & $2,392.30$ & \pm & 5.78 \\
\hline KAZ & $2,442.54$ & $2,705.56$ & $2,652.11$ & \pm & 15.05 \\
\hline KEN & $2,049.15$ & $2,847.27$ & $2,716.10$ & \pm & 37.12 \\
\hline KGZ & $2,299.55$ & $2,679.74$ & $2,625.15$ & \pm & 12.15 \\
\hline KHM & $2,232.78$ & $2,439.18$ & $2,320.65$ & \pm & 5.08 \\
\hline KOR & $2,740.54$ & $2,927.71$ & $2,868.08$ & \pm & 6.47 \\
\hline LAO & $2,206.34$ & $2,355.38$ & $2,240.91$ & \pm & 4.77 \\
\hline LBN & $2,753.29$ & $3,029.78$ & $2,967.82$ & \pm & 9.24 \\
\hline LBR & $2,381.97$ & $2,847.84$ & $2,673.10$ & \pm & 19.75 \\
\hline LBY & $2,605.59$ & $2,817.15$ & $2,759.82$ & \pm & 13.46 \\
\hline LKA & $2,338.20$ & $2,564.05$ & $2,457.36$ & \pm & 11.94 \\
\hline LSO & $2,417.60$ & $2,727.53$ & $2,595.83$ & \pm & 47.79 \\
\hline MDA & $2,350.09$ & $2,761.50$ & $2,718.97$ & \pm & 11.60 \\
\hline MDG & $2,035.57$ & $2,482.89$ & $2,284.80$ & \pm & 9.39 \\
\hline MEX & $2,954.33$ & $3,025.35$ & $2,947.81$ & \pm & 27.60 \\
\hline MLI & $2,355.90$ & $2,649.54$ & $2,534.29$ & \pm & 8.11 \\
\hline MMR & $2,350.99$ & $2,611.04$ & $2,495.89$ & \pm & 7.39 \\
\hline MNG & $2,287.71$ & $3,393.64$ & $3,321.80$ & \pm & 25.60 \\
\hline MOR & $3,236.67$ & $3,707.64$ & $3,637.09$ & \pm & 14.84 \\
\hline MOZ & $2,151.97$ & $2,640.05$ & $2,491.99$ & \pm & 18.33 \\
\hline MRT & $2,718.06$ & $3,283.54$ & $3,161.00$ & \pm & 29.95 \\
\hline MWI & $2,251.50$ & $2,431.78$ & $2,306.09$ & \pm & 53.14 \\
\hline MYS & $2,785.21$ & $3,302.40$ & $3,228.30$ & \pm & 15.12 \\
\hline NAM & $2,278.96$ & $2,886.46$ & $2,781.53$ & \pm & 14.42 \\
\hline NER & $2,257.59$ & $2,932.87$ & $2,842.29$ & \pm & 20.10 \\
\hline NGA & $2,806.69$ & $3,194.26$ & $3,058.42$ & \pm & 16.19 \\
\hline NIC & $2,133.22$ & $2,551.82$ & $2,474.28$ & \pm & 19.16 \\
\hline NLD & $2,838.35$ & $2,841.29$ & $2,799.05$ & \pm & 7.02 \\
\hline NOR & $2,955.96$ & $2,890.57$ & $2,843.09$ & \pm & 12.14 \\
\hline
\end{tabular}




\begin{tabular}{|c|c|c|c|c|c|}
\hline NPL & $2,296.37$ & $2,821.58$ & $2,699.92$ & \pm & 9.81 \\
\hline NZL & $2,462.03$ & $2,570.10$ & $2,525.70$ & \pm & 8.20 \\
\hline OAO & $2,459.88$ & $2,768.60$ & $2,740.78$ & \pm & 2.49 \\
\hline OBN & $3,343.40$ & $3,427.79$ & $3,410.40$ & \pm & 2.64 \\
\hline $\mathrm{OIO}$ & $2,600.08$ & $2,735.48$ & $2,711.51$ & \pm & 3.65 \\
\hline OPO & $2,693.24$ & $2,825.79$ & $2,806.09$ & \pm & 3.52 \\
\hline OSA & $3,050.02$ & $3,035.97$ & $3,014.42$ & \pm & 2.45 \\
\hline PAK & $2,180.15$ & $2,491.57$ & $2,438.03$ & \pm & 9.83 \\
\hline PAN & $2,347.75$ & $2,598.17$ & $2,523.49$ & \pm & 5.27 \\
\hline PER & $2,308.53$ & $2,513.11$ & $2,433.81$ & \pm & 5.84 \\
\hline PHL & $2,418.65$ & $2,596.38$ & $2,503.85$ & \pm & 6.47 \\
\hline PNG & $2,207.64$ & $3,055.80$ & $2,980.48$ & \pm & 8.70 \\
\hline POL & $2,953.75$ & $3,104.70$ & $3,064.36$ & \pm & 10.21 \\
\hline PRT & $3,052.36$ & $3,140.76$ & $3,079.19$ & \pm & 10.90 \\
\hline PRY & $2,537.20$ & $2,750.28$ & $2,686.68$ & \pm & 16.97 \\
\hline RAP & $3,269.00$ & $3,411.57$ & $3,313.93$ & \pm & 21.73 \\
\hline ROU & $2,402.04$ & $2,553.22$ & $2,514.52$ & \pm & 8.16 \\
\hline RUS & $2,766.29$ & $2,930.39$ & $2,882.56$ & \pm & 10.28 \\
\hline RWA & $2,085.11$ & $3,037.86$ & $2,907.00$ & \pm & 16.35 \\
\hline SAU & $2,781.54$ & $2,906.64$ & $2,838.64$ & \pm & 7.87 \\
\hline $\mathrm{SDN}$ & $2,138.46$ & $2,440.27$ & $2,385.31$ & \pm & 7.92 \\
\hline SEN & $2,322.04$ & $2,721.97$ & $2,565.34$ & \pm & 10.24 \\
\hline SLB & $2,428.77$ & $2,954.64$ & $2,860.72$ & \pm & 10.61 \\
\hline SLE & $2,098.53$ & $2,389.50$ & $2,243.47$ & \pm & 11.55 \\
\hline SLV & $2,401.25$ & $2,546.05$ & $2,482.20$ & \pm & 23.87 \\
\hline SOM & $1,545.65$ & $2,819.31$ & $2,757.40$ & \pm & 9.50 \\
\hline SPP & $2,864.48$ & $2,819.30$ & $2,771.12$ & \pm & 8.91 \\
\hline SVK & $2,491.31$ & $2,594.83$ & $2,557.94$ & \pm & 8.84 \\
\hline SVN & $2,720.31$ & $2,818.76$ & $2,777.98$ & \pm & 7.12 \\
\hline SWE & $2,715.72$ & $2,721.98$ & $2,679.88$ & \pm & 9.41 \\
\hline SWZ & $2,376.59$ & $2,791.05$ & $2,665.94$ & \pm & 24.03 \\
\hline SYR & $2,633.98$ & $3,142.79$ & $3,077.29$ & \pm & 10.99 \\
\hline TCD & $2,023.21$ & $2,517.72$ & $2,435.75$ & \pm & 11.87 \\
\hline TGO & $2,315.43$ & $2,792.82$ & $2,632.84$ & \pm & 25.25 \\
\hline THA & $2,739.83$ & $3,085.86$ & $3,009.50$ & \pm & 3.56 \\
\hline TJK & $1,832.33$ & $2,174.50$ & $2,125.66$ & \pm & 15.38 \\
\hline TKM & $2,420.84$ & $2,775.02$ & $2,713.96$ & \pm & 21.54 \\
\hline TLS & $2,076.92$ & $2,596.92$ & $2,500.46$ & \pm & 9.95 \\
\hline TUN & $2,969.90$ & $3,357.28$ & $3,288.87$ & \pm & 17.92 \\
\hline TUR & $3,025.61$ & $3,094.74$ & $3,031.88$ & \pm & 13.32 \\
\hline TZA & $2,207.67$ & $2,711.31$ & $2,579.43$ & \pm & 23.97 \\
\hline UGA & $2,366.76$ & $2,905.16$ & $2,796.68$ & \pm & 14.47 \\
\hline UKP & $2,934.04$ & 2,966.19 & $2,917.00$ & \pm & 11.04 \\
\hline UKR & $2,390.67$ & $2,607.53$ & $2,566.67$ & \pm & 7.37 \\
\hline URY & $2,714.51$ & $2,910.41$ & $2,848.27$ & \pm & 6.94 \\
\hline
\end{tabular}




\begin{tabular}{cccccc} 
USA & $2,907.66$ & $2,820.88$ & $2,772.26$ & \pm & 5.97 \\
UZB & $2,115.05$ & $2,468.52$ & $2,411.82$ & \pm & 21.69 \\
VEN & $2,405.29$ & $2,511.38$ & $2,454.34$ & \pm & 11.37 \\
VNM & $2,489.61$ & $2,756.79$ & $2,640.25$ & \pm & 6.64 \\
VUT & $2,733.66$ & $3,419.38$ & $3,306.06$ & \pm & 11.53 \\
YEM & $1,875.84$ & $2,060.40$ & $2,016.77$ & \pm \\
ZAF & $2,980.50$ & $3,488.20$ & $3,387.83$ & \pm & 18.61 \\
ZMB & $1,909.38$ & $2,880.79$ & $2,724.42$ & \pm & 52.08 \\
ZWE & $2,040.07$ & $2,731.40$ & $2,623.07$ & \pm & 39.42 \\
\hline
\end{tabular}

Table A8.6: Food availability (in kcal per capita per day) in 2050 by major food group and aggregate region (World, HIC: high-income countries, UMC: upper middle-income countries, LMC: lower middleincome countries, LIC: low-income countries) for the reference scenario without climate change (SSP2_NoCC) and for the mean of the main climate change scenarios (including standard deviation) (SSP2_NoCC, SSP2_CC_std), with and without accounting for waste at the consumption level.

\begin{tabular}{|c|c|c|c|c|c|c|c|c|c|}
\hline \multirow[b]{2}{*}{$\begin{array}{l}\text { Scenario and } \\
\text { region }\end{array}$} & \multicolumn{9}{|c|}{ Food availability (kcal/cap/d) } \\
\hline & Total & $\begin{array}{l}\text { Fruits \& } \\
\text { vegetables }\end{array}$ & $\begin{array}{l}\text { All } \\
\text { meat }\end{array}$ & Diary & Cereals & $\begin{array}{l}\text { Roots \& } \\
\text { tubers }\end{array}$ & $\begin{array}{l}\text { Oilseeds \& } \\
\text { pulses }\end{array}$ & Processed oils & $\begin{array}{l}\text { Sugar } \\
\text { crops }\end{array}$ \\
\hline \multicolumn{10}{|c|}{ without accounting for waste at the consumption level } \\
\hline \multicolumn{10}{|l|}{ World } \\
\hline SSP2_NoCC & $3,106.9$ & 214.3 & 229.6 & 197.2 & $1,356.6$ & 160.3 & 137.9 & 210.3 & 244.3 \\
\hline SSP2_CC & $3,008.3$ & 205.9 & 227.8 & 196.5 & $1,287.7$ & 152.6 & 133.8 & 208.1 & 241.4 \\
\hline SSP2_CC_std & 10.8 & 1.6 & 0.3 & 0.1 & 10.3 & 1.1 & 0.7 & 0.3 & 2.5 \\
\hline \multicolumn{10}{|l|}{ HIC } \\
\hline SSP2_NoCC & $3,433.6$ & 222.3 & 348.5 & 344.3 & 937.6 & 98.2 & 65.0 & 214.0 & 300.7 \\
\hline SSP2_CC & $3,372.5$ & 213.8 & 345.7 & 343.7 & 902.2 & 95.9 & 62.9 & 211.9 & 297.6 \\
\hline SSP2_CC_std & 10.8 & 1.5 & 0.5 & 0.1 & 11.9 & 0.4 & 0.4 & 0.3 & 2.7 \\
\hline \multicolumn{10}{|l|}{ UMC } \\
\hline SSP2_NoCC & $3,214.8$ & 192.3 & 311.3 & 257.3 & $1,186.4$ & 125.8 & 113.7 & 185.0 & 395.7 \\
\hline SSP2_CC & $3,143.7$ & 185.4 & 308.4 & 256.7 & $1,140.8$ & 121.9 & 111.1 & 183.3 & 391.5 \\
\hline SSP2_CC_std & 6.5 & 1.2 & 0.4 & 0.1 & 4.7 & 0.5 & 0.6 & 0.3 & 3.6 \\
\hline \multicolumn{10}{|l|}{ LMC } \\
\hline SSP2_NoCC & $3,118.1$ & 224.0 & 218.1 & 182.2 & $1,478.9$ & 146.1 & 139.9 & 228.8 & 240.1 \\
\hline SSP2_CC & $3,010.0$ & 214.9 & 216.6 & 181.3 & $1,399.8$ & 139.3 & 136.0 & 226.4 & 236.9 \\
\hline SSP2_CC_std & 13.8 & 1.5 & 0.3 & 0.1 & 14.1 & 1.0 & 0.6 & 0.4 & 2.6 \\
\hline \multicolumn{10}{|l|}{ LIC } \\
\hline SSP2_NoCC & $2,730.0$ & 187.7 & 136.0 & 95.3 & $1,394.8$ & 270.9 & 196.1 & 161.5 & 113.3 \\
\hline SSP2_CC & $2,612.7$ & 180.6 & 134.8 & 94.8 & $1,314.7$ & 253.9 & 189.1 & 159.4 & 111.9 \\
\hline SSP2_CC_std & 10.2 & 2.0 & 0.2 & 0.1 & 6.3 & 2.6 & 1.2 & 0.2 & 1.2 \\
\hline
\end{tabular}




\begin{tabular}{|c|c|c|c|c|c|c|c|c|c|}
\hline \multicolumn{10}{|c|}{ with accounting for waste at the consumption level } \\
\hline \multicolumn{10}{|l|}{ World } \\
\hline SSP2_NoCC & $2,878.3$ & 189.4 & 212.9 & 187.6 & $1,225.3$ & 150.8 & 135.3 & 210.3 & 244.3 \\
\hline SSP2_CC & $2,787.2$ & 182.0 & 211.2 & 186.9 & $1,162.3$ & 143.4 & 131.3 & 208.1 & 241.4 \\
\hline SSP2_CC_std & 9.4 & 1.4 & 0.3 & 0.1 & 9.0 & 1.0 & 0.7 & 0.3 & 2.5 \\
\hline \multicolumn{10}{|l|}{ HIC } \\
\hline SSP2_NoCC & $2,899.9$ & 174.8 & 311.7 & 308.9 & 719.1 & 77.4 & 62.5 & 214.0 & 300.7 \\
\hline SSP2_CC & $2,850.4$ & 168.1 & 309.1 & 308.3 & 692.0 & 75.6 & 60.6 & 211.9 & 297.6 \\
\hline SSP2_CC_std & 7.8 & 1.2 & 0.4 & 0.1 & 9.0 & 0.3 & 0.4 & 0.3 & 2.7 \\
\hline \multicolumn{10}{|l|}{ UMC } \\
\hline SSP2_NoCC & $2,983.5$ & 170.1 & 291.2 & 246.0 & $1,046.5$ & 115.5 & 111.4 & 185.0 & 395.7 \\
\hline SSP2_CC & $2,918.8$ & 164.0 & 288.5 & 245.4 & $1,005.8$ & 111.8 & 108.8 & 183.3 & 391.5 \\
\hline SSP2_CC_std & 6.2 & 1.0 & 0.4 & 0.1 & 4.0 & 0.5 & 0.6 & 0.3 & 3.6 \\
\hline \multicolumn{10}{|l|}{ LMC } \\
\hline SSP2_NoCC & $2,920.4$ & 200.3 & 202.8 & 176.8 & $1,346.8$ & 138.6 & 137.2 & 228.8 & 240.1 \\
\hline SSP2_CC & $2,820.5$ & 192.2 & 201.3 & 176.0 & $1,274.4$ & 132.2 & 133.4 & 226.4 & 236.9 \\
\hline SSP2_CC_std & 12.3 & 1.4 & 0.2 & 0.1 & 12.6 & 0.9 & 0.6 & 0.4 & 2.6 \\
\hline \multicolumn{10}{|l|}{ LIC } \\
\hline SSP2_NoCC & $2,652.0$ & 176.1 & 131.2 & 94.1 & $1,346.5$ & 264.8 & 194.0 & 161.5 & 113.3 \\
\hline SSP2_CC & $2,538.0$ & 169.4 & 130.1 & 93.6 & $1,268.7$ & 248.1 & 187.1 & 159.4 & 111.9 \\
\hline SSP2_CC_std & 9.9 & 1.9 & 0.2 & 0.1 & 6.2 & 2.5 & 1.2 & 0.2 & 1.2 \\
\hline
\end{tabular}




\section{Appendix A9: Supplementary health results}

Table A9.1 lists the health impacts associated with the changes in food availability and consumption for the future consumption scenarios with and without climate change. The basis for comparison is a baseline with 2010 levels of food consumption and weight levels, but with all-cause death rates and population structures of 2050. Adopting this baseline allowed us to isolate the health impacts of changes in dietary and weight-related risk factors between 2010 and 2050 when comparing it to the reference and climate change scenarios, and to estimate the impacts of climate change in 2050 by calculating the difference between the reference scenario and the climate-change scenarios.

Figure A9.1 disaggregated the total number of climate-related deaths by risk factor and cause of death, and Tables A9.2-A9.4 resolve the climate-related health impacts on the country level. Table A9.2 lists the climaterelated deaths in the ten most impacted and three least impacted countries. The greatest numbers of climaterelated deaths in 2050 occurred in China (248 thousand; 95\% CI: 169-332 thousand; CC SD: 51 thousand) and India (136 thousand; 95\% CI: 88-176 thousand; CC SD: 25 thousand), whose numbers of climate-related deaths were an order of magnitude larger than those of any other country. China alone accounted for $43 \%$ of all climaterelated deaths, and China and India together accounted for $73 \%$. Venezuela and South Africa were the two countries with the least negative climate-related health impacts, leading to a small number of avoided deaths. Tables A9.3 and A9.4 list the climate-related deaths by region and country in per capita terms and in absolute, respectively, and Tables A9.5 and A9.6 list those by risk factor.

Table A9.1: Deaths avoided (in thousands) due to changes in dietary and weight-related risk factors for the reference scenario without climate change and for the mean of the main climate-change scenarios in 2050. The basis for comparison is a baseline with 2010 levels of food consumption and weight levels, but with all-cause death rates and population structures of 2050. Adopting this baseline allowed us to isolate the health impacts of changes in dietary and weight-related risk factors between 2010 and 2050 when comparing it to the reference and climate change scenarios, and to estimate the impacts of climate change in $\mathbf{2 0 5 0}$ by calculating the difference between the reference scenario and the climate-change scenarios. Low and high values represent $95 \%$ confidence intervals, and CC SD represents the standard deviation of the main climate-change scenarios.

\begin{tabular}{|c|c|c|c|c|c|c|c|}
\hline \multirow{2}{*}{ Region } & \multicolumn{3}{|c|}{$\begin{array}{c}\text { Reference scenario } \\
\text { (without climate change) }\end{array}$} & \multicolumn{4}{|c|}{$\begin{array}{l}\text { Climate change scenario } \\
\text { (average and standard deviation) }\end{array}$} \\
\hline & mean & low & high & mean & low & high & $\mathrm{CC} \mathrm{SD}$ \\
\hline Global & 1,877 & 942 & 2,820 & 1,348 & 628 & 2,084 & 105 \\
\hline HIC & 113 & 73 & 152 & 74 & 50 & 99 & 9 \\
\hline AFR_LMIC & 156 & 69 & 242 & 128 & 58 & 198 & 4 \\
\hline AMR_LMIC & -6 & -33 & 21 & -8 & -27 & 10 & 6 \\
\hline EMR_LMIC & -43 & -86 & -2 & -56 & -87 & -25 & 2 \\
\hline EUR_LMIC & 13 & -42 & 68 & -1 & -43 & 41 & 4 \\
\hline SEA_LMIC & 1,119 & 773 & 1,450 & 956 & 672 & 1,233 & 29 \\
\hline WPR_LMIC & 519 & 190 & 877 & 255 & 12 & 523 & 53 \\
\hline
\end{tabular}

Regional abbreviations follow the WHO-World Bank classification: HIC: high-income countries; AFR_LMIC: low and middle-income countries of Africa; AMR_LMIC: low and middle-income countries of America; EMR_LMIC: low and middle-income countries of the Eastern Mediterranean; EUR_LMIC: low and middle income countries of Europe; SEA_LMIC: low and middle-income countries of South-East Asia; WPR_LMIC: low and middle-income countries of the Western Pacific). Appendix A6 lists the countries included in each region. 
Figure A9.1: Total number of climate-related deaths (in thousands) by cause of death and risk factor (FVC: fruit and vegetable consumption; MTC: red-meat consumption; UND: underweight; OVW: overweight; OBS: obesity).

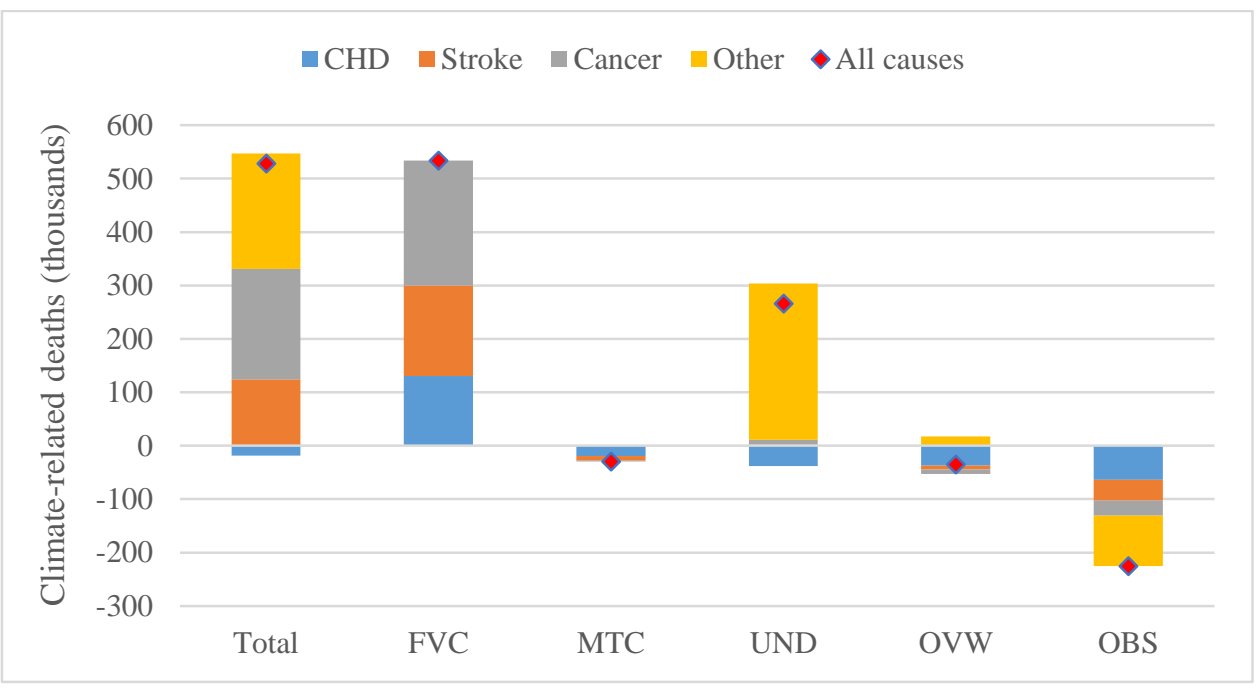

Table A9.2: Climate-related deaths (in thousands) in the ten most impacted and three least impacted countries. Low and high values represent $95 \%$ confidence intervals, and CC SD represents the standard deviation of the main climate-change scenarios.

\begin{tabular}{lrrrrr}
\hline \multirow{2}{*}{ Country } & \multicolumn{5}{c}{ Climate-related deaths (thousand) } \\
\cline { 2 - 6 } & \multicolumn{1}{c}{ mean } & \multicolumn{1}{c}{ low } & \multicolumn{1}{c}{ high } & CC SD & \% of total \\
\hline China & 247.97 & 168.54 & 331.49 & 50.74 & $47 \%$ \\
India & 135.97 & 87.69 & 175.80 & 24.62 & $26 \%$ \\
Vietnam & 10.70 & 6.64 & 14.29 & 1.92 & $2 \%$ \\
Bangladesh & 9.95 & 6.77 & 13.29 & 0.97 & $2 \%$ \\
USA & 8.64 & 5.27 & 11.72 & 2.25 & $2 \%$ \\
Indonesia & 7.95 & 1.50 & 14.53 & 1.57 & $2 \%$ \\
Japan & 7.62 & 6.84 & 8.41 & 1.49 & $1 \%$ \\
Russia & 7.46 & 1.65 & 13.17 & 2.26 & $1 \%$ \\
Iran & 5.66 & 2.53 & 8.65 & 0.89 & $1 \%$ \\
DR Congo & 4.94 & 3.09 & 6.84 & 0.73 & $1 \%$ \\
\hline Iraq & -0.57 & -1.27 & 0.09 & 0.37 & $0 \%$ \\
South Africa & -0.60 & -0.91 & -0.23 & 0.39 & $0 \%$ \\
Venezuela & -0.94 & -1.36 & -0.58 & 0.48 & $0 \%$ \\
\hline
\end{tabular}


Table A9.3: Climate-related deaths per capita (in deaths per million) by region and country. Low and high values represent $95 \%$ confidence intervals, and CC SD represents the standard deviation of the main climate-change scenarios.

\begin{tabular}{|c|c|c|c|c|}
\hline \multirow{2}{*}{ Region } & \multicolumn{4}{|c|}{ Climate-related deaths per capita (per million) } \\
\hline & mean & low & high & $\mathrm{CC} \mathrm{SD}$ \\
\hline Global & 77.99 & 46.35 & 108.54 & 15.52 \\
\hline HIC & 37.17 & 22.65 & 51.13 & 9.14 \\
\hline AFR_LMIC & 26.43 & 11.19 & 41.73 & 3.57 \\
\hline AMR_LMIC & 4.73 & -10.37 & 19.24 & 9.76 \\
\hline EMR_LMIC & 20.23 & 1.62 & 37.98 & 3.85 \\
\hline EUR_LMIC & 55.01 & 6.76 & 101.28 & 14.47 \\
\hline SEA_LMIC & 89.51 & 55.63 & 118.48 & 15.64 \\
\hline WPR_LMIC & 198.60 & 133.56 & 266.34 & 40.05 \\
\hline AFG & 40.77 & 28.93 & 51.86 & 14.61 \\
\hline AGO & 54.06 & 59.10 & 48.82 & 6.05 \\
\hline ALB & 88.10 & 43.23 & 125.68 & 14.21 \\
\hline ARG & 5.47 & -5.25 & 15.73 & 2.44 \\
\hline ARM & 80.95 & 22.99 & 132.89 & 13.79 \\
\hline AUS & 5.74 & -0.67 & 12.72 & 5.19 \\
\hline AUT & 29.04 & 8.84 & 46.10 & 14.60 \\
\hline AZE & 46.22 & 85.82 & 6.94 & 3.13 \\
\hline BDI & 44.42 & 25.79 & 60.99 & 4.72 \\
\hline BEN & 30.49 & 3.88 & 57.13 & 2.60 \\
\hline BFA & 32.15 & 21.85 & 43.22 & 3.48 \\
\hline BGD & 66.65 & 45.33 & 89.01 & 6.50 \\
\hline BGR & 4.82 & -19.40 & 25.98 & 5.30 \\
\hline BLR & 69.46 & -20.99 & 151.52 & 33.00 \\
\hline BLT & 83.52 & 39.83 & 126.69 & 27.22 \\
\hline BLX & 35.71 & 19.14 & 52.78 & 10.39 \\
\hline BLZ & -6.15 & -17.40 & 5.30 & 4.50 \\
\hline BOL & -26.39 & -38.97 & -15.46 & 7.17 \\
\hline BRA & 24.25 & 6.88 & 41.66 & 6.53 \\
\hline BTN & 46.02 & 17.55 & 68.73 & 14.56 \\
\hline BWA & -2.25 & -16.55 & 12.80 & 2.27 \\
\hline CAF & -7.57 & -21.14 & 4.44 & 1.69 \\
\hline CAN & 29.52 & 24.87 & 33.36 & 7.36 \\
\hline CHL & 4.02 & -10.97 & 19.35 & 8.96 \\
\hline CHM & 230.64 & 156.76 & 308.32 & 47.19 \\
\hline CHP & 15.50 & 3.78 & 26.84 & 5.77 \\
\hline CIV & 31.94 & 7.33 & 56.05 & 7.13 \\
\hline CMR & -8.72 & -27.65 & 9.70 & 5.24 \\
\hline COD & 56.23 & 35.19 & 77.93 & 8.33 \\
\hline COG & 13.17 & -7.57 & 31.36 & 3.38 \\
\hline $\mathrm{COL}$ & 0.33 & -13.81 & 13.24 & 10.39 \\
\hline CRB & 4.14 & 0.74 & 7.72 & 1.43 \\
\hline
\end{tabular}




\begin{tabular}{|c|c|c|c|c|}
\hline CRI & 6.24 & -8.03 & 21.24 & 7.36 \\
\hline CUB & -2.63 & -48.15 & 42.31 & 28.12 \\
\hline CYP & 4.42 & 9.78 & -1.46 & 2.82 \\
\hline CZE & 18.26 & -7.93 & 41.89 & 9.74 \\
\hline DEU & 18.07 & -0.51 & 36.04 & 11.40 \\
\hline DJI & -31.85 & -40.88 & -23.88 & 6.99 \\
\hline DNK & 20.44 & 7.34 & 35.04 & 7.21 \\
\hline DOM & -7.47 & -25.01 & 10.67 & 7.71 \\
\hline DZA & 21.25 & 4.48 & 40.04 & 1.90 \\
\hline ECU & -0.98 & -12.22 & 10.94 & 4.66 \\
\hline EGY & 24.58 & -1.69 & 48.68 & 7.33 \\
\hline ERI & 24.25 & 11.00 & 36.61 & 9.56 \\
\hline ETH & 33.85 & 23.51 & 43.51 & 7.65 \\
\hline FJI & -23.32 & -31.05 & -15.36 & 5.60 \\
\hline FNP & 2.59 & -17.55 & 20.23 & 4.44 \\
\hline FRP & 32.56 & 22.04 & 41.97 & 7.06 \\
\hline GAB & -7.54 & -26.34 & 11.75 & 5.54 \\
\hline GEO & 32.36 & -3.04 & 77.95 & 7.18 \\
\hline GHA & 34.06 & 6.05 & 59.87 & 10.93 \\
\hline GIN & 35.49 & 9.97 & 56.29 & 6.41 \\
\hline GMB & 0.17 & -13.61 & 14.80 & 0.99 \\
\hline GNB & 64.01 & 31.71 & 92.86 & 6.24 \\
\hline GNQ & 50.75 & 77.79 & 26.04 & 10.77 \\
\hline GRC & 123.66 & 76.57 & 167.11 & 26.21 \\
\hline GSA & -4.48 & -17.23 & 9.42 & 2.99 \\
\hline GTM & -9.55 & -16.89 & -2.36 & 10.37 \\
\hline HND & -5.89 & -13.29 & 2.17 & 11.00 \\
\hline HRV & 18.80 & -3.73 & 43.11 & 8.74 \\
\hline HTI & -13.26 & -29.89 & 1.69 & 4.02 \\
\hline HUN & 57.49 & 19.21 & 93.26 & 19.02 \\
\hline IDN & 35.07 & 6.63 & 64.08 & 6.93 \\
\hline IND & 104.95 & 67.69 & 135.70 & 19.00 \\
\hline IRL & 14.99 & 0.28 & 30.86 & 4.04 \\
\hline IRN & 74.51 & 33.29 & 113.96 & 11.75 \\
\hline IRQ & -12.74 & -28.15 & 2.11 & 8.26 \\
\hline ISL & 16.34 & 1.00 & 32.52 & 3.56 \\
\hline ISR & 48.78 & 34.64 & 59.90 & 7.85 \\
\hline ITP & 89.17 & 58.03 & 122.58 & 19.37 \\
\hline JAM & -7.84 & -27.18 & 8.85 & 4.37 \\
\hline JOR & 9.89 & 0.17 & 20.80 & 2.31 \\
\hline JPN & 81.74 & 73.33 & 90.21 & 16.03 \\
\hline KAZ & 42.97 & -1.27 & 86.65 & 6.94 \\
\hline KEN & 3.28 & -7.66 & 15.74 & 3.80 \\
\hline KGZ & 50.09 & 7.95 & 95.68 & 10.74 \\
\hline KHM & 59.24 & 43.38 & 76.10 & 2.66 \\
\hline
\end{tabular}




\begin{tabular}{|c|c|c|c|c|}
\hline KOR & 118.53 & 84.35 & 147.68 & 24.53 \\
\hline LAO & 53.80 & 39.72 & 67.40 & 4.70 \\
\hline LBN & 25.91 & 7.89 & 43.98 & 4.70 \\
\hline LBR & 31.06 & 7.36 & 51.15 & 5.24 \\
\hline LBY & 10.59 & -10.30 & 32.39 & 2.33 \\
\hline LKA & 73.33 & 42.60 & 101.13 & 11.47 \\
\hline LSO & 21.70 & 3.66 & 40.92 & 5.85 \\
\hline MDA & 65.58 & 0.41 & 133.43 & 16.04 \\
\hline MDG & 105.23 & 68.04 & 142.80 & 5.72 \\
\hline MEX & 0.37 & -14.81 & 13.69 & 17.82 \\
\hline MLI & 37.81 & 21.13 & 54.18 & 2.50 \\
\hline MMR & 86.66 & 51.25 & 110.50 & 18.06 \\
\hline MNG & -8.95 & -16.49 & -3.44 & 8.35 \\
\hline MOR & 46.57 & 17.22 & 75.09 & 7.58 \\
\hline MOZ & 13.20 & -10.73 & 35.76 & 1.99 \\
\hline MRT & -10.11 & -19.34 & -0.43 & 2.78 \\
\hline MWI & 68.74 & 50.66 & 84.44 & 26.12 \\
\hline MYS & -1.36 & -11.15 & 7.02 & 1.92 \\
\hline NAM & -16.52 & -30.06 & -4.45 & 2.96 \\
\hline NER & 13.51 & 5.82 & 19.44 & 2.42 \\
\hline NGA & 21.93 & 7.46 & 37.08 & 2.94 \\
\hline NIC & -42.02 & -49.00 & -34.10 & 12.77 \\
\hline NLD & 36.26 & 18.38 & 53.37 & 8.30 \\
\hline NOR & 8.31 & 7.25 & 9.26 & 2.72 \\
\hline NPL & 61.93 & 42.76 & 83.10 & 7.74 \\
\hline NZL & 29.62 & 13.33 & 43.88 & 6.64 \\
\hline OAO & 4.26 & -0.81 & 8.97 & 2.29 \\
\hline OBN & 45.81 & 29.24 & 60.92 & 12.12 \\
\hline OIO & 7.05 & 1.30 & 12.00 & 2.01 \\
\hline $\mathrm{OPO}$ & -6.01 & -9.06 & -4.14 & 1.17 \\
\hline OSA & 1.57 & 3.08 & -0.09 & 0.77 \\
\hline PAK & 9.32 & -3.55 & 21.59 & 1.45 \\
\hline PAN & -30.82 & -42.07 & -19.53 & 6.34 \\
\hline PER & -3.99 & -15.21 & 8.66 & 4.86 \\
\hline PHL & 41.55 & 20.94 & 62.49 & 4.93 \\
\hline PNG & 28.27 & -2.00 & 52.79 & 18.17 \\
\hline POL & 38.27 & 12.75 & 64.62 & 13.01 \\
\hline PRT & 75.60 & 44.58 & 103.10 & 18.18 \\
\hline PRY & 3.76 & -12.21 & 16.44 & 13.44 \\
\hline RAP & 0.39 & -10.04 & 10.20 & 2.16 \\
\hline ROU & 88.70 & 34.18 & 145.11 & 24.67 \\
\hline RUS & 67.56 & 14.93 & 119.21 & 20.43 \\
\hline RWA & 6.65 & -2.71 & 15.77 & 5.91 \\
\hline SAU & -2.29 & -17.20 & 11.46 & 1.56 \\
\hline SDN & 23.42 & 10.21 & 36.52 & 3.91 \\
\hline
\end{tabular}




\begin{tabular}{|c|c|c|c|c|}
\hline SEN & 15.99 & -3.34 & 36.59 & 1.80 \\
\hline SLB & -39.40 & -47.63 & -30.01 & 3.03 \\
\hline SLE & 43.79 & 4.40 & 83.97 & 5.72 \\
\hline SLV & -27.36 & -39.48 & -15.77 & 21.24 \\
\hline SOM & -36.24 & -42.37 & -29.91 & 6.16 \\
\hline SPP & 24.08 & 25.09 & 23.32 & 7.25 \\
\hline SVK & -2.46 & -32.10 & 29.37 & 6.98 \\
\hline SVN & 35.15 & 10.23 & 60.17 & 15.27 \\
\hline SWE & 4.55 & -9.16 & 19.86 & 3.62 \\
\hline SWZ & -14.43 & -34.69 & 5.20 & 5.26 \\
\hline SYR & 12.87 & -3.41 & 28.73 & 2.15 \\
\hline TCD & 19.93 & 7.83 & 31.83 & 2.86 \\
\hline TGO & 33.48 & 4.33 & 62.46 & 5.00 \\
\hline THA & 44.68 & 22.40 & 60.52 & 5.54 \\
\hline TJK & 13.00 & -4.47 & 29.77 & 2.90 \\
\hline TKM & 47.70 & -1.43 & 96.30 & 3.26 \\
\hline TLS & 10.23 & 3.44 & 16.64 & 0.77 \\
\hline TUN & 37.95 & 13.68 & 59.45 & 4.73 \\
\hline TUR & 55.38 & 32.14 & 77.28 & 10.43 \\
\hline TZA & 12.14 & -1.35 & 25.87 & 1.36 \\
\hline UGA & 23.72 & 14.81 & 32.27 & 6.62 \\
\hline UKP & 25.12 & 4.32 & 47.27 & 5.53 \\
\hline UKR & 38.93 & -32.09 & 101.31 & 14.78 \\
\hline URY & 3.90 & -14.99 & 22.07 & 6.82 \\
\hline USA & 27.72 & 16.92 & 37.60 & 7.21 \\
\hline UZB & 24.02 & -24.25 & 69.62 & 6.45 \\
\hline VEN & -29.48 & -42.56 & -18.18 & 14.96 \\
\hline VNM & 125.53 & 77.93 & 167.73 & 22.58 \\
\hline VUT & -19.45 & -24.75 & -14.58 & 1.84 \\
\hline YEM & -12.30 & -21.45 & -2.93 & 2.88 \\
\hline ZAF & -13.32 & -20.18 & -5.13 & 8.72 \\
\hline ZMB & -9.39 & -17.79 & 1.77 & 3.44 \\
\hline ZWE & -15.49 & -26.34 & -5.30 & 5.41 \\
\hline
\end{tabular}


Table A9.4: Climate-related deaths (in thousands) by region and country. Low and high values represent 95\% confidence intervals, and CC SD represents the standard deviation of the main climate-change scenarios.

\begin{tabular}{|c|c|c|c|c|}
\hline \multirow{2}{*}{ Region } & \multicolumn{4}{|c|}{ Climate-related deaths (thousand) } \\
\hline & mean & low & high & CC SD \\
\hline Global & 528.71 & 314.23 & 735.77 & 105.23 \\
\hline HIC & 38.47 & 23.44 & 52.91 & 9.45 \\
\hline AFR_LMIC & 27.69 & 11.72 & 43.73 & 3.74 \\
\hline AMR_LMIC & 2.67 & -5.87 & 10.88 & 5.52 \\
\hline EMR_LMIC & 12.36 & 0.99 & 23.21 & 2.35 \\
\hline EUR_LMIC & 14.34 & 1.76 & 26.41 & 3.77 \\
\hline SEA_LMIC & 163.52 & 101.62 & 216.44 & 28.57 \\
\hline WPR_LMIC & 264.27 & 177.72 & 354.41 & 53.29 \\
\hline AFG & 1.70 & 1.21 & 2.17 & 0.61 \\
\hline AGO & 1.47 & 1.60 & 1.32 & 0.16 \\
\hline ALB & 0.24 & 0.12 & 0.34 & 0.04 \\
\hline ARG & 0.21 & -0.20 & 0.59 & 0.09 \\
\hline ARM & 0.17 & 0.05 & 0.28 & 0.03 \\
\hline AUS & 0.17 & -0.02 & 0.37 & 0.15 \\
\hline AUT & 0.22 & 0.07 & 0.36 & 0.11 \\
\hline AZE & 0.40 & 0.75 & 0.06 & 0.03 \\
\hline BDI & 0.51 & 0.30 & 0.70 & 0.05 \\
\hline BEN & 0.37 & 0.05 & 0.70 & 0.03 \\
\hline BFA & 0.73 & 0.49 & 0.98 & 0.08 \\
\hline BGD & 9.95 & 6.77 & 13.29 & 0.97 \\
\hline BGR & 0.03 & -0.10 & 0.14 & 0.03 \\
\hline BLR & 0.47 & -0.14 & 1.02 & 0.22 \\
\hline BLT & 0.40 & 0.19 & 0.60 & 0.13 \\
\hline BLX & 0.39 & 0.21 & 0.57 & 0.11 \\
\hline BLZ & 0.00 & -0.01 & 0.00 & 0.00 \\
\hline BOL & -0.26 & -0.39 & -0.15 & 0.07 \\
\hline BRA & 4.49 & 1.27 & 7.71 & 1.21 \\
\hline BTN & 0.04 & 0.02 & 0.06 & 0.01 \\
\hline BWA & 0.00 & -0.03 & 0.02 & 0.00 \\
\hline CAF & -0.04 & -0.10 & 0.02 & 0.01 \\
\hline CAN & 1.13 & 0.95 & 1.28 & 0.28 \\
\hline CHL & 0.07 & -0.18 & 0.32 & 0.15 \\
\hline CHM & 247.97 & 168.54 & 331.49 & 50.74 \\
\hline CHP & 0.12 & 0.03 & 0.20 & 0.04 \\
\hline CIV & 0.64 & 0.15 & 1.12 & 0.14 \\
\hline CMR & -0.19 & -0.60 & 0.21 & 0.11 \\
\hline $\mathrm{COD}$ & 4.94 & 3.09 & 6.84 & 0.73 \\
\hline $\mathrm{COG}$ & 0.07 & -0.04 & 0.16 & 0.02 \\
\hline $\mathrm{COL}$ & 0.02 & -0.67 & 0.64 & 0.50 \\
\hline CRB & 0.01 & 0.00 & 0.02 & 0.00 \\
\hline
\end{tabular}




\begin{tabular}{|c|c|c|c|c|}
\hline CRI & 0.03 & -0.04 & 0.11 & 0.04 \\
\hline CUB & -0.02 & -0.38 & 0.34 & 0.22 \\
\hline CYP & 0.01 & 0.01 & 0.00 & 0.00 \\
\hline CZE & 0.18 & -0.08 & 0.40 & 0.09 \\
\hline DEU & 1.20 & -0.03 & 2.40 & 0.76 \\
\hline DJI & -0.03 & -0.04 & -0.02 & 0.01 \\
\hline DNK & 0.10 & 0.04 & 0.18 & 0.04 \\
\hline DOM & -0.07 & -0.24 & 0.10 & 0.07 \\
\hline DZA & 0.81 & 0.17 & 1.52 & 0.07 \\
\hline ECU & -0.01 & -0.19 & 0.17 & 0.07 \\
\hline EGY & 2.23 & -0.15 & 4.42 & 0.67 \\
\hline ERI & 0.19 & 0.09 & 0.28 & 0.07 \\
\hline ETH & 3.52 & 2.45 & 4.53 & 0.80 \\
\hline FJI & -0.02 & -0.02 & -0.01 & 0.00 \\
\hline FNP & 0.01 & -0.09 & 0.10 & 0.02 \\
\hline FRP & 1.96 & 1.32 & 2.52 & 0.42 \\
\hline GAB & -0.01 & -0.04 & 0.02 & 0.01 \\
\hline GEO & 0.08 & -0.01 & 0.20 & 0.02 \\
\hline GHA & 1.02 & 0.18 & 1.80 & 0.33 \\
\hline GIN & 0.34 & 0.10 & 0.54 & 0.06 \\
\hline GMB & 0.00 & -0.03 & 0.03 & 0.00 \\
\hline GNB & 0.10 & 0.05 & 0.15 & 0.01 \\
\hline GNQ & 0.05 & 0.07 & 0.02 & 0.01 \\
\hline GRC & 1.16 & 0.72 & 1.57 & 0.25 \\
\hline GSA & 0.00 & -0.02 & 0.01 & 0.00 \\
\hline GTM & -0.16 & -0.28 & -0.04 & 0.17 \\
\hline HND & -0.05 & -0.11 & 0.02 & 0.09 \\
\hline HRV & 0.06 & -0.01 & 0.15 & 0.03 \\
\hline HTI & -0.12 & -0.27 & 0.02 & 0.04 \\
\hline HUN & 0.43 & 0.14 & 0.69 & 0.14 \\
\hline IDN & 7.95 & 1.50 & 14.53 & 1.57 \\
\hline IND & 135.97 & 87.69 & 175.80 & 24.62 \\
\hline IRL & 0.07 & 0.00 & 0.15 & 0.02 \\
\hline IRN & 5.66 & 2.53 & 8.65 & 0.89 \\
\hline IRQ & -0.57 & -1.27 & 0.09 & 0.37 \\
\hline ISL & 0.01 & 0.00 & 0.01 & 0.00 \\
\hline ISR & 0.49 & 0.35 & 0.60 & 0.08 \\
\hline ITP & 4.63 & 3.01 & 6.36 & 1.01 \\
\hline JAM & -0.02 & -0.06 & 0.02 & 0.01 \\
\hline JOR & 0.10 & 0.00 & 0.20 & 0.02 \\
\hline JPN & 7.62 & 6.84 & 8.41 & 1.49 \\
\hline KAZ & 0.66 & -0.02 & 1.32 & 0.11 \\
\hline KEN & 0.16 & -0.37 & 0.77 & 0.18 \\
\hline KGZ & 0.24 & 0.04 & 0.45 & 0.05 \\
\hline KHM & 0.76 & 0.55 & 0.97 & 0.03 \\
\hline
\end{tabular}




\begin{tabular}{|c|c|c|c|c|}
\hline KOR & 4.71 & 3.35 & 5.86 & 0.97 \\
\hline LAO & 0.33 & 0.25 & 0.42 & 0.03 \\
\hline LBN & 0.10 & 0.03 & 0.18 & 0.02 \\
\hline LBR & 0.23 & 0.05 & 0.37 & 0.04 \\
\hline LBY & 0.08 & -0.08 & 0.24 & 0.02 \\
\hline LKA & 1.37 & 0.80 & 1.89 & 0.21 \\
\hline LSO & 0.04 & 0.01 & 0.07 & 0.01 \\
\hline MDA & 0.12 & 0.00 & 0.24 & 0.03 \\
\hline MDG & 3.11 & 2.01 & 4.22 & 0.17 \\
\hline MEX & 0.04 & -1.65 & 1.52 & 1.98 \\
\hline MLI & 0.81 & 0.45 & 1.15 & 0.05 \\
\hline MMR & 3.27 & 1.93 & 4.17 & 0.68 \\
\hline MNG & -0.02 & -0.05 & -0.01 & 0.02 \\
\hline MOR & 1.32 & 0.49 & 2.12 & 0.21 \\
\hline MOZ & 0.35 & -0.28 & 0.94 & 0.05 \\
\hline MRT & -0.04 & -0.08 & 0.00 & 0.01 \\
\hline MWI & 1.51 & 1.11 & 1.86 & 0.57 \\
\hline MYS & -0.04 & -0.36 & 0.23 & 0.06 \\
\hline NAM & -0.04 & -0.07 & -0.01 & 0.01 \\
\hline NER & 0.34 & 0.15 & 0.49 & 0.06 \\
\hline NGA & 4.52 & 1.54 & 7.65 & 0.61 \\
\hline NIC & -0.21 & -0.25 & -0.17 & 0.06 \\
\hline NLD & 0.54 & 0.27 & 0.79 & 0.12 \\
\hline NOR & 0.05 & 0.04 & 0.05 & 0.02 \\
\hline NPL & 2.26 & 1.56 & 3.03 & 0.28 \\
\hline NZL & 0.14 & 0.06 & 0.20 & 0.03 \\
\hline OAO & 0.00 & 0.00 & 0.01 & 0.00 \\
\hline OBN & 0.61 & 0.39 & 0.82 & 0.16 \\
\hline OIO & 0.02 & 0.00 & 0.03 & 0.00 \\
\hline OPO & 0.00 & 0.00 & 0.00 & 0.00 \\
\hline OSA & 0.01 & 0.02 & 0.00 & 0.00 \\
\hline PAK & 1.88 & -0.72 & 4.36 & 0.29 \\
\hline PAN & -0.12 & -0.16 & -0.08 & 0.02 \\
\hline PER & -0.10 & -0.39 & 0.22 & 0.12 \\
\hline PHL & 4.41 & 2.22 & 6.63 & 0.52 \\
\hline PNG & 0.23 & -0.02 & 0.42 & 0.15 \\
\hline POL & 1.13 & 0.37 & 1.90 & 0.38 \\
\hline PRT & 0.71 & 0.42 & 0.97 & 0.17 \\
\hline PRY & 0.03 & -0.09 & 0.12 & 0.10 \\
\hline RAP & 0.01 & -0.29 & 0.29 & 0.06 \\
\hline ROU & 1.33 & 0.51 & 2.17 & 0.37 \\
\hline RUS & 7.46 & 1.65 & 13.17 & 2.26 \\
\hline RWA & 0.09 & -0.04 & 0.22 & 0.08 \\
\hline SAU & -0.09 & -0.71 & 0.47 & 0.06 \\
\hline SDN & 1.28 & 0.56 & 2.00 & 0.21 \\
\hline
\end{tabular}




\begin{tabular}{|c|c|c|c|c|}
\hline SEN & 0.24 & -0.05 & 0.55 & 0.03 \\
\hline SLB & -0.03 & -0.03 & -0.02 & 0.00 \\
\hline SLE & 0.32 & 0.03 & 0.61 & 0.04 \\
\hline SLV & -0.12 & -0.18 & -0.07 & 0.09 \\
\hline SOM & -0.34 & -0.39 & -0.28 & 0.06 \\
\hline SPP & 1.06 & 1.11 & 1.03 & 0.32 \\
\hline SVK & -0.01 & -0.15 & 0.14 & 0.03 \\
\hline SVN & 0.06 & 0.02 & 0.11 & 0.03 \\
\hline SWE & 0.04 & -0.09 & 0.19 & 0.04 \\
\hline SWZ & -0.01 & -0.04 & 0.01 & 0.01 \\
\hline SYR & 0.32 & -0.08 & 0.71 & 0.05 \\
\hline TCD & 0.29 & 0.12 & 0.47 & 0.04 \\
\hline TGO & 0.23 & 0.03 & 0.44 & 0.03 \\
\hline THA & 2.69 & 1.35 & 3.65 & 0.33 \\
\hline TJK & 0.07 & -0.02 & 0.17 & 0.02 \\
\hline TKM & 0.23 & -0.01 & 0.46 & 0.02 \\
\hline TLS & 0.01 & 0.00 & 0.02 & 0.00 \\
\hline TUN & 0.39 & 0.14 & 0.61 & 0.05 \\
\hline TUR & 4.06 & 2.36 & 5.67 & 0.77 \\
\hline TZA & 0.73 & -0.08 & 1.57 & 0.08 \\
\hline UGA & 1.17 & 0.73 & 1.60 & 0.33 \\
\hline UKP & 1.51 & 0.26 & 2.84 & 0.33 \\
\hline UKR & 1.24 & -1.02 & 3.22 & 0.47 \\
\hline URY & 0.01 & -0.04 & 0.06 & 0.02 \\
\hline USA & 8.64 & 5.27 & 11.72 & 2.25 \\
\hline UZB & 0.60 & -0.61 & 1.75 & 0.16 \\
\hline VEN & -0.94 & -1.36 & -0.58 & 0.48 \\
\hline VNM & 10.70 & 6.64 & 14.29 & 1.92 \\
\hline VUT & -0.01 & -0.01 & 0.00 & 0.00 \\
\hline YEM & -0.43 & -0.75 & -0.10 & 0.10 \\
\hline $\mathrm{ZAF}$ & -0.60 & -0.91 & -0.23 & 0.39 \\
\hline ZMB & -0.16 & -0.29 & 0.03 & 0.06 \\
\hline ZWE & -0.13 & -0.23 & -0.05 & 0.05 \\
\hline
\end{tabular}


Table A9.5: Climate-related deaths (in thousands) by region and risk factor (FVC: fruit and vegetable consumption; MTC: red-meat consumption; UND: underweight; OVW: overweight; OBS: obesity).

\begin{tabular}{|c|c|c|c|c|c|c|}
\hline \multirow{2}{*}{ Region } & \multicolumn{6}{|c|}{ Climate-related deaths (thousands) } \\
\hline & Total & $\mathrm{FVC}$ & MTC & UND & OVW & OBS \\
\hline Global & 528.71 & 533.55 & -29.07 & 266.16 & -34.94 & -225.42 \\
\hline HIC & 38.47 & 67.05 & -9.48 & 10.01 & -1.26 & -27.94 \\
\hline AFR_LMIC & 27.69 & 14.21 & -1.11 & 53.45 & -1.65 & -37.68 \\
\hline AMR_LMIC & 2.67 & 23.72 & -2.78 & 5.97 & -0.36 & -24.45 \\
\hline EMR_LMIC & 12.36 & 24.69 & -0.98 & 10.67 & -1.75 & -20.92 \\
\hline EUR_LMIC & 14.34 & 32.45 & -4.01 & 1.33 & -0.75 & -15.67 \\
\hline SEA_LMIC & 163.52 & 89.51 & -1.27 & 146.79 & -20.96 & -56.88 \\
\hline WPR_LMIC & 264.27 & 274.90 & -9.39 & 37.64 & -8.16 & -39.91 \\
\hline $\mathrm{AFG}$ & 1.70 & 0.46 & -0.05 & 2.04 & -0.24 & -0.50 \\
\hline AGO & 1.47 & 0.18 & -0.03 & 2.39 & -0.03 & -1.04 \\
\hline ALB & 0.24 & 0.35 & -0.01 & 0.02 & 0.00 & -0.12 \\
\hline ARG & 0.21 & 1.20 & -0.23 & 0.19 & 0.00 & -0.97 \\
\hline ARM & 0.17 & 0.28 & -0.01 & 0.02 & 0.00 & -0.14 \\
\hline AUS & 0.17 & 1.32 & -0.27 & 0.13 & -0.02 & -1.01 \\
\hline AUT & 0.22 & 0.53 & -0.18 & 0.05 & -0.01 & -0.16 \\
\hline AZE & 0.40 & 0.92 & -0.01 & 0.10 & -0.02 & -0.58 \\
\hline BDI & 0.51 & 0.35 & -0.01 & 0.59 & -0.02 & -0.43 \\
\hline BEN & 0.37 & 0.18 & -0.01 & 1.06 & -0.04 & -0.82 \\
\hline BFA & 0.73 & 0.10 & -0.07 & 0.99 & -0.04 & -0.22 \\
\hline BGD & 9.95 & 1.92 & -0.03 & 10.99 & -1.61 & -1.36 \\
\hline BGR & 0.03 & 0.34 & -0.06 & 0.05 & -0.01 & -0.31 \\
\hline BLR & 0.47 & 1.31 & -0.27 & 0.01 & -0.04 & -0.57 \\
\hline BLT & 0.40 & 0.54 & -0.12 & 0.00 & 0.00 & -0.03 \\
\hline BLX & 0.39 & 0.55 & -0.10 & 0.03 & 0.00 & -0.09 \\
\hline BLZ & 0.00 & 0.01 & 0.00 & 0.00 & 0.00 & -0.01 \\
\hline BOL & -0.26 & 0.18 & -0.04 & 0.18 & 0.00 & -0.59 \\
\hline BRA & 4.49 & 10.24 & -1.51 & 2.04 & -0.18 & -6.26 \\
\hline BTN & 0.04 & 0.07 & 0.00 & 0.03 & -0.01 & -0.05 \\
\hline BWA & 0.00 & 0.01 & 0.00 & 0.09 & 0.00 & -0.10 \\
\hline CAF & -0.04 & 0.04 & -0.02 & 0.20 & -0.01 & -0.24 \\
\hline CAN & 1.13 & 2.55 & -0.28 & 0.19 & -0.03 & -1.28 \\
\hline CHL & 0.07 & 0.78 & -0.09 & 0.11 & 0.00 & -0.76 \\
\hline CHM & 247.97 & 261.70 & -8.54 & 23.63 & -6.06 & -31.50 \\
\hline CHP & 0.12 & 0.31 & -0.08 & 0.09 & -0.02 & -0.19 \\
\hline CIV & 0.64 & 0.42 & -0.02 & 1.51 & -0.04 & -1.25 \\
\hline CMR & -0.19 & 0.42 & -0.02 & 0.84 & -0.02 & -1.45 \\
\hline COD & 4.94 & 0.65 & -0.02 & 6.98 & -0.15 & -2.56 \\
\hline $\mathrm{COG}$ & 0.07 & 0.07 & 0.00 & 0.28 & -0.01 & -0.27 \\
\hline $\mathrm{COL}$ & 0.02 & 1.80 & -0.14 & 0.68 & -0.11 & -2.27 \\
\hline CRB & 0.01 & 0.02 & 0.00 & 0.00 & 0.00 & -0.02 \\
\hline CRI & 0.03 & 0.24 & -0.02 & 0.04 & 0.00 & -0.24 \\
\hline
\end{tabular}




\begin{tabular}{|c|c|c|c|c|c|c|}
\hline CUB & -0.02 & 0.91 & -0.05 & 0.18 & -0.03 & -1.09 \\
\hline CYP & 0.01 & 0.05 & 0.00 & 0.02 & 0.00 & -0.06 \\
\hline CZE & 0.18 & 0.62 & -0.20 & 0.03 & 0.00 & -0.28 \\
\hline DEU & 1.20 & 4.29 & -1.29 & 0.52 & -0.10 & -2.22 \\
\hline DJI & -0.03 & 0.01 & -0.01 & 0.03 & 0.00 & -0.06 \\
\hline DNK & 0.10 & 0.28 & -0.07 & 0.05 & -0.01 & -0.15 \\
\hline DOM & -0.07 & 0.42 & -0.03 & 0.11 & -0.01 & -0.58 \\
\hline DZA & 0.81 & 1.63 & 0.00 & 0.83 & -0.04 & -1.64 \\
\hline ECU & -0.01 & 0.58 & -0.03 & 0.20 & -0.01 & -0.78 \\
\hline EGY & 2.23 & 5.65 & -0.29 & 0.35 & 0.07 & -3.80 \\
\hline ERI & 0.19 & 0.01 & 0.00 & 0.32 & -0.03 & -0.11 \\
\hline ETH & 3.52 & 0.31 & -0.04 & 4.09 & -0.17 & -0.67 \\
\hline FJI & -0.02 & 0.01 & 0.00 & 0.00 & 0.00 & -0.03 \\
\hline FNP & 0.01 & 0.26 & -0.07 & 0.04 & -0.01 & -0.20 \\
\hline FRP & 1.96 & 2.99 & -0.41 & 0.71 & -0.07 & -1.27 \\
\hline GAB & -0.01 & 0.05 & 0.00 & 0.07 & 0.00 & -0.12 \\
\hline GEO & 0.08 & 0.26 & -0.03 & 0.00 & 0.00 & -0.15 \\
\hline GHA & 1.02 & 1.10 & -0.04 & 2.15 & -0.09 & -2.16 \\
\hline GIN & 0.34 & 0.33 & -0.02 & 0.58 & -0.03 & -0.55 \\
\hline GMB & 0.00 & 0.01 & 0.00 & 0.09 & 0.00 & -0.10 \\
\hline GNB & 0.10 & 0.02 & 0.00 & 0.19 & -0.01 & -0.10 \\
\hline GNQ & 0.05 & 0.01 & 0.00 & 0.09 & 0.00 & -0.05 \\
\hline GRC & 1.16 & 1.39 & -0.08 & 0.07 & -0.01 & -0.21 \\
\hline GSA & 0.00 & 0.03 & 0.00 & 0.02 & 0.00 & -0.05 \\
\hline GTM & -0.16 & 0.22 & -0.01 & 0.17 & 0.00 & -0.56 \\
\hline HND & -0.05 & 0.16 & -0.01 & 0.06 & -0.01 & -0.26 \\
\hline HRV & 0.06 & 0.22 & -0.04 & 0.02 & -0.01 & -0.13 \\
\hline HTI & -0.12 & 0.15 & -0.01 & 0.30 & -0.01 & -0.57 \\
\hline HUN & 0.43 & 0.72 & -0.14 & 0.03 & -0.01 & -0.19 \\
\hline IDN & 7.95 & 11.10 & -0.08 & 14.68 & -3.08 & -15.31 \\
\hline IND & 135.97 & 70.23 & -0.90 & 110.64 & -15.17 & -34.23 \\
\hline IRL & 0.07 & 0.25 & -0.06 & 0.02 & 0.00 & -0.13 \\
\hline IRN & 5.66 & 8.42 & -0.01 & 0.55 & -0.16 & -3.24 \\
\hline IRQ & -0.57 & 1.28 & -0.01 & 0.27 & 0.01 & -2.17 \\
\hline ISL & 0.01 & 0.02 & 0.00 & 0.00 & 0.00 & -0.01 \\
\hline ISR & 0.49 & 0.60 & -0.02 & 0.02 & 0.00 & -0.12 \\
\hline ITP & 4.63 & 5.81 & -0.75 & 0.17 & -0.04 & -0.54 \\
\hline JAM & -0.02 & 0.09 & 0.00 & 0.03 & 0.00 & -0.14 \\
\hline JOR & 0.10 & 0.23 & 0.00 & 0.02 & 0.00 & -0.17 \\
\hline JPN & 7.62 & 6.31 & -0.49 & 4.64 & -0.69 & -2.16 \\
\hline KAZ & 0.66 & 1.80 & -0.25 & 0.10 & -0.02 & -1.04 \\
\hline KEN & 0.16 & 0.65 & -0.06 & 1.63 & -0.07 & -2.03 \\
\hline KGZ & 0.24 & 0.51 & -0.04 & 0.03 & -0.02 & -0.28 \\
\hline KHM & 0.76 & 0.09 & -0.01 & 0.88 & -0.05 & -0.15 \\
\hline KOR & 4.71 & 5.02 & -0.16 & 0.76 & -0.16 & -0.99 \\
\hline
\end{tabular}




\begin{tabular}{|c|c|c|c|c|c|c|}
\hline LAO & 0.33 & 0.16 & -0.01 & 0.35 & -0.05 & -0.12 \\
\hline LBN & 0.10 & 0.18 & 0.00 & 0.01 & 0.00 & -0.10 \\
\hline LBR & 0.23 & 0.09 & -0.01 & 0.52 & -0.02 & -0.36 \\
\hline LBY & 0.08 & 0.33 & 0.00 & 0.03 & 0.00 & -0.29 \\
\hline LKA & 1.37 & 0.41 & -0.01 & 2.08 & -0.10 & -1.02 \\
\hline LSO & 0.04 & 0.01 & 0.00 & 0.13 & 0.00 & -0.10 \\
\hline MDA & 0.12 & 0.27 & -0.03 & 0.01 & -0.01 & -0.14 \\
\hline MDG & 3.11 & 0.41 & -0.05 & 4.02 & -0.29 & -0.97 \\
\hline MEX & 0.04 & 4.37 & -0.40 & 0.61 & 0.02 & -4.65 \\
\hline MLI & 0.81 & 0.24 & -0.02 & 1.25 & -0.04 & -0.62 \\
\hline MMR & 3.27 & 1.58 & -0.06 & 4.47 & -0.49 & -2.28 \\
\hline MNG & -0.02 & 0.07 & 0.00 & 0.01 & 0.00 & -0.10 \\
\hline MOR & 1.32 & 1.72 & -0.01 & 0.15 & -0.03 & -0.59 \\
\hline $\mathrm{MOZ}$ & 0.35 & 0.11 & -0.06 & 1.91 & -0.03 & -1.54 \\
\hline MRT & -0.04 & 0.02 & -0.01 & 0.12 & 0.00 & -0.16 \\
\hline MWI & 1.51 & 0.21 & -0.01 & 2.02 & 0.00 & -0.72 \\
\hline MYS & -0.04 & 0.74 & -0.02 & 0.28 & -0.05 & -1.02 \\
\hline NAM & -0.04 & 0.02 & -0.01 & 0.08 & 0.00 & -0.13 \\
\hline NER & 0.34 & 0.14 & -0.08 & 0.69 & -0.03 & -0.36 \\
\hline NGA & 4.52 & 3.40 & -0.22 & 9.19 & -0.26 & -7.73 \\
\hline NIC & -0.21 & 0.04 & 0.00 & 0.04 & 0.00 & -0.29 \\
\hline NLD & 0.54 & 0.94 & -0.11 & 0.20 & -0.02 & -0.47 \\
\hline NOR & 0.05 & 0.22 & -0.04 & 0.04 & -0.01 & -0.17 \\
\hline NPL & 2.26 & 1.04 & -0.07 & 2.22 & -0.37 & -0.60 \\
\hline NZL & 0.14 & 0.35 & -0.04 & 0.02 & 0.00 & -0.20 \\
\hline OAO & 0.00 & 0.01 & 0.00 & 0.00 & 0.00 & -0.01 \\
\hline OBN & 0.61 & 0.68 & -0.03 & 0.01 & 0.00 & -0.05 \\
\hline OIO & 0.02 & 0.03 & 0.00 & 0.03 & 0.00 & -0.04 \\
\hline $\mathrm{OPO}$ & 0.00 & 0.00 & 0.00 & 0.00 & 0.00 & 0.00 \\
\hline OSA & 0.01 & 0.03 & 0.00 & 0.04 & -0.01 & -0.04 \\
\hline PAK & 1.88 & 4.82 & -0.50 & 4.95 & -1.19 & -6.31 \\
\hline PAN & -0.12 & 0.10 & -0.01 & 0.03 & 0.00 & -0.24 \\
\hline PER & -0.10 & 0.65 & -0.01 & 0.61 & -0.03 & -1.35 \\
\hline PHL & 4.41 & 4.08 & -0.23 & 6.13 & -0.66 & -4.99 \\
\hline PNG & 0.23 & 0.56 & -0.02 & 0.06 & 0.00 & -0.46 \\
\hline POL & 1.13 & 2.12 & -0.48 & 0.13 & -0.03 & -0.65 \\
\hline PRT & 0.71 & 1.04 & -0.10 & 0.07 & -0.01 & -0.29 \\
\hline PRY & 0.03 & 0.30 & -0.05 & 0.10 & -0.01 & -0.32 \\
\hline RAP & 0.01 & 0.68 & 0.00 & 0.06 & 0.01 & -0.75 \\
\hline ROU & 1.33 & 2.25 & -0.23 & 0.17 & -0.06 & -0.86 \\
\hline RUS & 7.46 & 15.54 & -2.15 & 0.36 & -0.23 & -6.43 \\
\hline RWA & 0.09 & 0.26 & -0.01 & 0.25 & -0.02 & -0.42 \\
\hline SAU & -0.09 & 1.15 & 0.00 & 0.16 & 0.02 & -1.44 \\
\hline SDN & 1.28 & 1.37 & -0.06 & 1.73 & -0.18 & -1.62 \\
\hline SEN & 0.24 & 0.14 & -0.01 & 0.99 & -0.03 & -0.84 \\
\hline
\end{tabular}




\begin{tabular}{|c|c|c|c|c|c|c|}
\hline SLB & -0.03 & 0.01 & 0.00 & 0.00 & 0.00 & -0.03 \\
\hline SLE & 0.32 & 0.09 & 0.00 & 0.94 & 0.00 & -0.72 \\
\hline SLV & -0.12 & 0.10 & -0.01 & 0.06 & 0.00 & -0.28 \\
\hline SOM & -0.34 & 0.05 & -0.05 & 0.07 & 0.00 & -0.38 \\
\hline SPP & 1.06 & 2.93 & -0.51 & 0.47 & -0.03 & -1.78 \\
\hline SVK & -0.01 & 0.34 & -0.10 & 0.02 & -0.01 & -0.26 \\
\hline SVN & 0.06 & 0.13 & -0.02 & 0.01 & 0.00 & -0.06 \\
\hline SWE & 0.04 & 0.42 & -0.11 & 0.08 & -0.02 & -0.33 \\
\hline SWZ & -0.01 & 0.01 & 0.00 & 0.05 & 0.00 & -0.08 \\
\hline SYR & 0.32 & 0.89 & 0.00 & 0.05 & 0.02 & -0.69 \\
\hline TCD & 0.29 & 0.03 & -0.02 & 0.64 & -0.01 & -0.34 \\
\hline TGO & 0.23 & 0.05 & -0.01 & 0.68 & -0.03 & -0.45 \\
\hline THA & 2.69 & 3.15 & -0.11 & 1.65 & -0.14 & -2.02 \\
\hline TJK & 0.07 & 0.26 & 0.00 & 0.12 & -0.03 & -0.28 \\
\hline TKM & 0.23 & 0.44 & -0.02 & 0.05 & -0.02 & -0.24 \\
\hline TLS & 0.01 & 0.00 & 0.00 & 0.03 & 0.00 & -0.01 \\
\hline TUN & 0.39 & 0.53 & 0.00 & 0.04 & 0.00 & -0.20 \\
\hline TUR & 4.06 & 5.29 & -0.04 & 0.15 & -0.02 & -1.38 \\
\hline TZA & 0.73 & 0.66 & -0.06 & 2.45 & -0.05 & -2.31 \\
\hline UGA & 1.17 & 0.73 & -0.04 & 1.46 & -0.02 & -0.99 \\
\hline UKP & 1.51 & 3.85 & -0.53 & 0.30 & -0.03 & -2.11 \\
\hline UKR & 1.24 & 4.32 & -0.56 & 0.06 & -0.18 & -2.58 \\
\hline URY & 0.01 & 0.14 & -0.02 & 0.03 & 0.00 & -0.14 \\
\hline USA & 8.64 & 18.72 & -2.75 & 0.81 & 0.07 & -8.00 \\
\hline UZB & 0.60 & 2.38 & -0.19 & 0.22 & -0.10 & -1.88 \\
\hline VEN & -0.94 & 1.02 & -0.11 & 0.19 & 0.02 & -2.06 \\
\hline VNM & 10.70 & 7.50 & -0.56 & 6.30 & -1.30 & -1.48 \\
\hline VUT & -0.01 & 0.00 & 0.00 & 0.00 & 0.00 & -0.01 \\
\hline YEM & -0.43 & 0.47 & 0.00 & 0.54 & -0.06 & -1.39 \\
\hline ZAF & -0.60 & 0.93 & -0.07 & 0.29 & 0.00 & -1.78 \\
\hline ZMB & -0.16 & 0.06 & -0.01 & 0.49 & -0.01 & -0.68 \\
\hline ZWE & -0.13 & 0.03 & -0.02 & 0.27 & 0.00 & -0.40 \\
\hline
\end{tabular}


Table A9.6: Climate-related deaths per capita (in deaths per million) by region and risk factor (FVC: fruit and vegetable consumption; MTC: red-meat consumption; UND: underweight; OVW: overweight; OBS: obesity).

\begin{tabular}{|c|c|c|c|c|c|c|}
\hline \multirow{2}{*}{ Region } & \multicolumn{6}{|c|}{ Climate-related deaths per capita (per million) } \\
\hline & Total & FVC & MTC & UND & OVW & OBS \\
\hline Global & 77.99 & 78.71 & -4.29 & 39.26 & -5.15 & -33.25 \\
\hline HIC & 37.17 & 64.80 & -9.16 & 9.67 & -1.21 & -27.00 \\
\hline AFR_LMIC & 26.43 & 13.57 & -1.06 & 51.00 & -1.58 & -35.96 \\
\hline AMR_LMIC & 4.73 & 41.95 & -4.92 & 10.56 & -0.64 & -43.24 \\
\hline EMR_LMIC & 20.23 & 40.41 & -1.61 & 17.47 & -2.87 & -34.23 \\
\hline EUR_LMIC & 55.01 & 124.46 & -15.36 & 5.08 & -2.87 & -60.10 \\
\hline SEA_LMIC & 89.51 & 49.00 & -0.69 & 80.35 & -11.47 & -31.14 \\
\hline WPR_LMIC & 198.60 & 206.59 & -7.06 & 28.29 & -6.13 & -29.99 \\
\hline AFG & 40.77 & 11.12 & -1.22 & 48.77 & -5.85 & -11.92 \\
\hline AGO & 54.06 & 6.79 & -1.19 & 88.21 & -1.12 & -38.39 \\
\hline ALB & 88.10 & 130.90 & -5.46 & 6.70 & -1.65 & -45.51 \\
\hline $\mathrm{ARG}$ & 5.47 & 31.73 & -5.98 & 5.10 & -0.03 & -25.69 \\
\hline ARM & 80.95 & 136.33 & -4.18 & 10.29 & -1.13 & -68.69 \\
\hline AUS & 5.74 & 45.92 & -9.44 & 4.57 & -0.53 & -35.08 \\
\hline AUT & 29.04 & 68.50 & -23.42 & 6.32 & -1.43 & -20.70 \\
\hline AZE & 46.22 & 105.49 & -1.17 & 11.79 & -2.28 & -66.50 \\
\hline BDI & 44.42 & 30.13 & -0.66 & 51.06 & -2.08 & -37.53 \\
\hline BEN & 30.49 & 14.40 & -0.67 & 86.24 & -3.12 & -66.87 \\
\hline BFA & 32.15 & 4.24 & -3.31 & 43.56 & -1.58 & -9.91 \\
\hline BGD & 66.65 & 12.84 & -0.22 & 73.61 & -10.81 & -9.11 \\
\hline BGR & 4.82 & 64.40 & -10.74 & 9.84 & -1.99 & -58.39 \\
\hline BLR & 69.46 & 193.79 & -39.80 & 1.40 & -5.89 & -83.90 \\
\hline BLT & 83.52 & 113.06 & -24.27 & 0.68 & -0.51 & -7.10 \\
\hline BLX & 35.71 & 51.35 & -9.72 & 2.81 & -0.37 & -8.29 \\
\hline BLZ & -6.15 & 29.51 & -1.32 & 4.68 & 0.32 & -40.20 \\
\hline BOL & -26.39 & 17.82 & -3.64 & 17.93 & -0.28 & -59.24 \\
\hline BRA & 24.25 & 55.30 & -8.18 & 11.01 & -1.00 & -33.82 \\
\hline BTN & 46.02 & 71.34 & -2.23 & 36.04 & -10.00 & -55.66 \\
\hline BWA & -2.25 & 7.47 & -2.00 & 46.10 & -0.24 & -53.62 \\
\hline CAF & -7.57 & 8.25 & -5.02 & 40.28 & -1.18 & -47.97 \\
\hline $\mathrm{CAN}$ & 29.52 & 66.50 & -7.35 & 5.06 & -0.79 & -33.41 \\
\hline CHL & 4.02 & 46.64 & -5.13 & 6.65 & 0.07 & -45.71 \\
\hline $\mathrm{CHM}$ & 230.64 & 243.41 & -7.94 & 21.98 & -5.63 & -29.30 \\
\hline $\mathrm{CHP}$ & 15.50 & 41.33 & -10.39 & 11.72 & -2.04 & -25.19 \\
\hline CIV & 31.94 & 21.00 & -0.90 & 75.61 & -2.26 & -62.63 \\
\hline CMR & -8.72 & 19.46 & -0.87 & 38.64 & -0.71 & -66.66 \\
\hline COD & 56.23 & 7.36 & -0.26 & 79.46 & -1.76 & -29.13 \\
\hline COG & 13.17 & 13.15 & -0.78 & 53.98 & -2.00 & -52.13 \\
\hline COL & 0.33 & 37.10 & -2.81 & 13.96 & -2.25 & -46.77 \\
\hline CRB & 4.14 & 11.65 & -1.26 & 1.39 & -0.02 & -7.75 \\
\hline
\end{tabular}




\begin{tabular}{|c|c|c|c|c|c|c|}
\hline CRI & 6.24 & 45.08 & -2.96 & 7.71 & -0.58 & -44.24 \\
\hline CUB & -2.63 & 114.68 & -6.57 & 23.01 & -3.99 & 137.72 \\
\hline CYP & 4.42 & 37.79 & -1.62 & 13.41 & -1.35 & -43.47 \\
\hline CZE & 18.26 & 64.26 & -20.30 & 2.79 & -0.41 & -29.25 \\
\hline DEU & 18.07 & 64.43 & -19.40 & 7.81 & -1.45 & -33.31 \\
\hline DJI & -31.85 & 9.77 & -6.69 & 31.56 & -3.84 & -58.77 \\
\hline DNK & 20.44 & 54.97 & -14.09 & 9.81 & -1.77 & -28.47 \\
\hline DOM & -7.47 & 43.16 & -3.26 & 11.45 & -1.02 & -59.55 \\
\hline DZA & 21.25 & 43.07 & 0.06 & 21.79 & -1.11 & -43.24 \\
\hline ECU & -0.98 & 38.05 & -2.20 & 13.29 & -0.48 & -51.61 \\
\hline EGY & 24.58 & 62.25 & -3.16 & 3.85 & 0.72 & -41.85 \\
\hline ERI & 24.25 & 1.24 & -0.56 & 41.56 & -3.24 & -14.52 \\
\hline ETH & 33.85 & 2.97 & -0.37 & 39.26 & -1.65 & -6.45 \\
\hline FJI & -23.32 & 19.00 & -2.62 & 4.21 & 0.80 & -45.32 \\
\hline FNP & 2.59 & 52.71 & -15.38 & 8.11 & -2.53 & -40.49 \\
\hline FRP & 32.56 & 49.84 & -6.75 & 11.89 & -1.17 & -21.17 \\
\hline GAB & -7.54 & 28.96 & -2.32 & 43.05 & -1.05 & -76.98 \\
\hline GEO & 32.36 & 98.62 & -12.77 & 0.33 & -1.73 & -58.30 \\
\hline GHA & 34.06 & 36.64 & -1.22 & 71.64 & -3.06 & -71.87 \\
\hline GIN & 35.49 & 34.54 & -1.74 & 60.52 & -3.11 & -57.75 \\
\hline GMB & 0.17 & 5.99 & -1.12 & 44.92 & -1.41 & -47.95 \\
\hline GNB & 64.01 & 13.09 & -3.09 & 119.32 & -3.56 & -60.90 \\
\hline GNQ & 50.75 & 11.78 & -0.03 & 94.07 & -1.88 & -52.81 \\
\hline GRC & 123.66 & 147.92 & -8.48 & 7.02 & -1.28 & -22.60 \\
\hline GSA & -4.48 & 31.21 & -1.50 & 17.10 & -1.36 & -51.00 \\
\hline GTM & -9.55 & 13.29 & -0.48 & 10.27 & -0.12 & -33.18 \\
\hline HND & -5.89 & 19.54 & -1.29 & 6.68 & -0.61 & -31.23 \\
\hline HRV & 18.80 & 65.19 & -12.61 & 7.32 & -2.39 & -39.41 \\
\hline HTI & -13.26 & 16.73 & -0.98 & 33.26 & -0.81 & -63.20 \\
\hline HUN & 57.49 & 98.03 & -18.68 & 3.56 & -0.99 & -25.88 \\
\hline IDN & 35.07 & 48.94 & -0.36 & 64.72 & -13.57 & -67.51 \\
\hline IND & 104.95 & 54.21 & -0.69 & 85.40 & -11.71 & -26.42 \\
\hline IRL & 14.99 & 49.72 & -11.31 & 3.47 & -0.54 & -26.36 \\
\hline IRN & 74.51 & 110.87 & -0.10 & 7.19 & -2.12 & -42.62 \\
\hline IRQ & -12.74 & 28.49 & -0.14 & 6.09 & 0.19 & -48.26 \\
\hline ISL & 16.34 & 44.19 & -5.72 & 4.51 & -0.85 & -26.20 \\
\hline ISR & 48.78 & 59.76 & -1.74 & 2.33 & -0.09 & -11.72 \\
\hline ITP & 89.17 & 111.82 & -14.38 & 3.31 & -0.71 & -10.40 \\
\hline JAM & -7.84 & 44.52 & -1.87 & 13.26 & -0.43 & -65.07 \\
\hline JOR & 9.89 & 24.15 & 0.04 & 1.62 & 0.34 & -17.42 \\
\hline JPN & 81.74 & 67.60 & -5.27 & 49.74 & -7.35 & -23.12 \\
\hline KAZ & 42.97 & 118.00 & -16.60 & 6.62 & -1.55 & -67.96 \\
\hline KEN & 3.28 & 13.45 & -1.29 & 33.40 & -1.36 & -41.79 \\
\hline KGZ & 50.09 & 109.30 & -7.64 & 5.42 & -3.98 & -59.30 \\
\hline KHM & 59.24 & 6.72 & -0.47 & 69.03 & -3.81 & -12.07 \\
\hline
\end{tabular}




\begin{tabular}{|c|c|c|c|c|c|c|}
\hline KOR & 118.53 & 126.58 & -3.93 & 19.21 & -3.93 & -25.04 \\
\hline LAO & 53.80 & 25.06 & -0.84 & 55.59 & -8.36 & -18.56 \\
\hline LBN & 25.91 & 46.27 & -0.32 & 2.74 & 0.00 & -25.24 \\
\hline LBR & 31.06 & 11.69 & -1.12 & 72.00 & -2.28 & -49.21 \\
\hline LBY & 10.59 & 44.78 & 0.02 & 4.09 & 0.41 & -40.01 \\
\hline LKA & 73.33 & 21.96 & -0.53 & 111.50 & -5.29 & -54.78 \\
\hline LSO & 21.70 & 5.68 & -1.51 & 75.82 & 0.14 & -58.42 \\
\hline MDA & 65.58 & 149.72 & -14.47 & 4.02 & -3.45 & -78.67 \\
\hline MDG & 105.23 & 13.95 & -1.76 & 136.24 & -9.65 & -32.83 \\
\hline MEX & 0.37 & 39.36 & -3.57 & 5.49 & 0.22 & -41.85 \\
\hline MLI & 37.81 & 11.22 & -1.14 & 58.71 & -1.73 & -29.13 \\
\hline MMR & 86.66 & 41.96 & -1.62 & 118.38 & -12.91 & -60.43 \\
\hline MNG & -8.95 & 24.11 & -0.96 & 4.09 & 0.22 & -37.26 \\
\hline MOR & 46.57 & 60.85 & -0.29 & 5.37 & -1.13 & -20.99 \\
\hline $\mathrm{MOZ}$ & 13.20 & 4.22 & -2.12 & 72.49 & -1.19 & -58.38 \\
\hline MRT & -10.11 & 4.15 & -2.34 & 27.43 & -0.56 & -38.32 \\
\hline MWI & 68.74 & 9.70 & -0.56 & 92.04 & -0.22 & -32.72 \\
\hline MYS & -1.36 & 22.72 & -0.68 & 8.70 & -1.48 & -31.43 \\
\hline NAM & -16.52 & 8.00 & -2.66 & 32.59 & -0.61 & -53.78 \\
\hline NER & 13.51 & 5.31 & -2.97 & 27.02 & -1.15 & -14.08 \\
\hline NGA & 21.93 & 16.49 & -1.07 & 44.55 & -1.26 & -37.50 \\
\hline NIC & -42.02 & 7.25 & -0.74 & 7.19 & 0.30 & -56.48 \\
\hline NLD & 36.26 & 63.65 & -7.62 & 13.44 & -1.63 & -31.63 \\
\hline NOR & 8.31 & 40.09 & -7.08 & 7.19 & -1.32 & -30.37 \\
\hline NPL & 61.93 & 28.68 & -1.99 & 60.85 & -10.05 & -16.34 \\
\hline NZL & 29.62 & 75.09 & -7.64 & 3.53 & 0.07 & -42.46 \\
\hline OAO & 4.26 & 10.03 & -1.30 & 8.04 & -0.42 & -12.76 \\
\hline OBN & 45.81 & 50.69 & -2.51 & 0.96 & -0.11 & -3.49 \\
\hline OIO & 7.05 & 13.16 & -0.41 & 11.21 & -0.86 & -16.39 \\
\hline OPO & -6.01 & 6.37 & -1.29 & 0.90 & 0.16 & -12.29 \\
\hline OSA & 1.57 & 4.68 & -0.06 & 6.37 & -2.30 & -7.13 \\
\hline PAK & 9.32 & 23.88 & -2.50 & 24.53 & -5.90 & -31.29 \\
\hline PAN & -30.82 & 24.52 & -3.38 & 8.61 & -0.06 & -61.42 \\
\hline PER & -3.99 & 25.51 & -0.57 & 23.99 & -1.08 & -52.94 \\
\hline PHL & 41.55 & 38.42 & -2.17 & 57.75 & -6.20 & -47.03 \\
\hline PNG & 28.27 & 69.53 & -2.66 & 7.41 & 0.13 & -57.36 \\
\hline POL & 38.27 & 72.18 & -16.18 & 4.44 & -0.93 & -22.16 \\
\hline PRT & 75.60 & 110.25 & -11.04 & 7.56 & -0.79 & -30.52 \\
\hline PRY & 3.76 & 41.57 & -7.13 & 14.19 & -1.43 & -44.84 \\
\hline RAP & 0.39 & 23.84 & -0.07 & 2.17 & 0.37 & -26.17 \\
\hline ROU & 88.70 & 150.35 & -15.28 & 11.38 & -4.00 & -57.26 \\
\hline RUS & 67.56 & 140.69 & -19.42 & 3.27 & -2.05 & -58.16 \\
\hline RWA & 6.65 & 18.47 & -0.59 & 18.01 & -1.13 & -30.29 \\
\hline SAU & -2.29 & 27.98 & -0.09 & 3.99 & 0.55 & -35.15 \\
\hline SDN & 23.42 & 25.10 & -1.14 & 31.53 & -3.29 & -29.58 \\
\hline
\end{tabular}




\begin{tabular}{|c|c|c|c|c|c|c|}
\hline SEN & 15.99 & 8.98 & -0.94 & 65.81 & -1.93 & -55.86 \\
\hline SLB & -39.40 & 8.64 & -1.18 & 4.21 & 0.82 & -52.03 \\
\hline SLE & 43.79 & 12.75 & -0.43 & 129.92 & -0.04 & -98.96 \\
\hline SLV & -27.36 & 22.29 & -1.15 & 12.76 & -0.18 & -61.73 \\
\hline SOM & -36.24 & 5.08 & -5.65 & 7.65 & -0.30 & -41.19 \\
\hline SPP & 24.08 & 66.57 & -11.47 & 10.61 & -0.78 & -40.28 \\
\hline SVK & -2.46 & 73.48 & -20.93 & 3.44 & -2.21 & -57.32 \\
\hline SVN & 35.15 & 74.31 & -11.40 & 6.04 & -0.48 & -34.37 \\
\hline SWE & 4.55 & 43.38 & -11.62 & 8.63 & -2.44 & -33.62 \\
\hline SWZ & -14.43 & 14.21 & -3.68 & 53.73 & 0.21 & -78.86 \\
\hline SYR & 12.87 & 36.08 & -0.10 & 2.06 & 0.63 & -27.91 \\
\hline TCD & 19.93 & 2.12 & -1.23 & 43.16 & -1.01 & -22.72 \\
\hline TGO & 33.48 & 7.76 & -1.33 & 97.05 & -4.64 & -64.72 \\
\hline THA & 44.68 & 52.32 & -1.85 & 27.40 & -2.30 & -33.48 \\
\hline TJK & 13.00 & 46.20 & -0.68 & 20.88 & -4.68 & -50.68 \\
\hline TKM & 47.70 & 92.37 & -4.96 & 10.29 & -4.96 & -50.03 \\
\hline TLS & 10.23 & 1.55 & -0.59 & 24.00 & -2.67 & -11.49 \\
\hline TUN & 37.95 & 51.69 & -0.34 & 4.30 & -0.35 & -19.61 \\
\hline TUR & 55.38 & 72.12 & -0.57 & 2.06 & -0.21 & -18.75 \\
\hline TZA & 12.14 & 10.93 & -0.94 & 40.55 & -0.85 & -38.11 \\
\hline UGA & 23.72 & 14.69 & -0.80 & 29.56 & -0.50 & -20.12 \\
\hline UKP & 25.12 & 64.18 & -8.77 & 4.96 & -0.49 & -35.06 \\
\hline UKR & 38.93 & 135.83 & -17.66 & 1.80 & -5.64 & -81.05 \\
\hline URY & 3.90 & 52.42 & -6.77 & 11.85 & -1.01 & -53.97 \\
\hline USA & 27.72 & 60.05 & -8.83 & 2.61 & 0.22 & -25.65 \\
\hline UZB & 24.02 & 94.65 & -7.37 & 8.66 & -3.94 & -74.90 \\
\hline VEN & -29.48 & 31.87 & -3.60 & 5.82 & 0.50 & -64.56 \\
\hline VNM & 125.53 & 87.97 & -6.55 & 73.91 & -15.22 & -17.39 \\
\hline VUT & -19.45 & 8.39 & -2.48 & 2.89 & 0.34 & -28.72 \\
\hline YEM & -12.30 & 13.40 & -0.05 & 15.44 & -1.75 & -39.79 \\
\hline ZAF & -13.32 & 20.77 & -1.51 & 6.39 & 0.00 & -39.65 \\
\hline ZMB & -9.39 & 3.39 & -0.69 & 29.90 & -0.91 & -41.02 \\
\hline ZWE & -15.49 & 3.29 & -2.37 & 31.56 & 0.02 & -46.39 \\
\hline
\end{tabular}




\section{Appendix A10: Research in context}

Previous studies of the health impacts of climate change have either analysed complementary causes of death, or focused on the impacts of climate change on agriculture and health in terms of changes in food security and caloric availability. ${ }^{97,98}$ A recent WHO report integrated several analyses that quantified climate-related mortality caused by heat, coastal flooding, diarrhoeal disease, malaria, dengue and undernutrition in $2050 .{ }^{99}$ Figure A10 adopts the WHO report's central estimates and compares those to our results to illustrate the relevance of our focus.

Figure A10: Comparison of the number of climate-related deaths due to changes in dietary and weightrelated risks in $\mathbf{2 0 5 0}$, estimated in this study, with the number of climate-related deaths due to heat, coastal flooding, diarrhoeal disease, malaria, dengue, and child undernutrition in 2050, estimated for the WHO. ${ }^{99}$ The number of climate-related deaths due to changes in dietary and weight-related risks are averaged across socio-economic pathways (see Table 2) and displayed for different representative concentration pathways (RCPs).

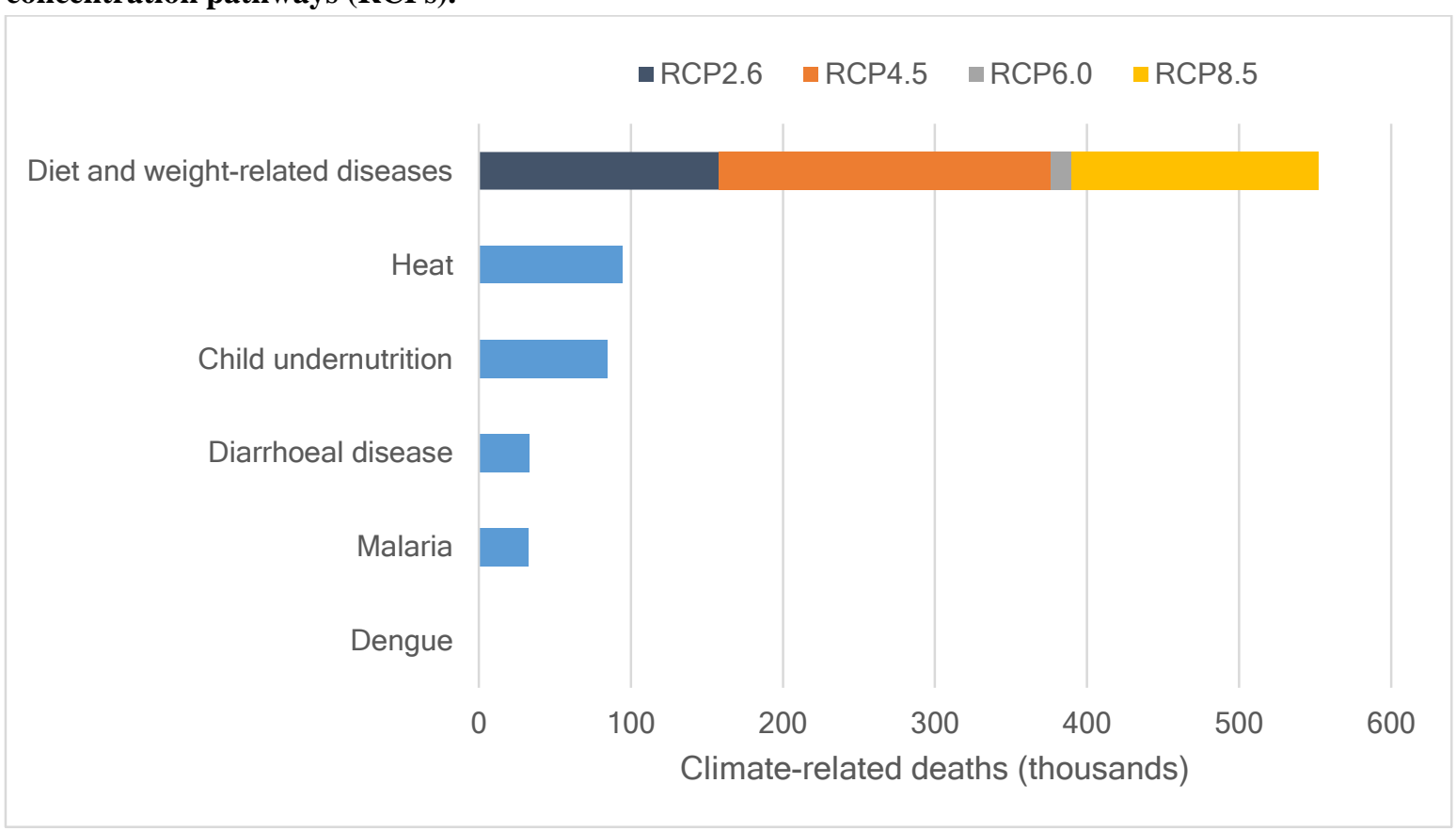




\section{Appendix A11: Supplementary discussion}

Several factors not included in this analysis could change future estimates of climate-related mortality from dietary and weight-related risk factors. They include explicit analyses of climate extremes, climatic impacts on fisheries and aquaculture, direct heat and water stress on livestock, climate impacts on the nutritional quality of foods, and longer-term analyses of climate impacts. Most of those factors can be expected to increase the climate-related health burden estimated in this study.

First, we did not include an explicit analysis of climate extremes in our assessment. Our modelling framework included climate and crop models with high regional and temporal resolution (up to daily time steps), but in assessing the biophysical yield shocks of climate change, all yield changes in a harvest year were summed and averaged across multiple different weather realizations. ${ }^{2}$ This procedure focusses on the most likely impacts and provides less weight to less likely but potentially high impact events. ${ }^{100}$

Second, we modelled the impacts of climate change on livestock production by accounting for climate-related changes in feed production, prices, and herd sizes. ${ }^{1}$ However, these indirect impacts of climate change on livestock production do not account for some potential direct impacts, such as heat exposure and water availability. This suggests that the impacts of climate change on livestock production could be more responsive to climate change than found in this study. A greater climate-related reduction in red meat consumption would lead to a greater number of avoided deaths, which would reduce the total number of climate-related deaths.

Third, we chose to focus on the impacts of climate change on agriculture, which means we did not include fisheries and aquaculture in our assessment. Low consumption of seafood omega- 3 fatty acids is an established risk factor for premature mortality. ${ }^{47}$ Climate-related decreases in fish consumption are therefore likely to increase the climate-related health burden if reductions in seafood omega- 3 fatty acids cannot be compensated for, e.g. by increased consumption of non-marine omega- 3 fatty acids, such as alpha-linolenic ones. ${ }^{101}$

Fourth, we did not include climate-related changes in the nutritional content of foods in our assessment. Experiments have indicated that elevated concentrations of carbon dioxide could decrease the micro and macronutrient content of food crops. ${ }^{102}$ Such an effect would corroborate the negative health impacts found here, because a greater amount of e.g. fruits and vegetables would be needed to realize the same health benefits.

Fifth, the negative impacts of climate change are expected to be higher by the end of the century. Our analysis focussed on the year 2050, which is in line with recent impact assessment that have focussed on climate-related impacts on agriculture. $.^{95}, 99$ Projections for the year 2050 are considered long term from an economic perspective, and longer projections are complicated by uncertainties of market condition and responses further into the future. However, climate models indicate that the negative yield impacts of climate change are relatively modest by mid-century, but increase more rapidly thereafter. ${ }^{36,97}$

Finally, we want to highlight that our focus on the country level may hide important health inequalities and differentiated responses to dietary and weight-related risk factors on the local level. For example, we estimated that in many regions, the number of avoided deaths from climate-related reductions in overweight and obesity could exceed the number of deaths from climate-related increases in underweight. The estimates are based on analysing shifts in a country's weight distribution following changes in caloric availability - a method that follows current practice in assuming that all population groups are subject to weight changes. ${ }^{99}$ However, food secure groups within a country might be better able, than food insecure groups, to adapt to changes in food prices associated with changes in caloric availability without necessitating weight changes. Food-secure groups in developing countries currently have a greater prevalence of overweight and obesity, ${ }^{103}$ something that could lower the weight response to price changes. However, the opposite is the case for developed countries, ${ }^{104}$ and it is expected that the association between socio-economic status and overweight changes from positive to negative 
when income increases beyond a certain threshold. ${ }^{103,105}$ It is therefore not clear how our estimates for 2050 would change if we were able to resolve such differentiated impacts within countries and socio-economic groups. 


\section{References}

1 Rosengrant MW, IMPACT Development Team. International Model for Policy Analysis of Agricultural Commodities and Trade (IMPACT): Model Description. Washington, D.C.: International Food Policy Research Institute, 2012.

2 Robinson S, Mason-D’Croz D, Islam S, et al. The International Model for Policy Analysis of Agricultural Commodities and Trade (IMPACT) -- Model description for version 3. 2015; published online Oct.

3 Evenson RE, Rosengrant MW. Productivity Projections for Commodity Marketing Modeling. Paper presented at the final workshop of the International Cooperative Research Project on 'Projections and Policy Implications of Medium and Long-Term Rice Supply and Demand', organized by IFPRI, IRRI, and CCER, Beijing, China, April 23-26, 1995. 1995.

4 Evenson RE, Pray C, Rosengrant MW. Agricultural Research and Productivity Growth in India. IFPRI Research Report No. 109. 1999.

5 Hoogenboom G, Jones JW, Wilkens PW, et al. Decision Support System for Agrotechnology Transfer (DSSAT). ver. 4.5 [CD-ROM]. Univ Hawaii Honol Hawaii 2012.

6 Jones JW, Hoogenboom G, Porter CH, et al. The DSSAT cropping system model. Eur J Agron 2003; 18: 235-65.

7 Edenhofer O, Pichs-Madruga R, Sokona Y, Farahani E, Kadner S. Climate Change 2014: Mitigation of Climate Change. Contribution of Working Group III to the Fifth Assessment Report of the Intergovernmental Panel on Climate Change. IPCC, 2014.

8 USDA. Commodity and Food Elasticities. Retrieved from http://www.ers.usda.gov/Data/Elasticities/. 1998.

9 GAMS. General Algebraic Modeling System (GAMS). GAMS, Washington, D.C. Retrieved from www.gams.com. 2012.

10 World Bank. Manufactures Unit Value Index. 2000. http://data.worldbank.org/data-catalog/MUV-index.

11 World Bank. Prospects Commodity Markets. 2012. http://go.worldbank.org/4ROCCIEQ50.

12 OECD-AMAD. Agricultural market Access Data Base. Retrieved from www.oecd.org/site/amad in 2013. 2010.

13 Narayanan BG, Walmsley TL. Global trade, assistance, and production: the GTAP 7 data base. Cent Glob Trade Anal Purdue Univ 2008.

14 International Trade Center. User Guide - Market Access Map: Making Tariffs and Market Access Barriers Transparent. Market Analysis Section, Division of Product and Market Development, International Trade Center, Geneva, December. 2006.

15 Boumellassa H, Laborde D, Mitaritonna C. A picture of tariff protection across the world in 2004: MAcMapHS6, version 2. Intl Food Policy Res Inst, 2009.

16 OECD. Agricultural Policy Monitoring and Evaluation 2014: OECD Countries. 2014.

17 Jones PG, Thornton PK, Heinke J. Generating characteristic daily weather data using downscaled climate model data from the IPCC Fourth Assessment. Available at: https://hc.app.box.com/shared/f2gk053td8. 2009.

18 Hempel S, Frieler K, Warszawski L, Schewe J, Piontek F. A trend-preserving bias correction-the ISI-MIP approach. Earth Syst Dyn 2013; 4: 219-36.

19 Piani C, Haerter JO, Coppola E. Statistical bias correction for daily precipitation in regional climate models over Europe. Theor Appl Climatol 2010; 99: 187-92. 
20 Weedon GP, Gomes S, Viterbo P, et al. Creation of the WATCH forcing data and its use to assess global and regional reference crop evaporation over land during the twentieth century. J Hydrometeorol 2011; 12: 82348.

21 You L, Wood-Sichra U, Fritz S, Guo Z, See L, Koo J. Spatial Production Allocation Model (SPAM) 2005 v2.0. Available from http://mapspam.info. 2014.

22 Müller C, Robertson RD. Projecting future crop productivity for global economic modeling. Agric Econ 2014; 45: 37-50.

23 Priestley CHB, Taylor RJ. On the assessment of surface heat flux and evaporation using large-scale parameters. Mon Weather Rev 1972; 100: 81-92.

24 Allen RG, Pereira LS, Raes D, Smith M, others. Crop evapotranspiration-Guidelines for computing crop water requirements-FAO Irrigation and drainage paper 56. FAO Rome 1998; 300: D05109.

25 Chen Y-H, Paltsev S, Reilly JM, Morris JF, Babiker MH. The MIT EPPA6 Model: Economic Growth, Energy Use, and Food Consumption. MIT Joint Program on the Science and Policy of Global Change, 2015 http://dspace.mit.edu/handle/1721.1/95765 (accessed Oct 18, 2015).

26 de Fraiture C. Integrated water and food analysis at the global and basin level. An application of WATERSIM. Water Resour Manag 2007; 21: 185-98.

27 Rosegrant MW, Cai X, Cline SA. World water and food to 2025: dealing with scarcity. Intl Food Policy Res Inst, 2002.

28 Doorenbos J, Kassam AH. Yield response to water. Irrig Drain Pap 1979; 33: 257.

29 KC S, Lutz W. The human core of the shared socioeconomic pathways: Population scenarios by age, sex, and level of education for all countries to 2100. Glob Environ Change 2014.

30 Chateau J, Dellink R, Lanzi E, Magne B. Long-term economic growth and environmental pressure: reference scenarios for future global projections. OECD. 2012.

31 O'Neill BC, Carter T, Ebi KL, et al. Meeting Report of the Workshop on The Nature and Use of New Socioeconomic Pathways for Climate Change Research. 2012. http://hal.cirad.fr/hal-00801931/ (accessed Jan 17, 2015).

32 O’Neill BC, Kriegler E, Ebi KL, et al. The roads ahead: Narratives for shared socioeconomic pathways describing world futures in the 21st century. Glob Environ Change 2015.

33 O’Neill BC, Kriegler E, Riahi K, et al. A new scenario framework for climate change research: The concept of shared socioeconomic pathways. Clim Change 2014; 122: 387-400.

34 Collins M, Knutti R, Arblaster JM, et al. Long-term climate change: projections, commitments and irreversibility. In: Climate Change 2013: The Physical Science Basis. Contribution of Working Group I to the Fifth Assessment Report of the Intergovernmental Panel on Climate Change. Cambridge, United Kingdom and New York, NY, USA: Cambridge University Press, 2013.

35 Van Vuuren DP, Edmonds J, Kainuma M, et al. The representative concentration pathways: an overview. Clim Change 2011; 109: 5-31.

36 Rosenzweig C, Elliott J, Deryng D, et al. Assessing agricultural risks of climate change in the 21 st century in a global gridded crop model intercomparison. Proc Natl Acad Sci 2014; 111: 3268-73.

37 Jones CD, Hughes JK, Bellouin N, et al. The HadGEM2-ES implementation of CMIP5 centennial simulations. Geosci Model Dev 2011; 4: 543-70. 
38 Dufresne J-L, Foujols M-A, Denvil S, et al. Climate change projections using the IPSL-CM5 Earth System Model: from CMIP3 to CMIP5. Clim Dyn 2013; 40: 2123-65.

39 Watanabe S, Hajima T, Sudo K, et al. MIROC-ESM 2010: Model description and basic results of CMIP520c3m experiments. Geosci Model Dev 2011; 4: 845-72.

40 Bondeau A, Smith PC, Zaehle S, et al. Modelling the role of agriculture for the 20th century global terrestrial carbon balance. Glob Change Biol 2007; 13: 679-706.

41 Food and Agriculture Organization of the United Nations. Food balance sheets: a handbook. Rome, 2001.

42 Hawkesworth S, Dangour AD, Johnston D, et al. Feeding the world healthily: the challenge of measuring the effects of agriculture on health. Philos Trans R Soc Lond B Biol Sci 2010; 365: 3083-97.

43 Kearney J. Food consumption trends and drivers. Philos Trans R Soc B Biol Sci 2010; 365: $2793-807$.

44 Gustavsson J, Cederberg C, Sonesson U, Van Otterdijk R, Meybeck A. Global food losses and food waste: extent, causes and prevention. FAO Rome, 2011.

45 Cover TM, Thomas JA. Elements of information theory. John Wiley \& Sons, 2012.

46 Murray CJ, Ezzati M, Lopez AD, Rodgers A, Vander Hoorn S. Comparative quantification of health risks: conceptual framework and methodological issues. Popul Health Metr 2003; 1: 1.

47 Lim SS, Vos T, Flaxman AD, et al. A comparative risk assessment of burden of disease and injury attributable to 67 risk factors and risk factor clusters in 21 regions, 1990-2010: a systematic analysis for the Global Burden of Disease Study 2010. The Lancet 2012; 380: 2224-60.

48 Rockhill B, Newman B, Weinberg C. Use and misuse of population attributable fractions. Am J Public Health 1998; 88: 15-9.

49 Ezzati M, Vander Hoorn S, Rodgers A, Lopez AD, Mathers CD, Murray CJ. Estimates of global and regional potential health gains from reducing multiple major risk factors. The Lancet 2003; 362: 271-80.

50 Prospective Studies Collaboration, Whitlock G, Lewington S, et al. Body-mass index and cause-specific mortality in 900000 adults: collaborative analyses of 57 prospective studies. Lancet 2009; 373: 1083-96.

51 Berrington de Gonzalez A, Hartge P, Cerhan JR, et al. Body-Mass Index and Mortality among 1.46 Million White Adults. N Engl J Med 2010; 363: 2211-9.

52 Micha R, Wallace SK, Mozaffarian D. Red and processed meat consumption and risk of incident coronary heart disease, stroke, and diabetes mellitus: a systematic review and meta-analysis. Circulation 2010; 121: 2271-83.

53 Chen G-C, Lv D-B, Pang Z, Liu Q-F. Red and processed meat consumption and risk of stroke: a metaanalysis of prospective cohort studies. Eur J Clin Nutr 2013; 67: 91-5.

54 Dauchet L, Amouyel P, Dallongeville J. Fruit and vegetable consumption and risk of stroke: a meta-analysis of cohort studies. Neurology 2005; 65: 1193-7.

55 Dauchet L, Amouyel P, Hercberg S, Dallongeville J. Fruit and vegetable consumption and risk of coronary heart disease: a meta-analysis of cohort studies. J Nutr 2006; 136: 2588-93.

56 WCRF/AICR. Food, Nutrition, Physical Activity, and the Prevention of Cancer: A Global Perspective. Washington, DC, USA: AICR, 2007.

57 Willett WC, Manson JE, Stampfer MJ, et al. Weight, weight change, and coronary heart disease in women: Risk within the 'normal' weight range. JAMA 1995; 273: 461-5. 
58 Asia Pacific Cohort Studies Collaboration. Body mass index and cardiovascular disease in the Asia-Pacific Region: an overview of 33 cohorts involving 310000 participants. Int J Epidemiol 2004; 33: 751-8.

59 Song Y-M, Sung J, Smith GD, Ebrahim S. Body Mass Index and Ischemic and Hemorrhagic Stroke A Prospective Study in Korean Men. Stroke 2004; 35: 831-6.

60 Rexrode KM, Hennekens $\mathrm{CH}$, Willett WC, et al. A prospective study of body mass index, weight change, and risk of stroke in women. JAMA 1997; 277: 1539-45.

61 Calle EE, Rodriguez C, Walker-Thurmond K, Thun MJ. Overweight, obesity, and mortality from cancer in a prospectively studied cohort of U.S. adults. N Engl J Med 2003; 348: 1625-38.

62 Reeves GK, Pirie K, Beral V, et al. Cancer incidence and mortality in relation to body mass index in the Million Women Study: cohort study. BMJ 2007; 335: 1134

63 Parr CL, Batty GD, Lam TH, et al. Body-mass index and cancer mortality in the Asia-Pacific Cohort Studies Collaboration: pooled analyses of 424,519 participants. Lancet Oncol 2010; 11: 741-52.

64 Calle EE, Kaaks R. Overweight, obesity and cancer: epidemiological evidence and proposed mechanisms. Nat Rev Cancer 2004; 4: 579-91.

65 Willett WC, Dietz WH, Colditz GA. Guidelines for healthy weight. N Engl J Med 1999; 341: 427-34.

66 Chiolero A, Kaufman JS. Metabolic mediators of body-mass index and cardiovascular risk. The Lancet 2014; 383: 2042

67 Yusuf S, Hawken S, Ounpuu S, et al. Effect of potentially modifiable risk factors associated with myocardial infarction in 52 countries (the INTERHEART study): case-control study. Lancet 2004; 364: 937-52.

68 Khaw K-T, Wareham N, Bingham S, Welch A, Luben R, Day N. Combined Impact of Health Behaviours and Mortality in Men and Women: The EPIC-Norfolk Prospective Population Study. PLoS Med 2008; 5: e12.

69 Dam RM van, Li T, Spiegelman D, Franco OH, Hu FB. Combined Impact of Lifestyle Factors on Mortality: Prospective Cohort Study in US Women. BMJ 2008; 337: 742-5.

70 Huxley RR, Ansary-Moghaddam A, Clifton P, Czernichow S, Parr CL, Woodward M. The impact of dietary and lifestyle risk factors on risk of colorectal cancer: a quantitative overview of the epidemiological evidence. Int J Cancer J Int Cancer 2009; 125: 171-80.

71 Nechuta SJ, Shu X-O, Li H-L, et al. Combined impact of lifestyle-related factors on total and cause-specific mortality among Chinese women: prospective cohort study. PLoS Med 2010; 7.

DOI:10.1371/journal.pmed.1000339.

72 World Health Organization. Physical status: the use and interpretation of anthropometry. Report of a WHO Expert Committee. Technical Report Series No. 854. Geneva, Switzerland: World Health Organization, 1995.

73 Yusuf S, Reddy S, Ounpuu S, Anand S. Global burden of cardiovascular diseases: part I: general considerations, the epidemiologic transition, risk factors, and impact of urbanization. Circulation 2001; 104: 2746-53.

74 Key TJ, Schatzkin A, Willett WC, Allen NE, Spencer EA, Travis RC. Diet, nutrition and the prevention of cancer. Public Health Nutr 2004; 7: 187-200.

75 Sinha R, Cross AJ, Graubard BI, Leitzmann MF, Schatzkin A. Meat intake and mortality: a prospective study of over half a million people. Arch Intern Med 2009; 169: 562-71.

76 Micha R, Michas G, Mozaffarian D. Unprocessed red and processed meats and risk of coronary artery disease and type 2 diabetes--an updated review of the evidence. Curr Atheroscler Rep 2012; 14: 515-24. 
77 Kaluza J, Wolk A, Larsson SC. Red meat consumption and risk of stroke: a meta-analysis of prospective studies. Stroke J Cereb Circ 2012; 43: 2556-60.

78 Larsson SC, Wolk A. Red and processed meat consumption and risk of pancreatic cancer: meta-analysis of prospective studies. Br J Cancer 2012; 106: 603-7.

79 WCRF/AICR. Continuous Update Project Report. Food, Nutrition, Physical Activity, and the Prevention of Pancreatic Cancer. 2012 http:// www.dietandcancerreport.org.

80 Song P, Lu M, Yin Q, et al. Red meat consumption and stomach cancer risk: a meta-analysis. J Cancer Res Clin Oncol 2014; published online March 29. DOI:10.1007/s00432-014-1637-z.

81 Zhu H, Yang X, Zhang C, et al. Red and Processed Meat Intake Is Associated with Higher Gastric Cancer Risk: A Meta-Analysis of Epidemiological Observational Studies. PLoS ONE 2013; 8: e70955.

82 Choi Y, Song S, Song Y, Lee JE. Consumption of red and processed meat and esophageal cancer risk: Metaanalysis. World J Gastroenterol WJG 2013; 19: 1020-9.

83 Salehi M, Moradi-Lakeh M, Salehi MH, Nojomi M, Kolahdooz F. Meat, fish, and esophageal cancer risk: a systematic review and dose-response meta-analysis. Nutr Rev 2013; 71: 257-67.

$84 \mathrm{Qu}$ X, Ben Q, Jiang Y. Consumption of red and processed meat and risk for esophageal squamous cell carcinoma based on a meta-analysis. Ann Epidemiol 2013; 23: 762-70.e1.

85 Huang W, Han Y, Xu J, Zhu W, Li Z. Red and processed meat intake and risk of esophageal adenocarcinoma: a meta-analysis of observational studies. Cancer Causes Control CCC 2013; 24: 193-201.

86 WCRF/AICR. Research. Continuous Update Project Report. Food, Nutrition, Physical Activity, and the Prevention of Colorectal Cancer. 2011.

87 World Health Organization. Diet, nutrition and the prevention of chronic diseases: report of a joint WHO/FAO expert consultation. Diamond Pocket Books (P) Ltd., 2003.

88 Bazzano LA, He J, Ogden LG, et al. Fruit and vegetable intake and risk of cardiovascular disease in US adults: the first National Health and Nutrition Examination Survey Epidemiologic Follow-up Study. Am J Clin Nutr 2002; 76: 93-9.

89 Rissanen TH, Voutilainen S, Virtanen JK, et al. Low Intake of Fruits, Berries and Vegetables Is Associated with Excess Mortality in Men: the Kuopio Ischaemic Heart Disease Risk Factor (KIHD) Study. J Nutr 2003; 133: 199-204.

90 Genkinger JM, Platz EA, Hoffman SC, Comstock GW, Helzlsouer KJ. Fruit, Vegetable, and Antioxidant Intake and All-Cause, Cancer, and Cardiovascular Disease Mortality in a Community-dwelling Population in Washington County, Maryland. Am J Epidemiol 2004; 160: 1223-33.

91 Agudo A, Cabrera L, Amiano P, et al. Fruit and vegetable intakes, dietary antioxidant nutrients, and total mortality in Spanish adults: findings from the Spanish cohort of the European Prospective Investigation into Cancer and Nutrition (EPIC-Spain). Am J Clin Nutr 2007; 85: 1634-42.

92 Nagura J, Iso H, Watanabe Y, et al. Fruit, vegetable and bean intake and mortality from cardiovascular disease among Japanese men and women: the JACC Study. Br J Nutr 2009; 102: 285-92.

93 Leenders M, Sluijs I, Ros MM, et al. Fruit and vegetable consumption and mortality: European prospective investigation into cancer and nutrition. Am J Epidemiol 2013; 178: 590-602.

94 He FJ, Nowson CA, Lucas M, MacGregor GA. Increased consumption of fruit and vegetables is related to a reduced risk of coronary heart disease: meta-analysis of cohort studies. J Hum Hypertens 2007; 21: 717-28. 
95 Nelson GC, Valin H, Sands RD, et al. Climate change effects on agriculture: Economic responses to biophysical shocks. Proc Natl Acad Sci 2014; 111: 3274-9.

96 Valin H, Sands RD, van der Mensbrugghe D, et al. The future of food demand: understanding differences in global economic models. Agric Econ 2014; 45: 51-67.

97 Porter JR, Xie L, Challinor A, et al. Food security and food production systems. In: Climate Change 2007: Impacts, Adaptation and Vulnerability. Contribution of Working Group II to the Fourth Assessment Report of the Intergovernmental Panel on Climate Change. Cambridge, United Kingdom and New York, NY, USA: Cambridge University Press, 2014: 485-533.

98 Smith KR, Woodward A, Campbell-Lendrum D, et al. Human health: Impacts, adaptation and co-benefits. In: Climate Change 2014: Impacts, Adaptation, and Vulnerability. Part A: Global and Sectoral Aspects. Contribution of Working Group II to the Fifth Assessment Report of the Interngovernmental Panel on Climate Change. Cambridge, United Kingdom and New York, NY, USA: Cambridge University Press, 2014: 709-54.

99 World Health Organization. Quantitative risk assessment of the effects of climate change on selected causes of death, 2030s and 2050s. Geneva, Switzerland: World Health Organization, 2014.

100 Sillmann J, Kharin VV, Zwiers FW, Zhang X, Bronaugh D. Climate extremes indices in the CMIP5 multimodel ensemble: Part 2. Future climate projections. J Geophys Res Atmospheres 2013; 118: $2473-93$.

101 Willett WC, Stampfer MJ. Current Evidence on Healthy Eating. Annu Rev Public Health 2013; 34: 77-95.

102 Myers SS, Zanobetti A, Kloog I, et al. Increasing CO2 threatens human nutrition. Nature 2014; 510: 13942.

103 Dinsa GD, Goryakin Y, Fumagalli E, Suhrcke M. Obesity and socioeconomic status in developing countries: a systematic review. Obes Rev 2012; 13: 1067-79.

104 McLaren L. Socioeconomic status and obesity. Epidemiol Rev 2007; 29: 29-48.

105 Monteiro CA, Moura EC, Conde WL, Popkin BM. Socioeconomic status and obesity in adult populations of developing countries: a review. Bull World Health Organ 2004; 82: 940-6. 